Supporting Information for

\title{
Discovery of Oral Anticancer 1,2-Bis(hydroxymethyl)benzo[g]pyrrolo[2,1- a]phthalazine Hybrids that Inhibit Angiogenesis and Induce DNA Crosslinks
}

Tai-Lin Chena, ${ }^{\mathrm{a}, \mathrm{b}}$, Anilkumar S. Patel ${ }^{\mathrm{a}, \mathrm{c}, \mathrm{l}}$, Vicky Jain ${ }^{\mathrm{a}, \mathrm{d}, \mathrm{l}}$, Ramajayam Kuppusamy ${ }^{\mathrm{a}}$, YiWen Lin ${ }^{\mathrm{a}}$, Ming-Hon Hou ${ }^{\mathrm{e}}$, Tsann-Long Su${ }^{\mathrm{a}, *}$, and Te-Chang Lee ${ }^{\mathrm{a}, *}$

anstitute of Biomedical Sciences, Academia Sinica, Taipei 11529, Taiwan. bSchool of Pharmacy, China Medical University, Taichung 40400, Taiwan 'Department of Chemistry, Atmiya University, Rajkot 360005, Gujarat, India dDepartment of Chemistry, Marwadi University, Rajkot 360003, Gujarat, India. eInstitute of Genomics and Bioinformatics, National Chung Hsing University, Taichung 40227, Taiwan

*Corresponding authors. Email: bmtcl@ibms.sinica.edu.tw (T.C.L.) and tlsu@ibms.sinica.edu.tw (T.L.S.) 
Table of Contents

\begin{tabular}{|c|c|}
\hline $\begin{array}{l}\text { Table S1. The cytotoxicity of compounds } \mathbf{1 9 a} \text { and } \mathbf{1 9 e} \text { to } \mathrm{KB} \text { and } \\
\mathrm{KB} / \text { vin } 10 \text { Cells }\end{array}$ & S3 \\
\hline $\begin{array}{l}\text { Table S2. The cytotoxicity of 19a and 19e to fetal human colon } \\
\text { epithelial (FHC) and human skin fibroblasts (CRL-1508) }\end{array}$ & S4 \\
\hline $\begin{array}{l}\text { Figure S1. }{ }^{1} \mathrm{H} \text { and }{ }^{13} \mathrm{C} \text { NMR, and EMS-MS spectra of all synthesized } \\
\text { intermediate compounds. } \quad \ldots \ldots \ldots \ldots \ldots \ldots \ldots \ldots \ldots \ldots \ldots \ldots \ldots \ldots \ldots \ldots \ldots \ldots \ldots \ldots \ldots\end{array}$ & \\
\hline 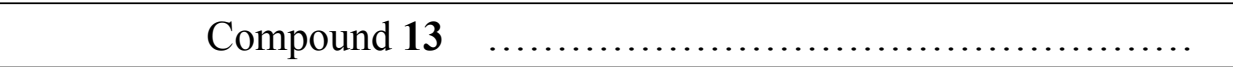 & S5 \\
\hline Compound $14 \quad \ldots \ldots \ldots \ldots . . .$. & S7 \\
\hline Compounds 15a-e ................ & S9 \\
\hline 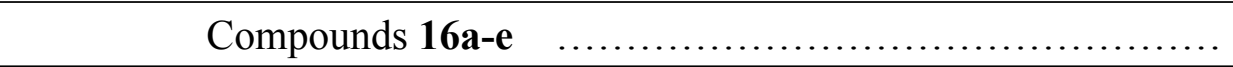 & S19 \\
\hline Compounds 17a-e $\quad \ldots \ldots \ldots \ldots \ldots \ldots \ldots \ldots \ldots \ldots$ & $\mathrm{S} 29$ \\
\hline Compounds 18a-e ..... & S39 \\
\hline \multicolumn{2}{|l|}{$\begin{array}{l}\text { Figure S2. }{ }^{1} \mathrm{H} \text { and }{ }^{13} \mathrm{C} \text { NMR, EMS-MS spectra and HPLC } \\
\text { chromatograms of all synthesized compounds. }\end{array}$} \\
\hline Compounds 19a-e $\quad \ldots . . . \ldots \ldots \ldots \ldots . . . . .$. & S49 \\
\hline Compounds 20a-e $\quad \ldots \ldots \ldots \ldots \ldots \ldots \ldots$ & S59 \\
\hline Figure S3. DNA melting temperature $(T m)$ assay. & S69 \\
\hline $\begin{array}{l}\text { Figure S4. Inhibition of hTopI and hTopII activity by benzo- } \\
\text { pyrrolo }[2,1-a] \text { phthalazine hybrids. }\end{array}$ & S70 \\
\hline References $\ldots \ldots \ldots \ldots$ & S71 \\
\hline
\end{tabular}


Supporting Information Table S1. The cytotoxicity of 19a and 19e to KB and $\mathrm{KB} /$ vin 10 cells

\begin{tabular}{lcc}
\hline Compounds & KB & KB/vin 10 \\
\hline $\mathbf{1 9 a}(\boldsymbol{\mu M})$ & $0.95 \pm 0.05$ & $0.56 \pm 0.14[0.59 \times]$ \\
$\mathbf{1 9 e}(\boldsymbol{\mu M})$ & $0.11 \pm 0.01$ & $0.19 \pm 0.03[1.73 \times]$ \\
Vincristine $(\mathbf{n M})$ & $5.45 \pm 0.81$ & $208.14 \pm 24.89[38.19 \times]$ \\
\hline The values of $\mathrm{IC}_{50}(\mu \mathrm{M})$ are the average \pm SD of at least 3 experiments using a series of 2-fold \\
dilutions. \\
bThe number in brackets is the resistance factor.
\end{tabular}


Supporting Information Table S2. The cytotoxicity of compounds 19a and 19e to human fetal colon epithelial cells (FHC) and human skin fibroblasts (CRL-1508)

\begin{tabular}{ccc}
\hline Compounds & FHC & CRL-1508 \\
\hline 19a $(\boldsymbol{\mu M})$ & $28.4 \pm 3.2$ & $5.5 \pm 2.7$ \\
19e $(\boldsymbol{\mu M})$ & $20.6 \pm 2.1$ & $2.2 \pm 0.2$ \\
\hline
\end{tabular}

aThe values of $\mathrm{IC}_{50}(\mu \mathrm{M})$ are the average \pm SD of at least 3 experiments using a series of 2-fold dilutions. 
Figure S1. ${ }^{1} \mathrm{H}$ and ${ }^{13} \mathrm{C}$ NMR spectrum of all synthesized intermediate compounds.

Compound 13 (500 MHz, DMSO- $d_{6}$ )

$\perp \mathrm{H}$
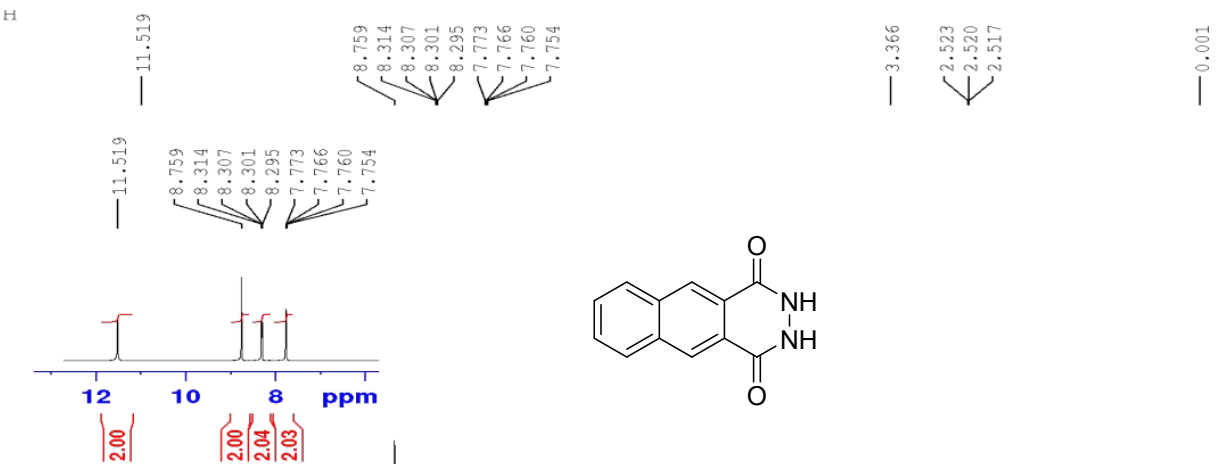

$13 \mathrm{C}$

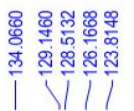

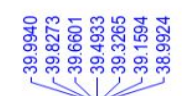

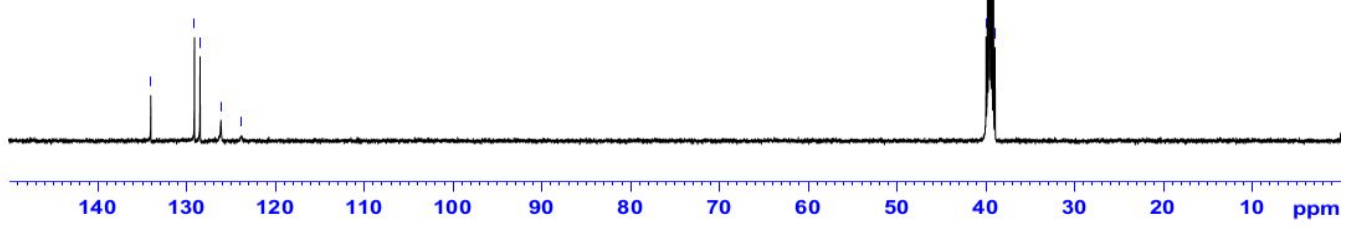

S5 


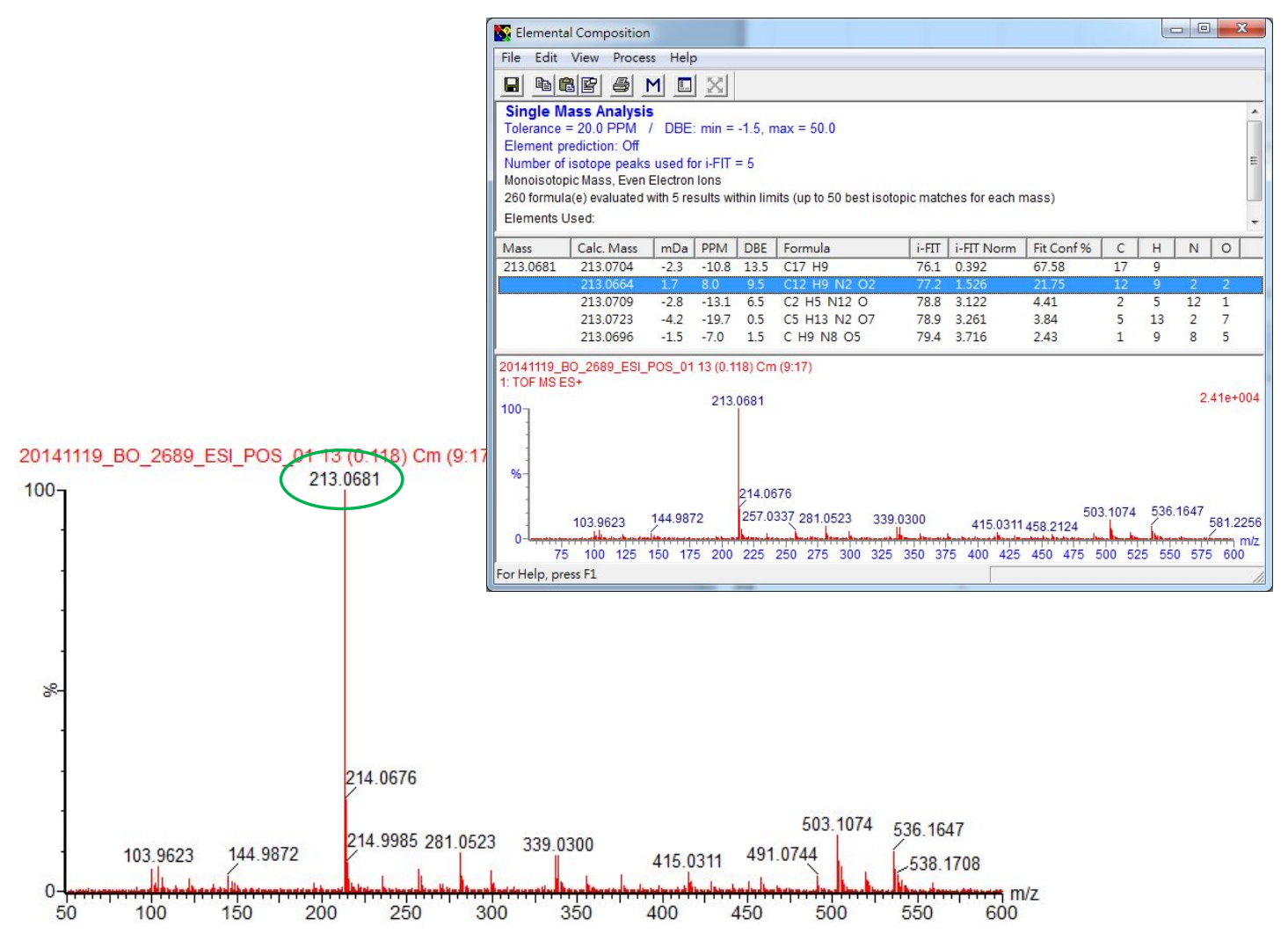


Compound 14 (500 MHz, DMSO- $d_{6}$ )
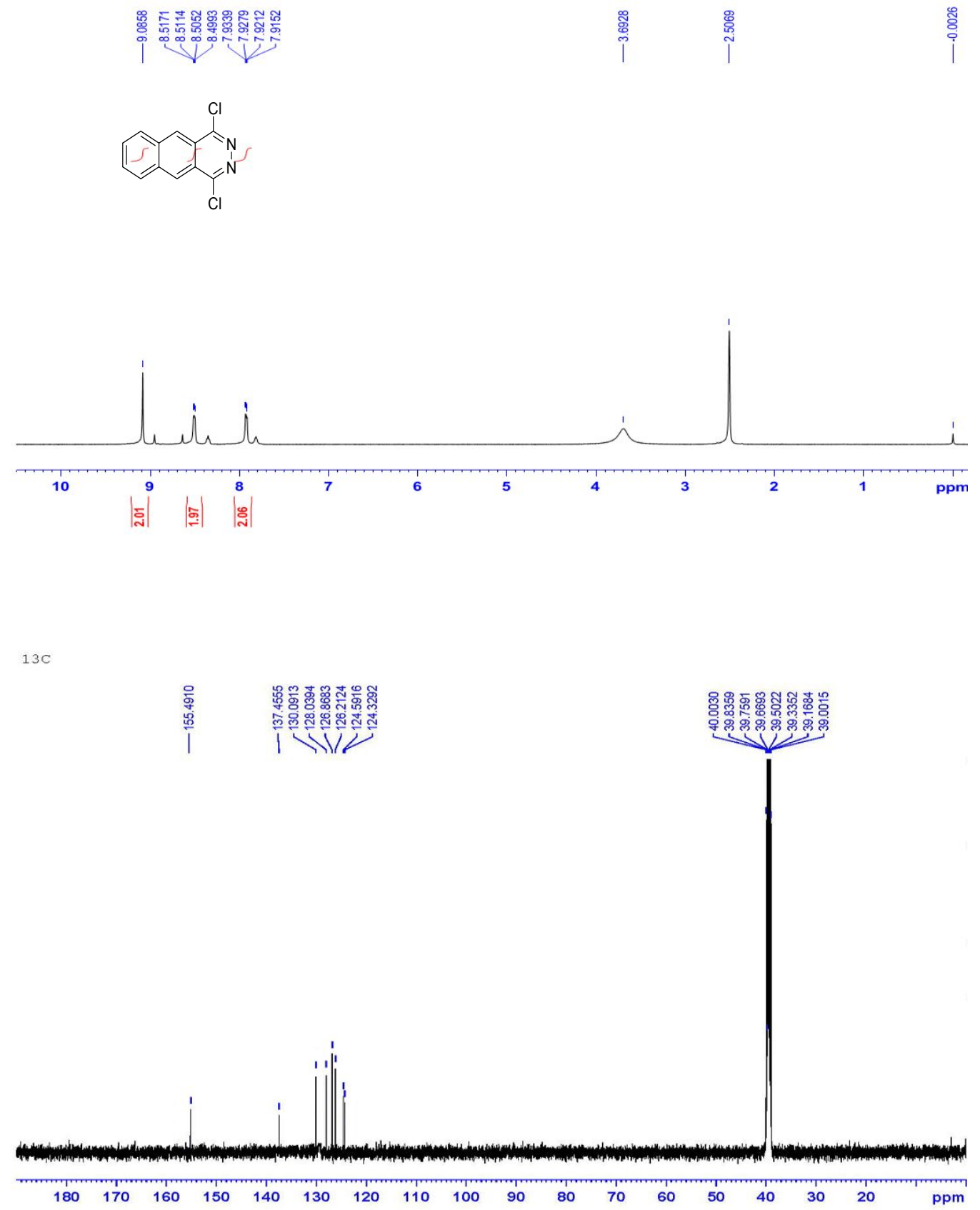


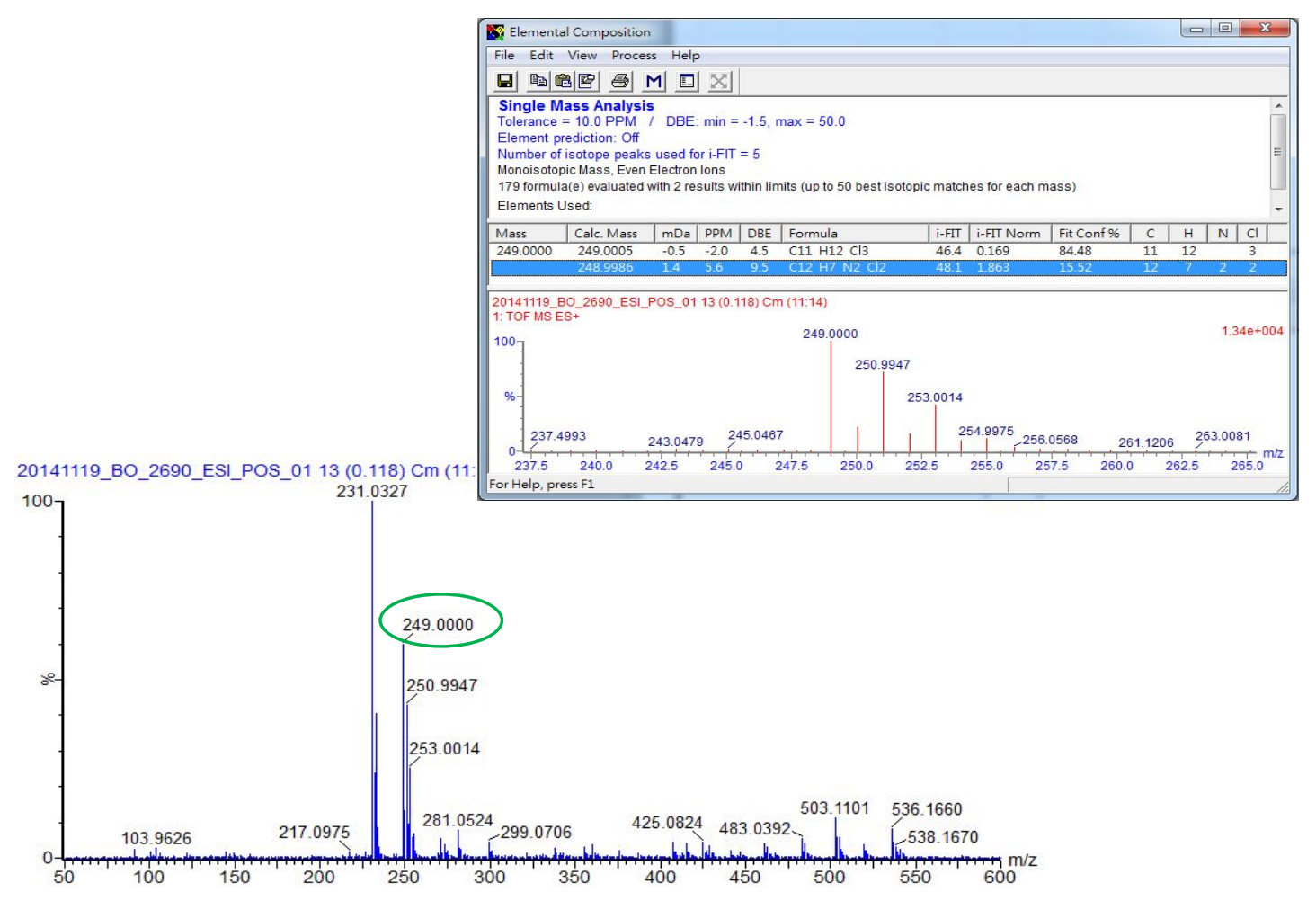


Compound 15a (500 MHz, DMSO- $d_{6}$ )
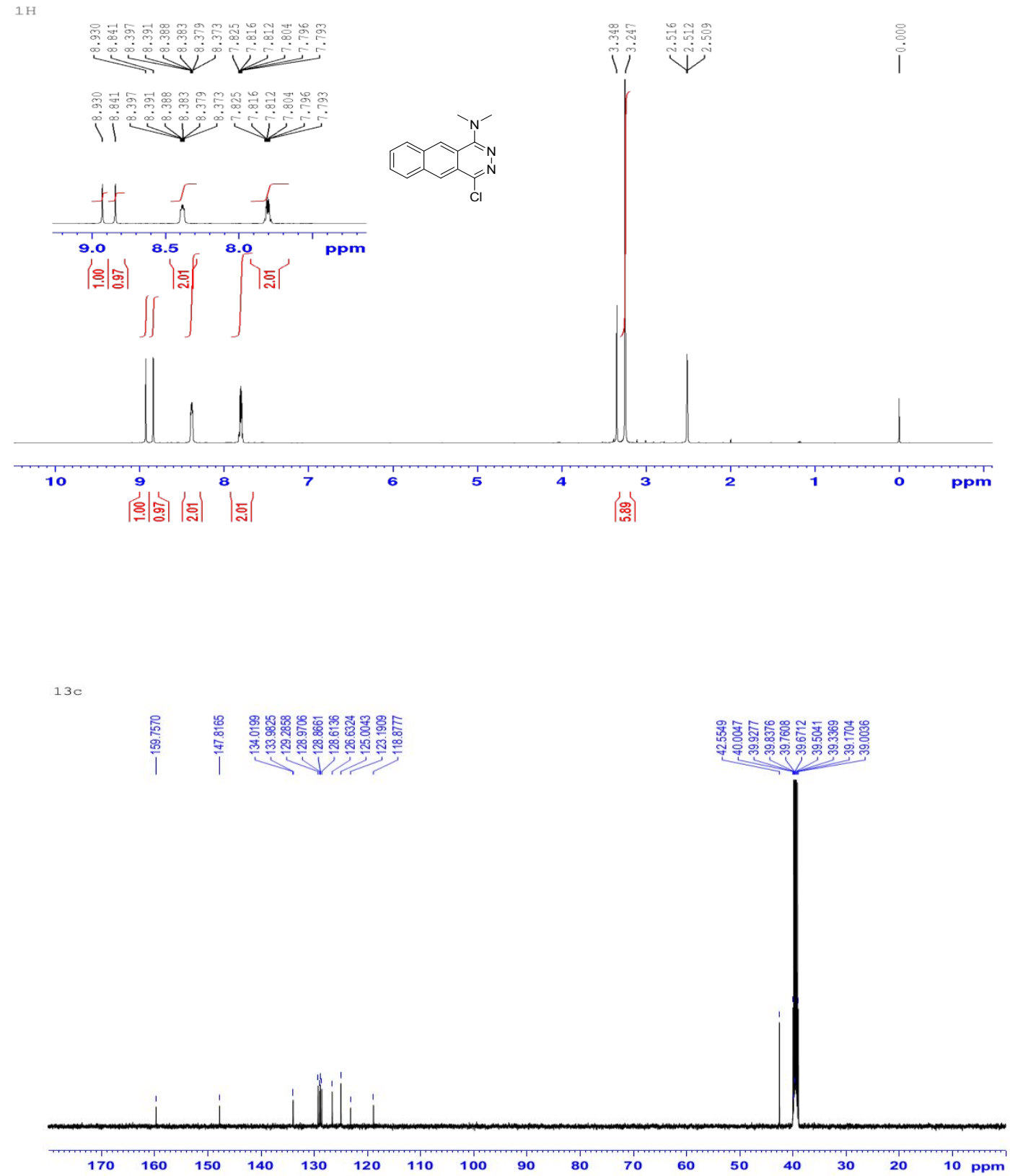


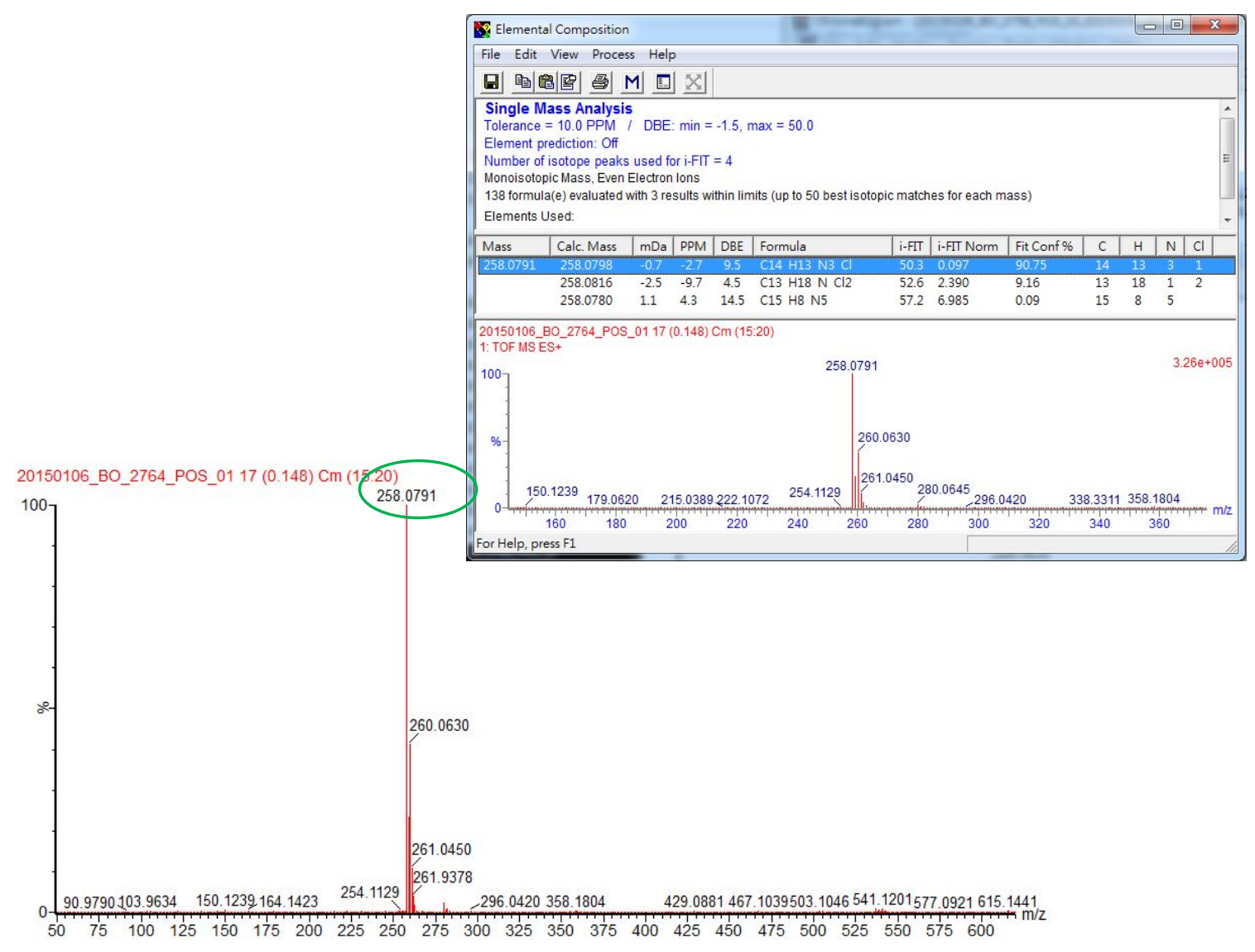


Compound 15b (500 MHz, DMSO-d $\left.d_{6}\right)$
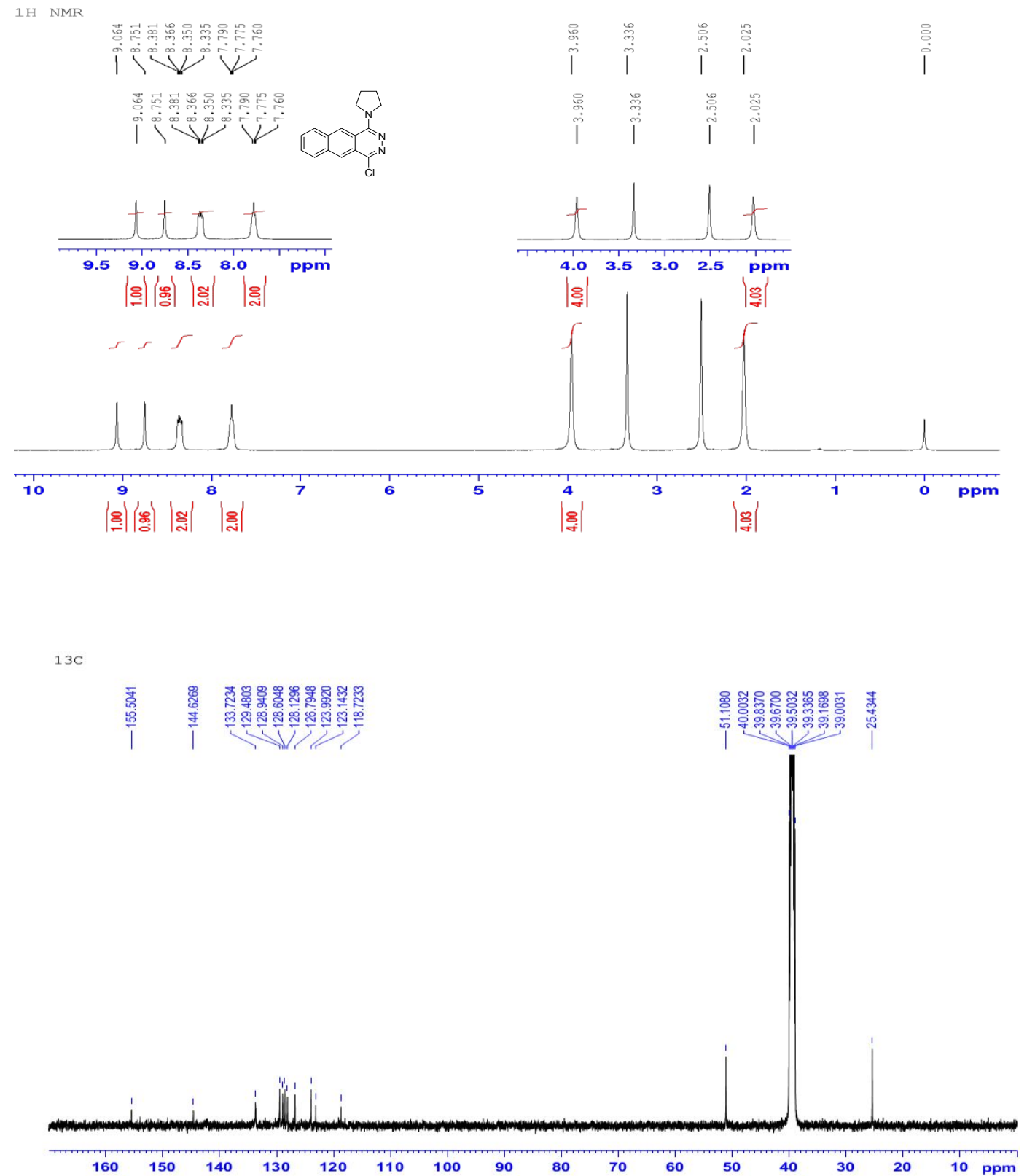


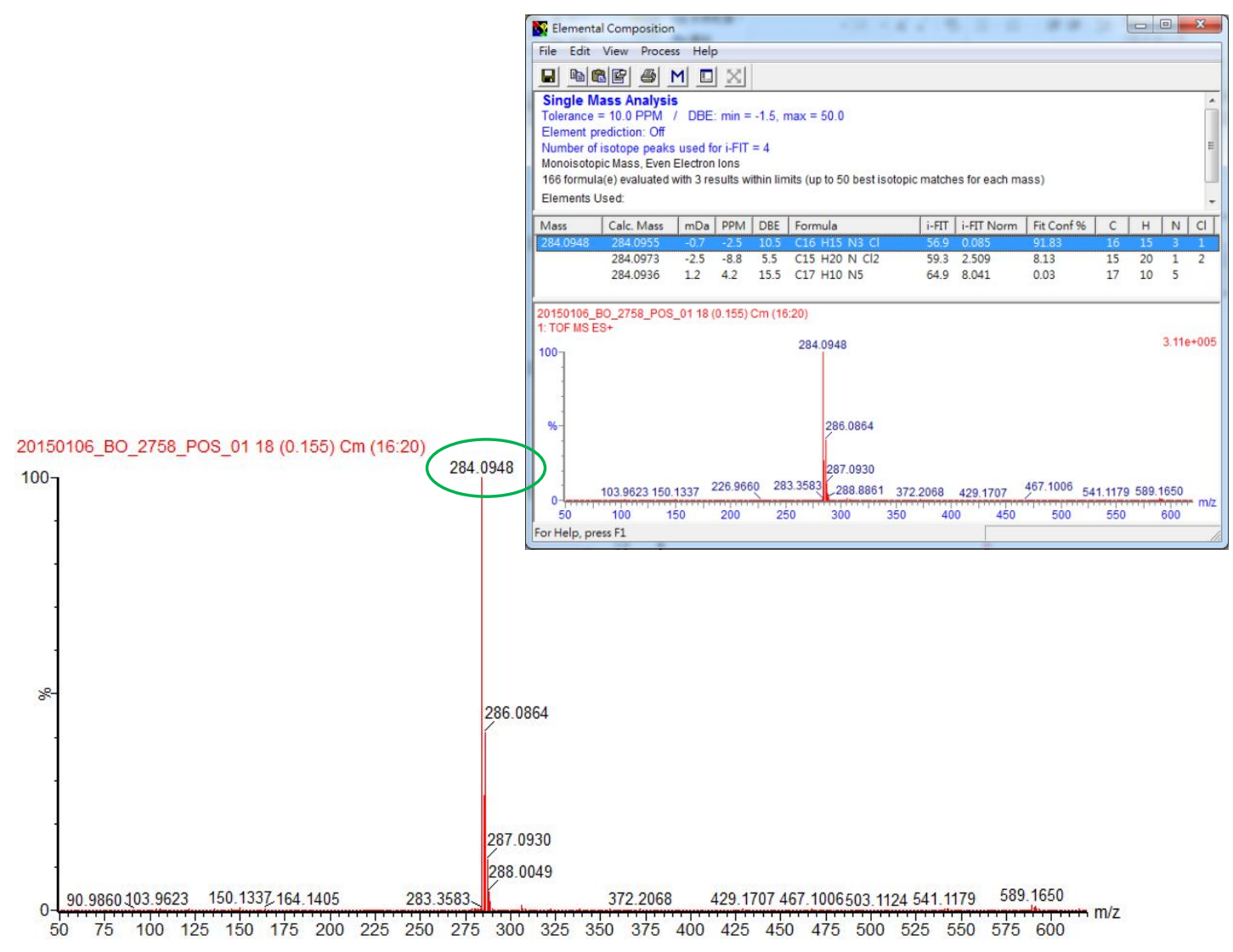




\section{Compound 15c (500 MHz, DMSO-d $\left.d_{6}\right)$}

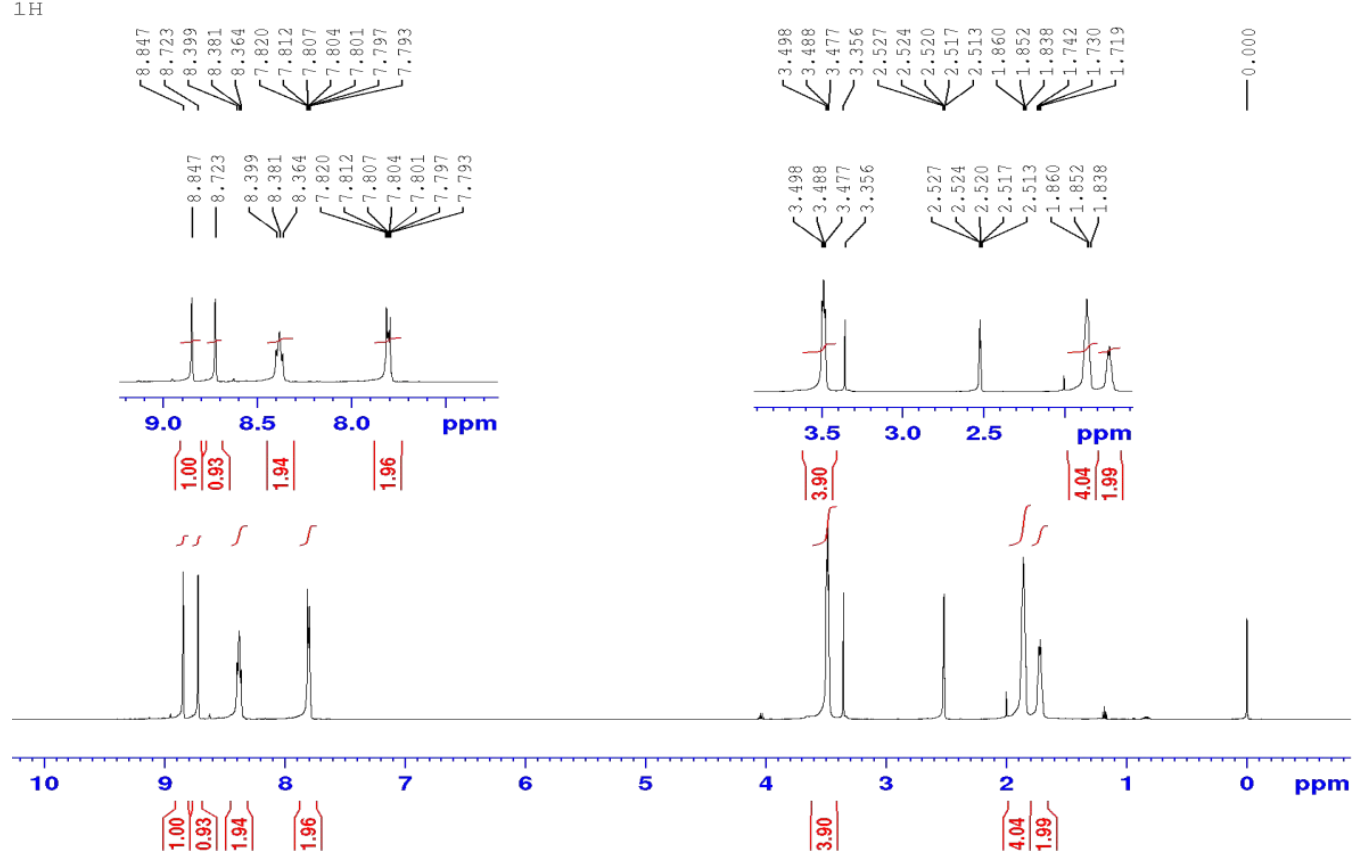

$13 \mathrm{C}$
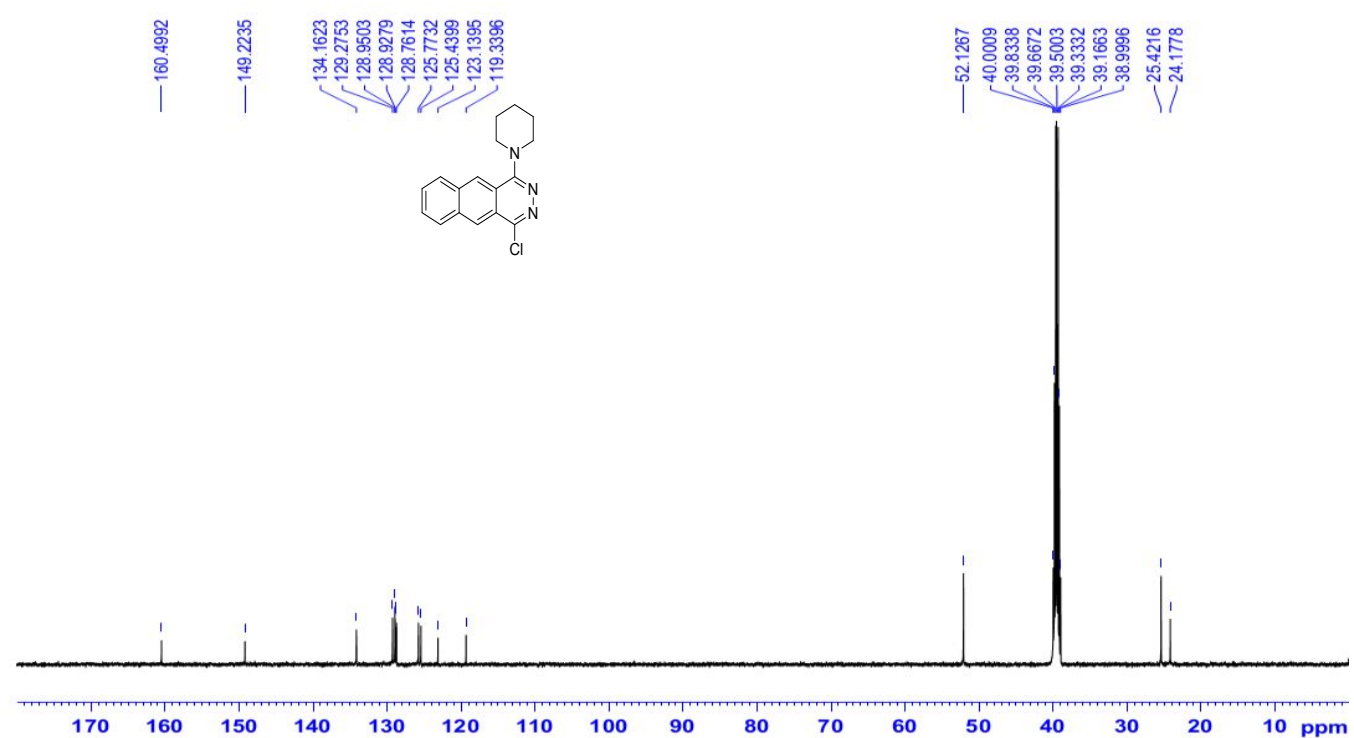


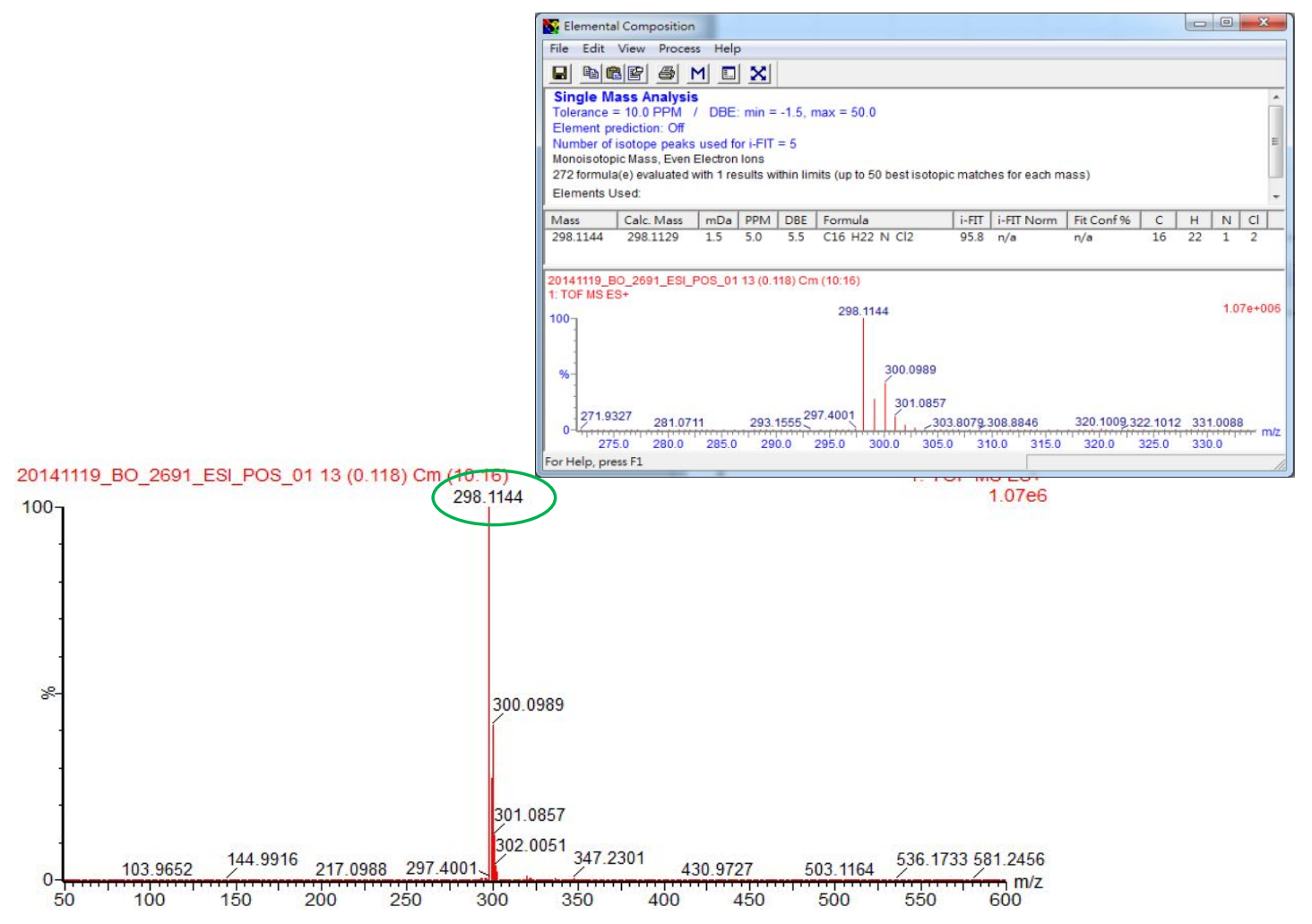




\section{Compound 15d (500 MHz, DMSO- $\left.d_{6}\right)$}

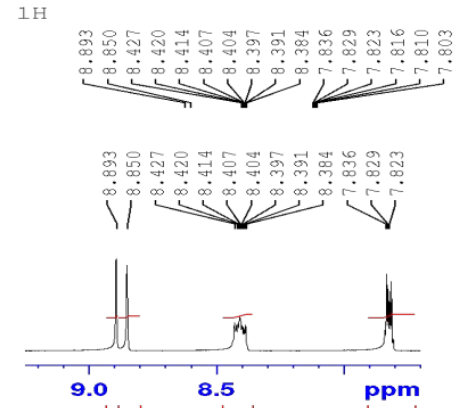

我国

|ำ|

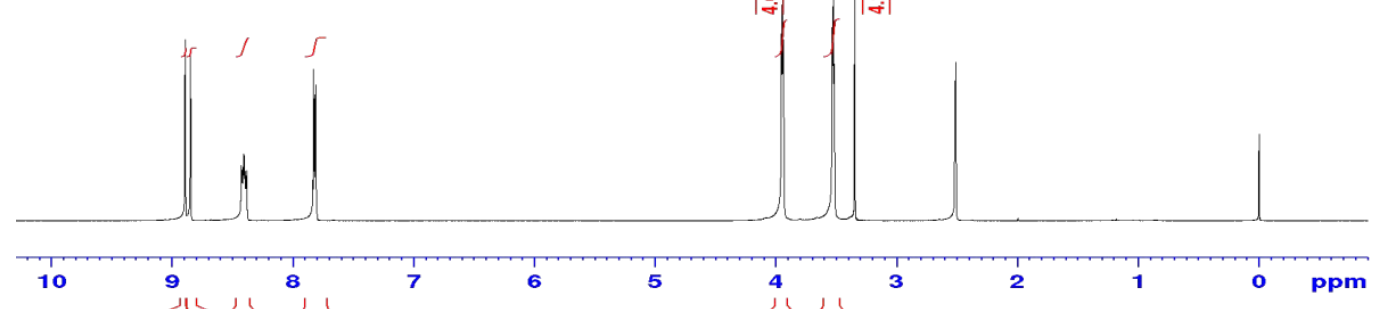

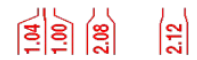

娄新

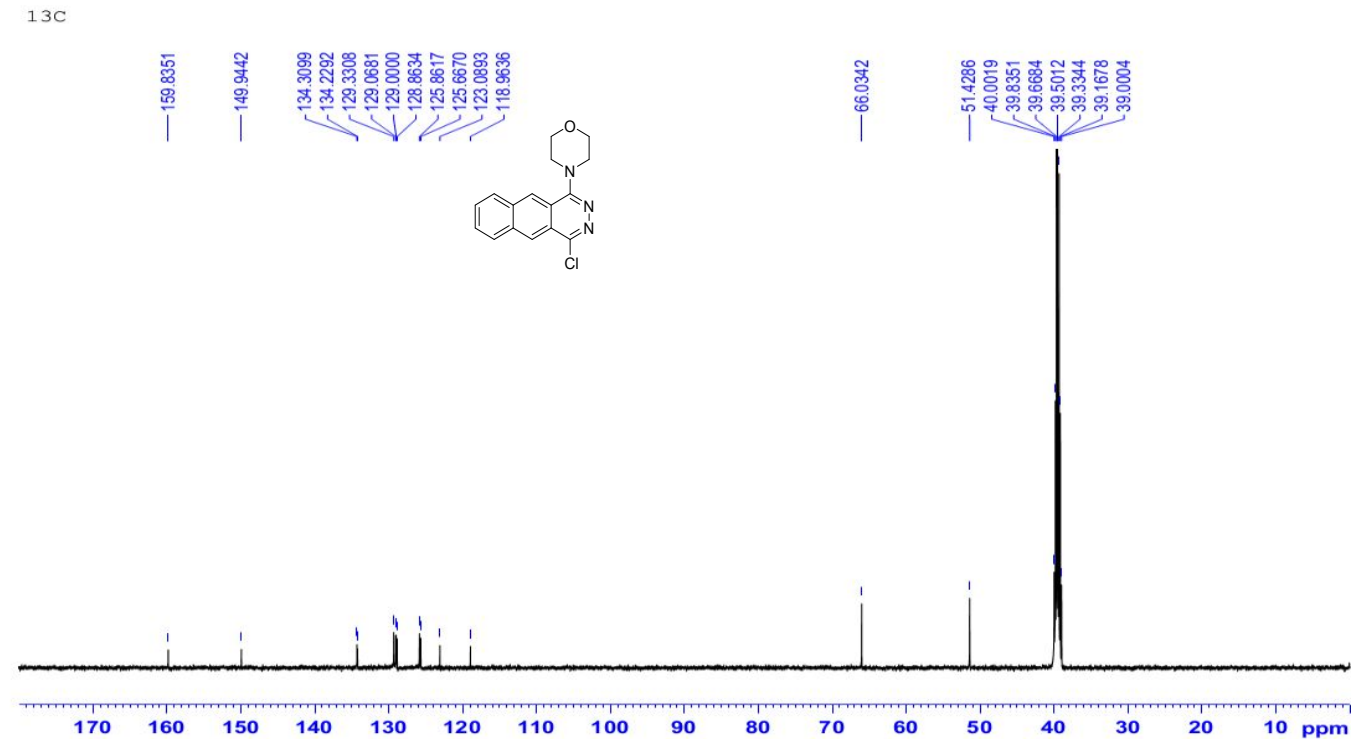




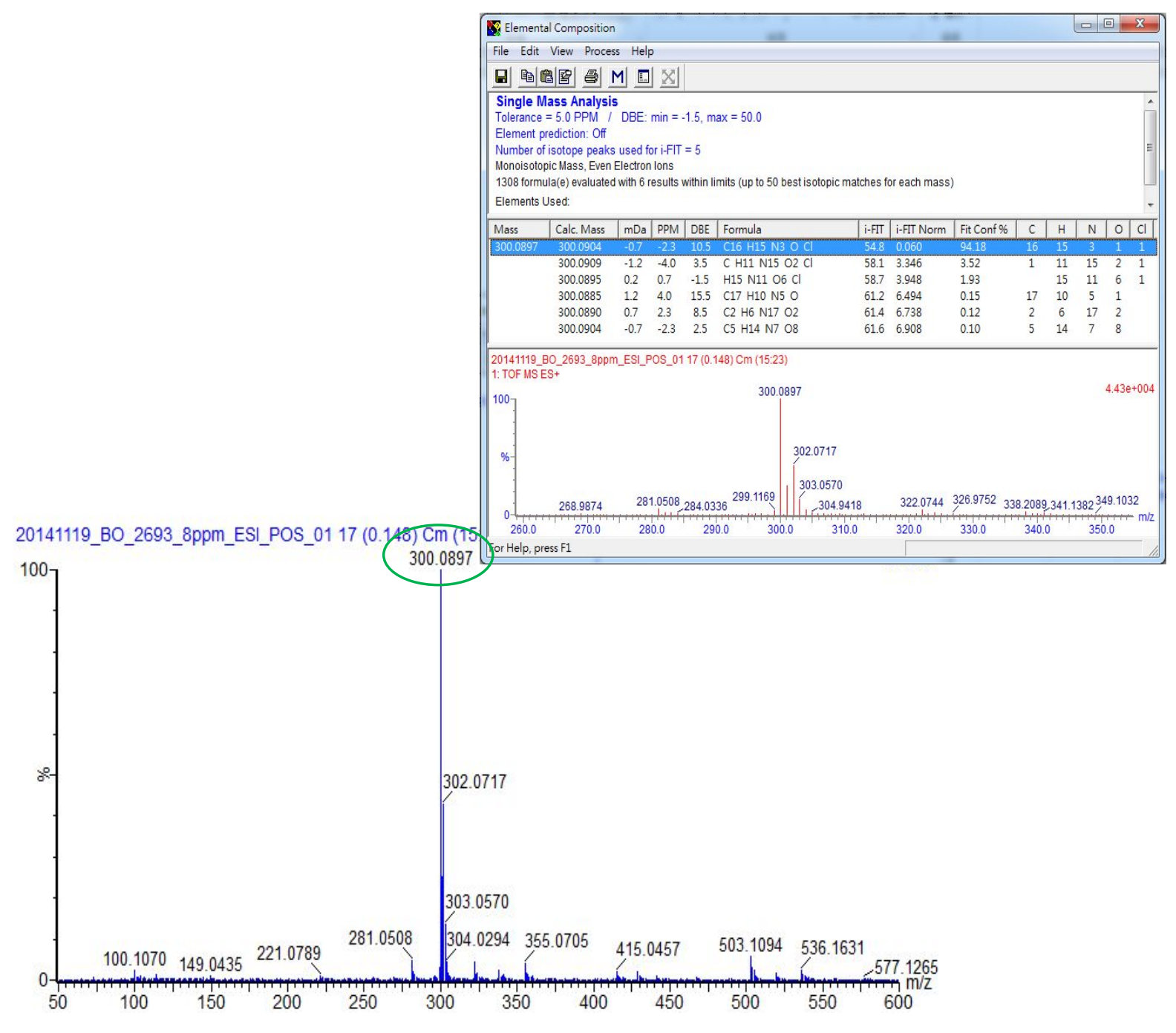




\section{Compound 15e (500 MHz, DMSO- $\left.d_{6}\right)$}
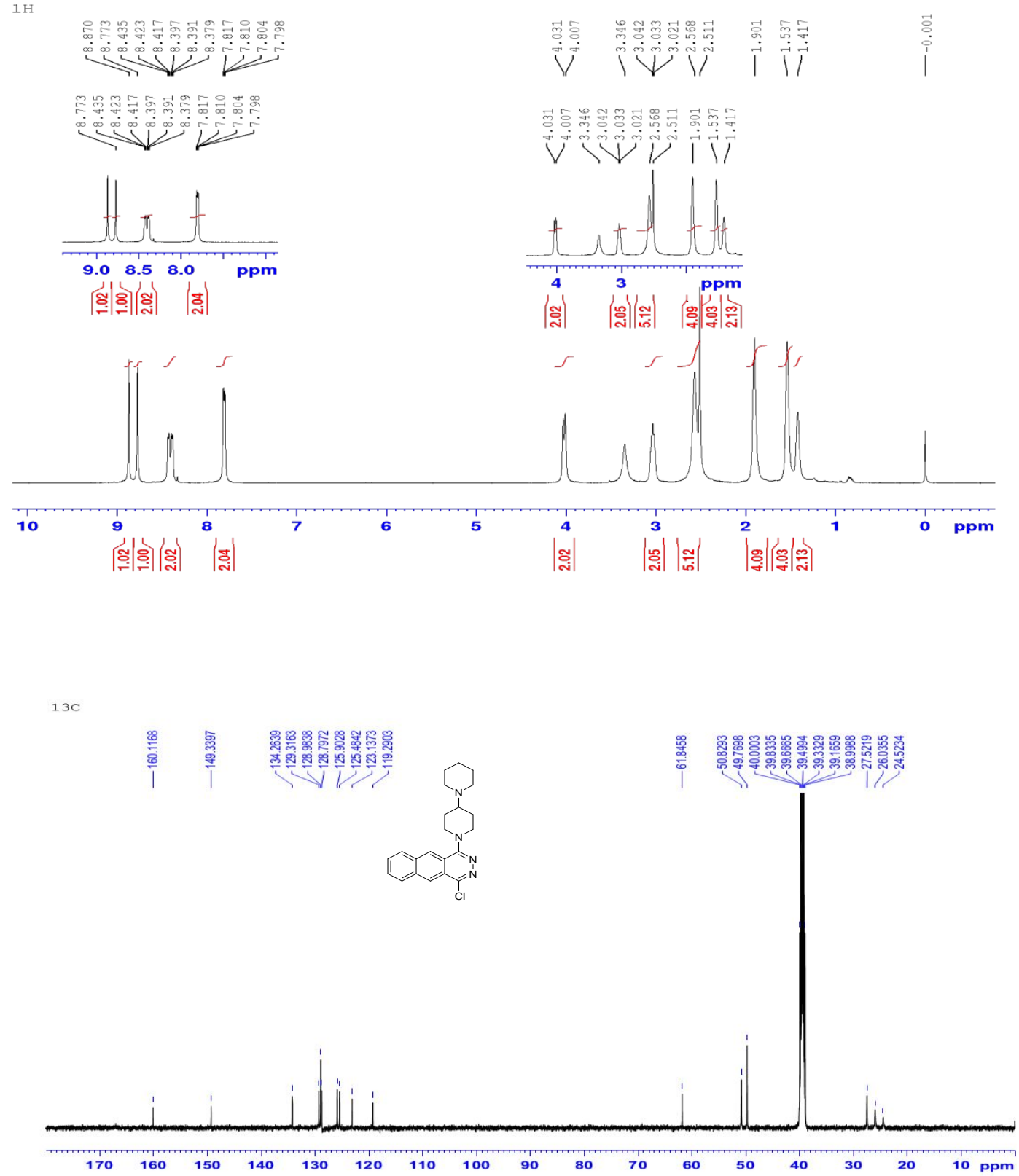
20150106_BO_2788_POS_02 17 (0.148) Cm (12:23)

$$
\begin{aligned}
& \text { File Ede Vilew Prosess }
\end{aligned}
$$

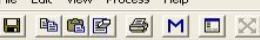

Single Mass Analysis
Tolerance $=10.0$ PPM / DBE: $\min =-1.5, \max =50.0$
Elo

Element prediction.

Number of isotope peaks used or I-n
Monoisotopic Mass. Even Electron lon

291 formula(e) evaluated with 3 results within limits (all results (up to 1000) for each mass)

$\begin{array}{lllllllll}381.1797 & 2.9 & 7.6 & 3.5 & \mathrm{C}_{12} \mathrm{H} / 26 \mathrm{~N} & \mathrm{N10} & \mathrm{Cl} & 741.7 & 10.9\end{array}$

20150106_BO_2788_POS_02 $17(0.148) \mathrm{Cm}$ (12.23)
1.: TOF MS ES+

For Help, press F1

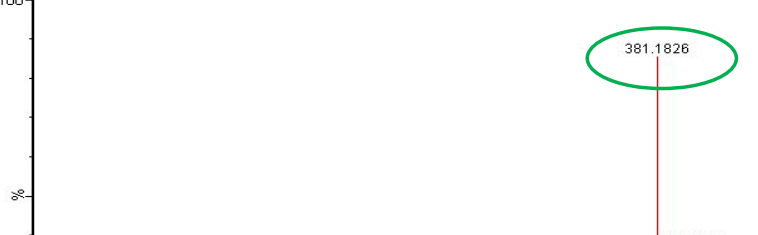

536.1649

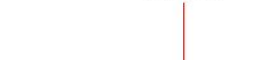

10

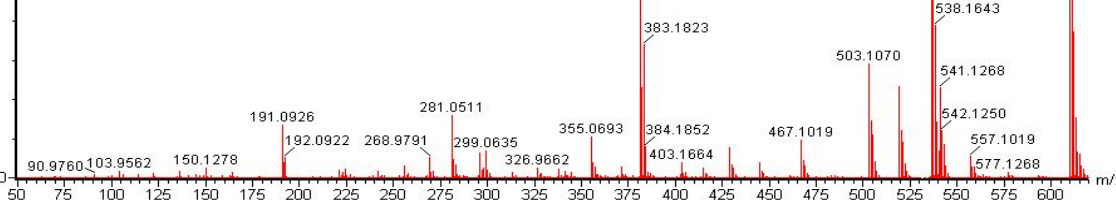

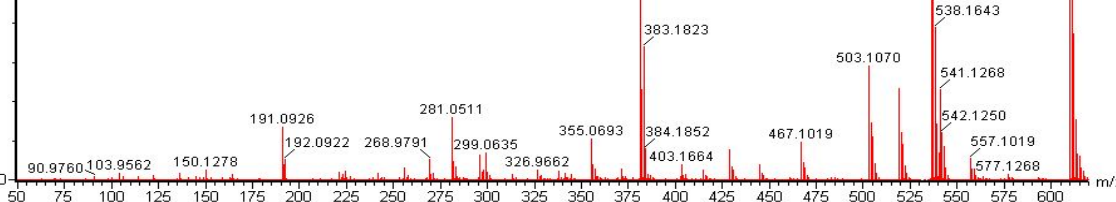

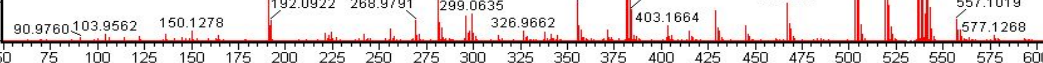




\section{Compound 16a (500 MHz, DMSO-d $\left.d_{6}\right)$}

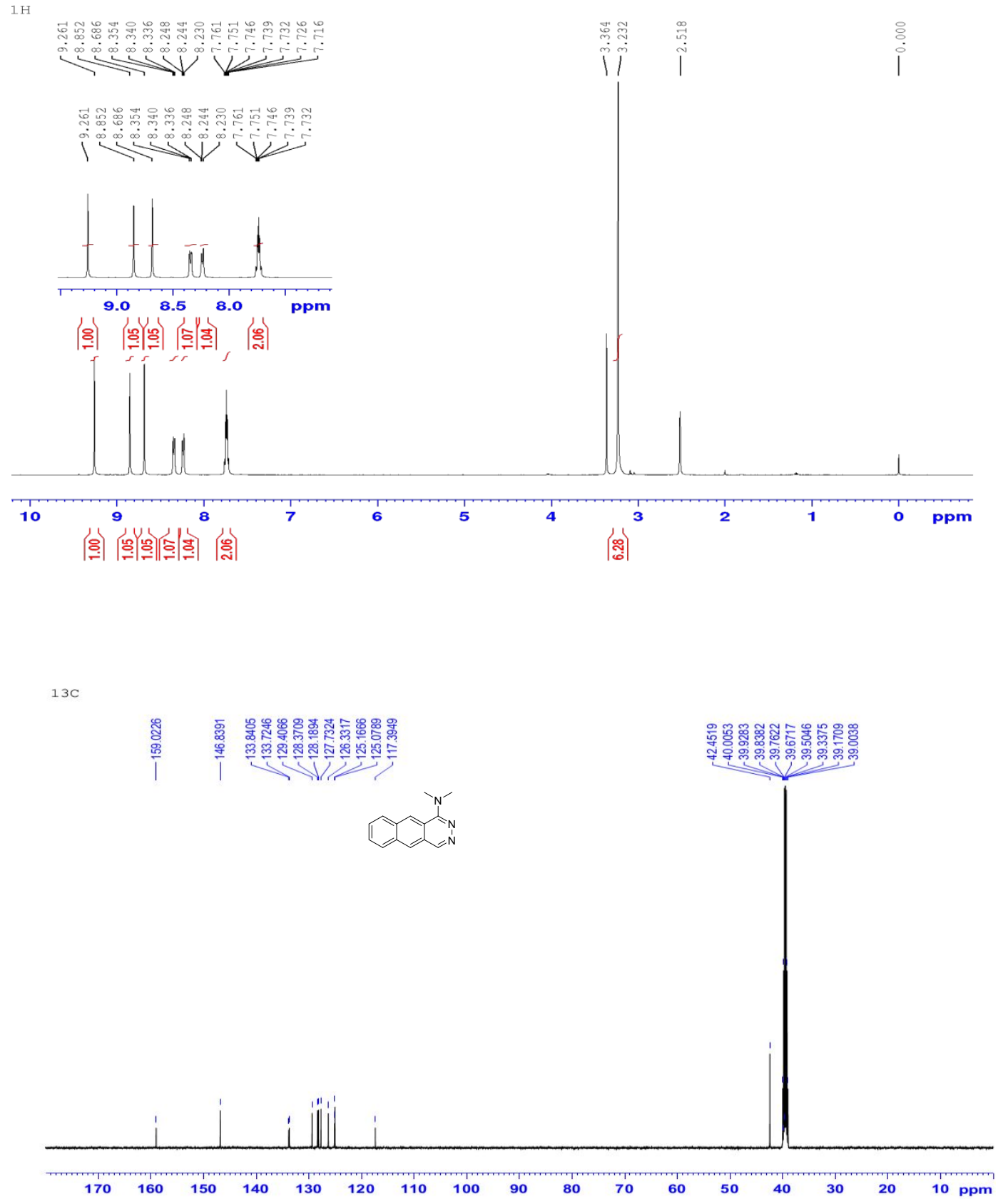




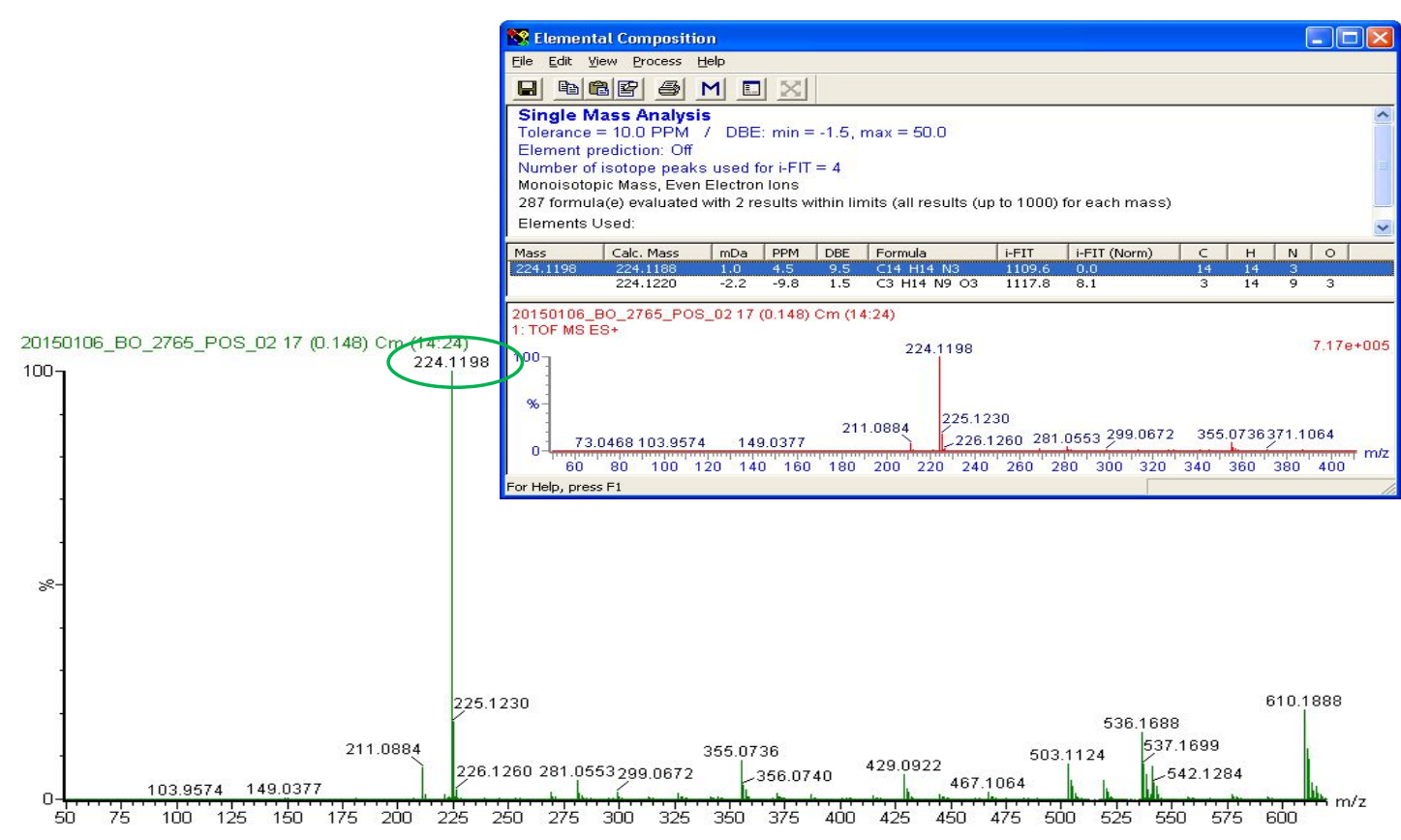




\section{Compound 16b (500 MHz, DMSO- $\left.d_{6}\right)$}
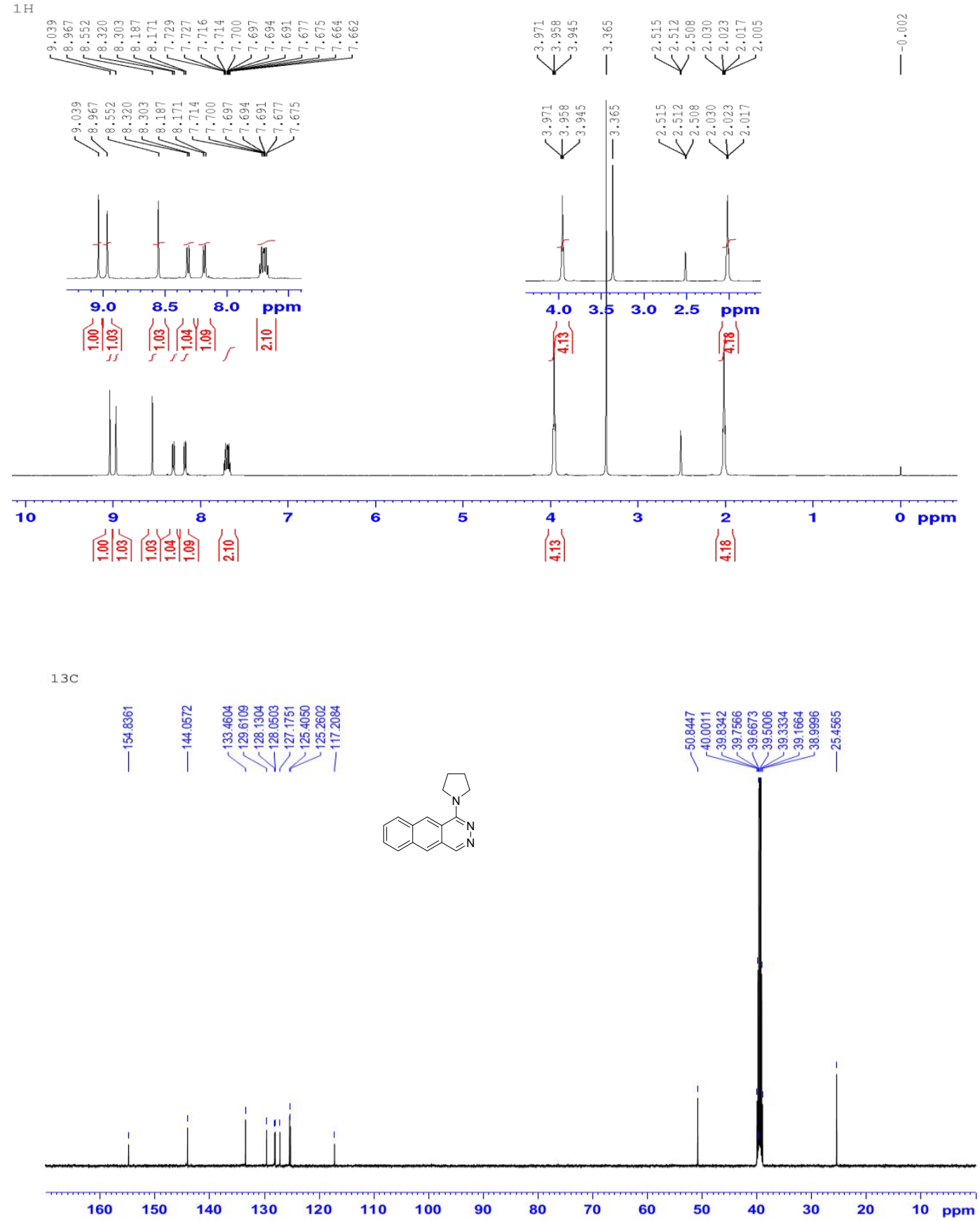


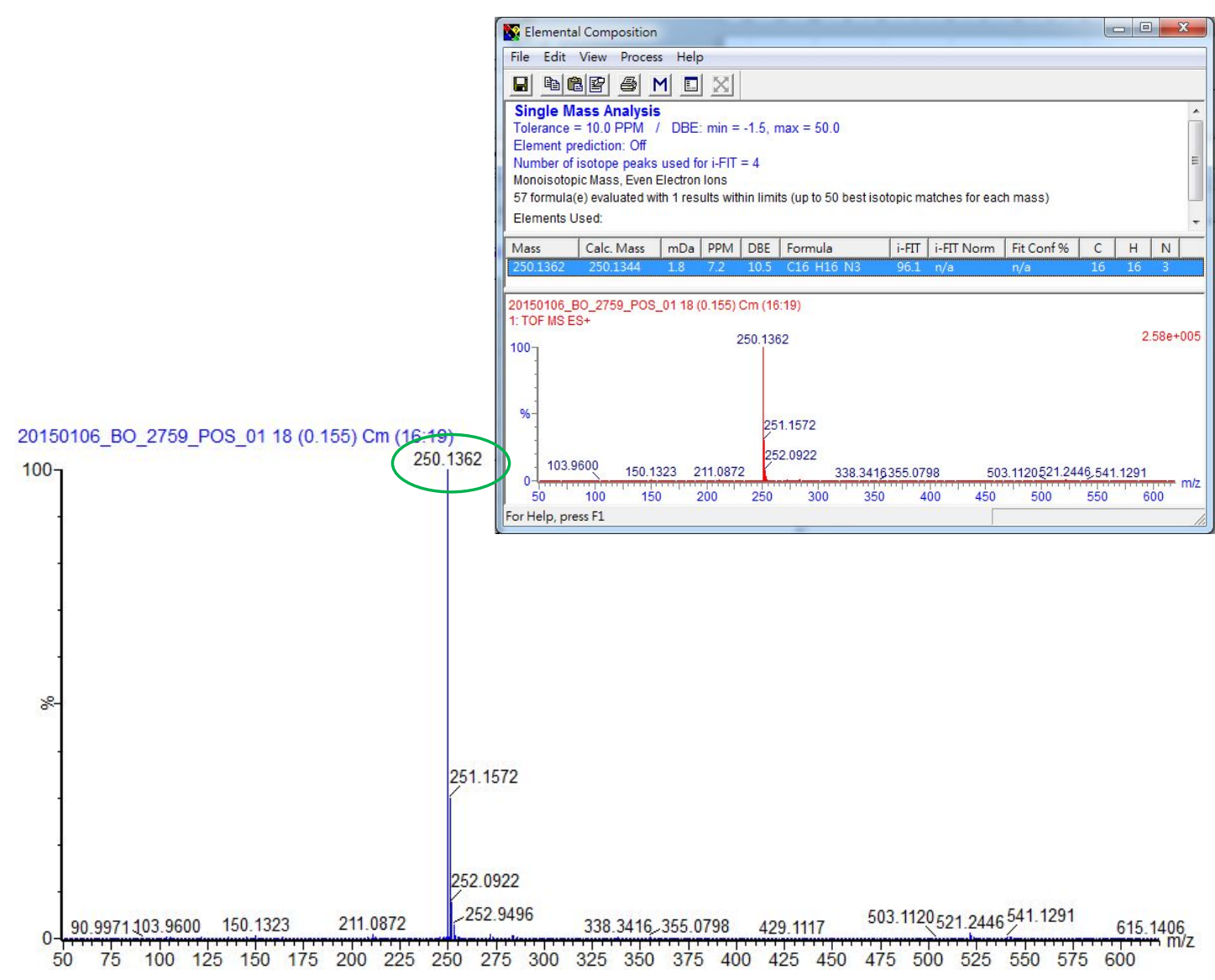




\section{Compound 16c (500 MHz, $\left.\mathrm{CDCl}_{3}\right)$}
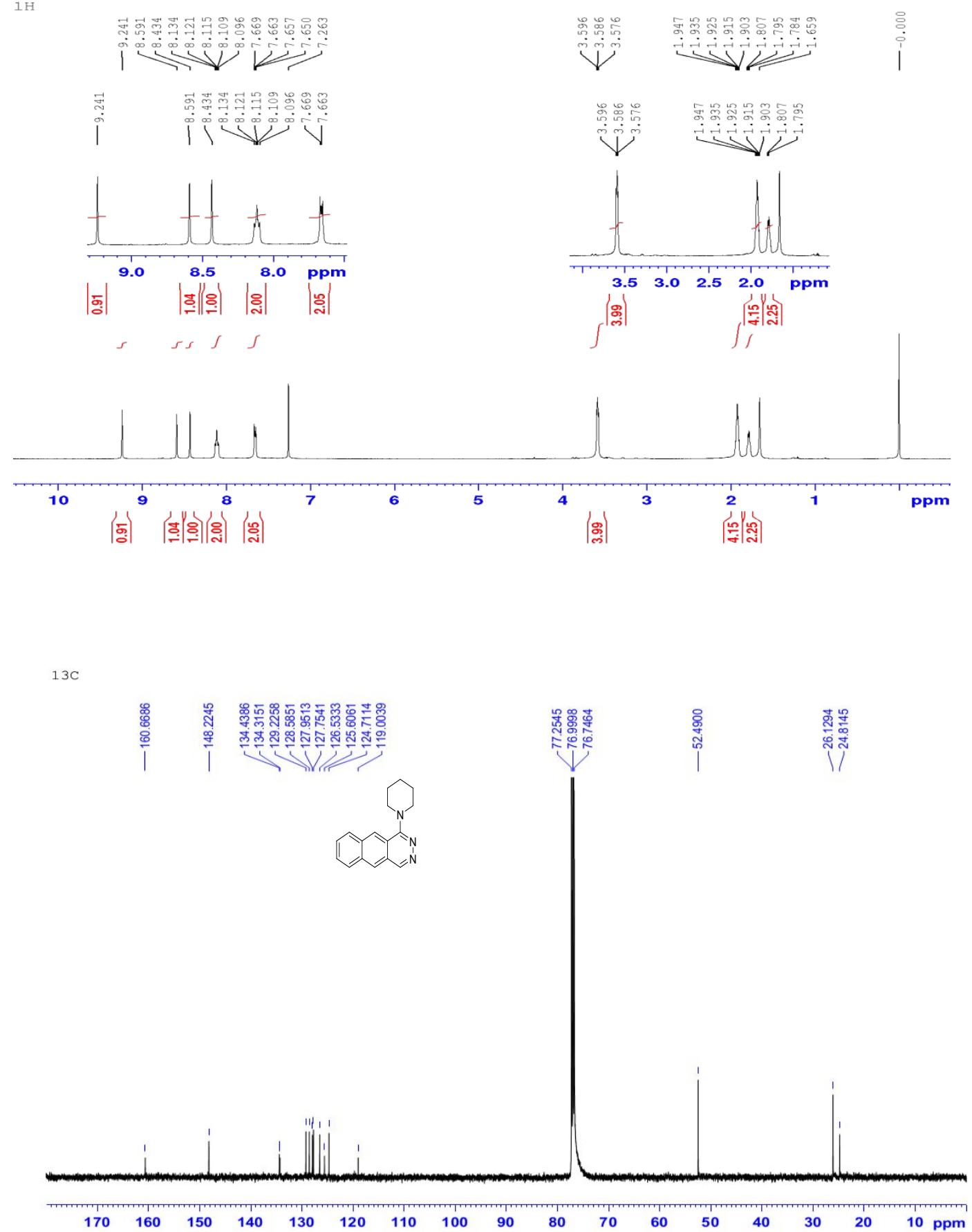


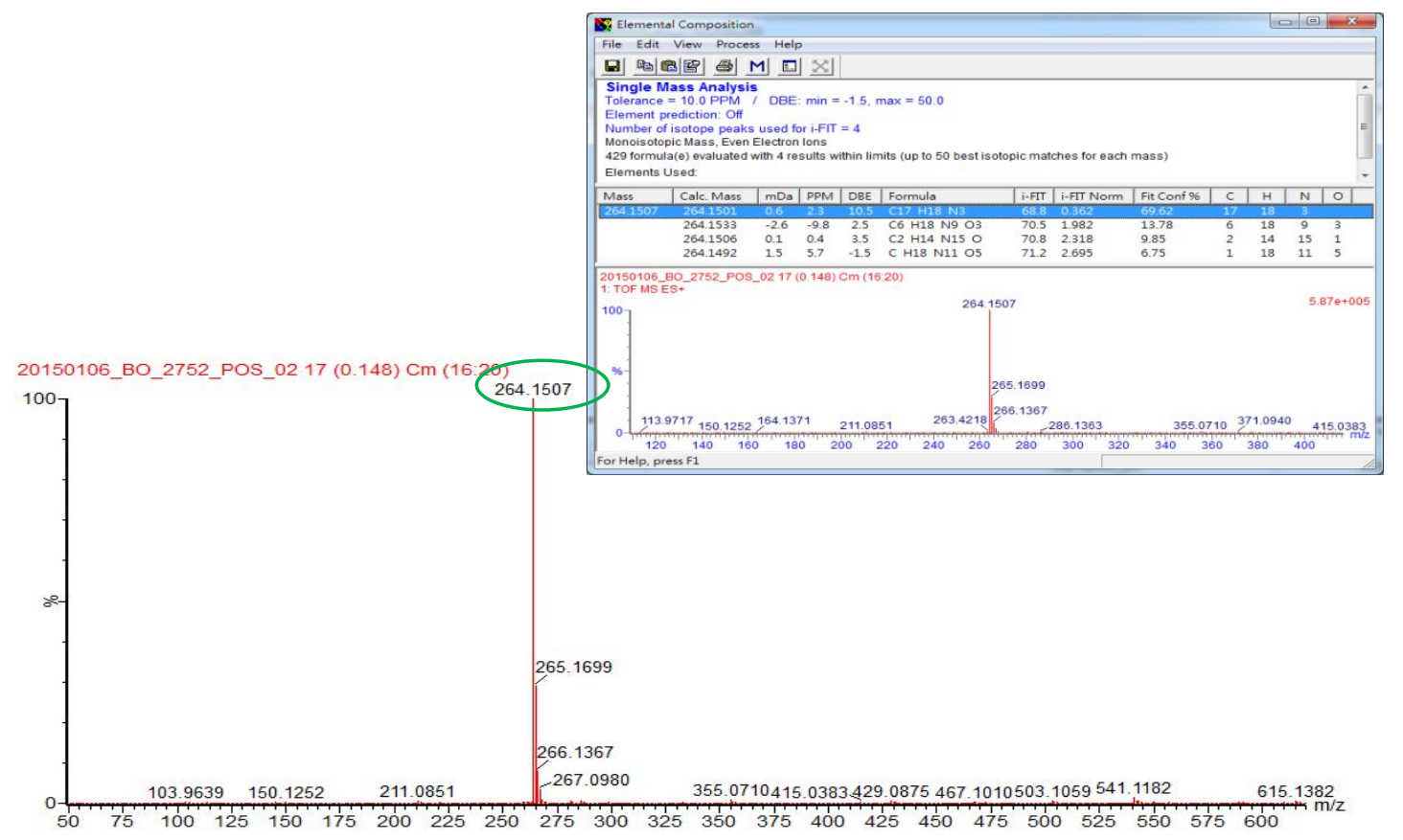




\section{Compound 16d (500 MHz, DMSO- $\left.d_{6}\right)$}

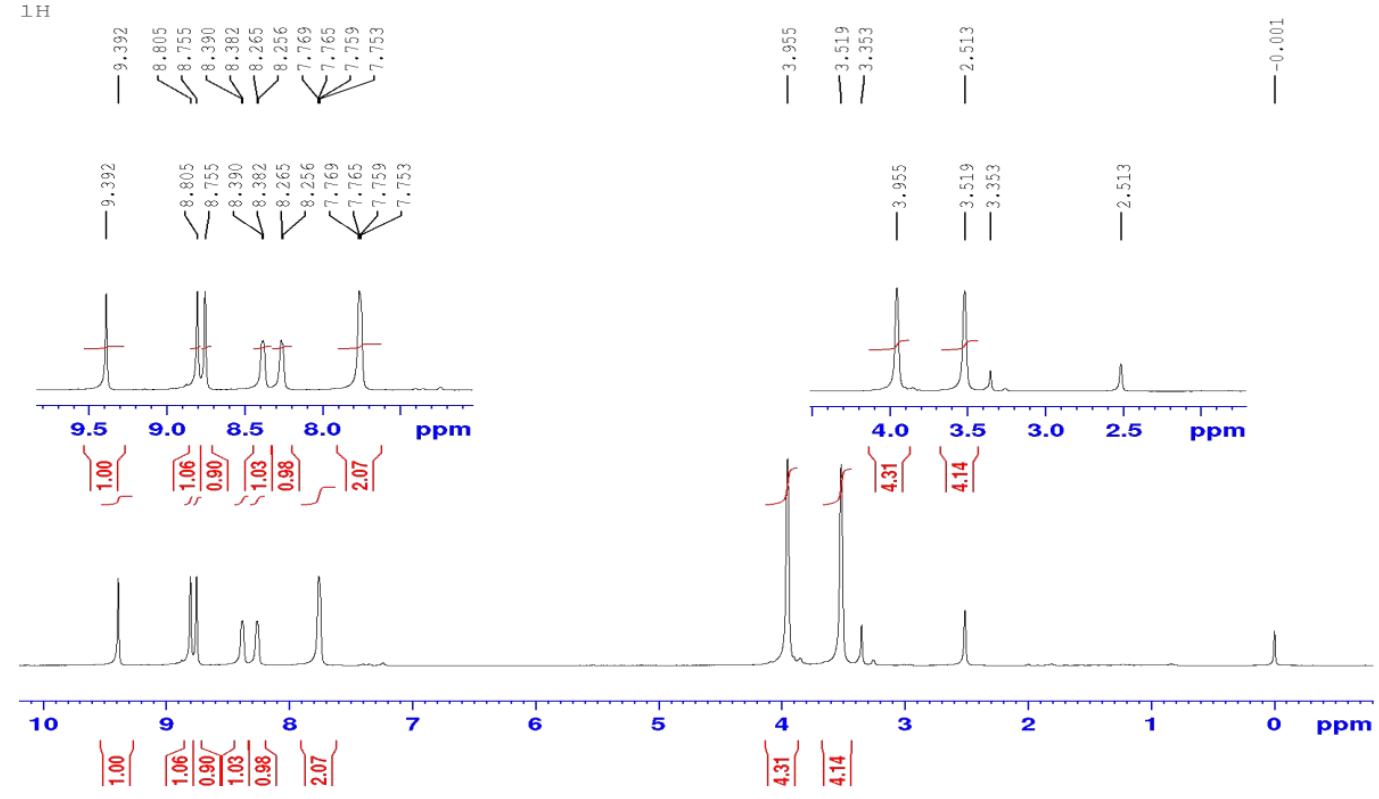

$13 c$
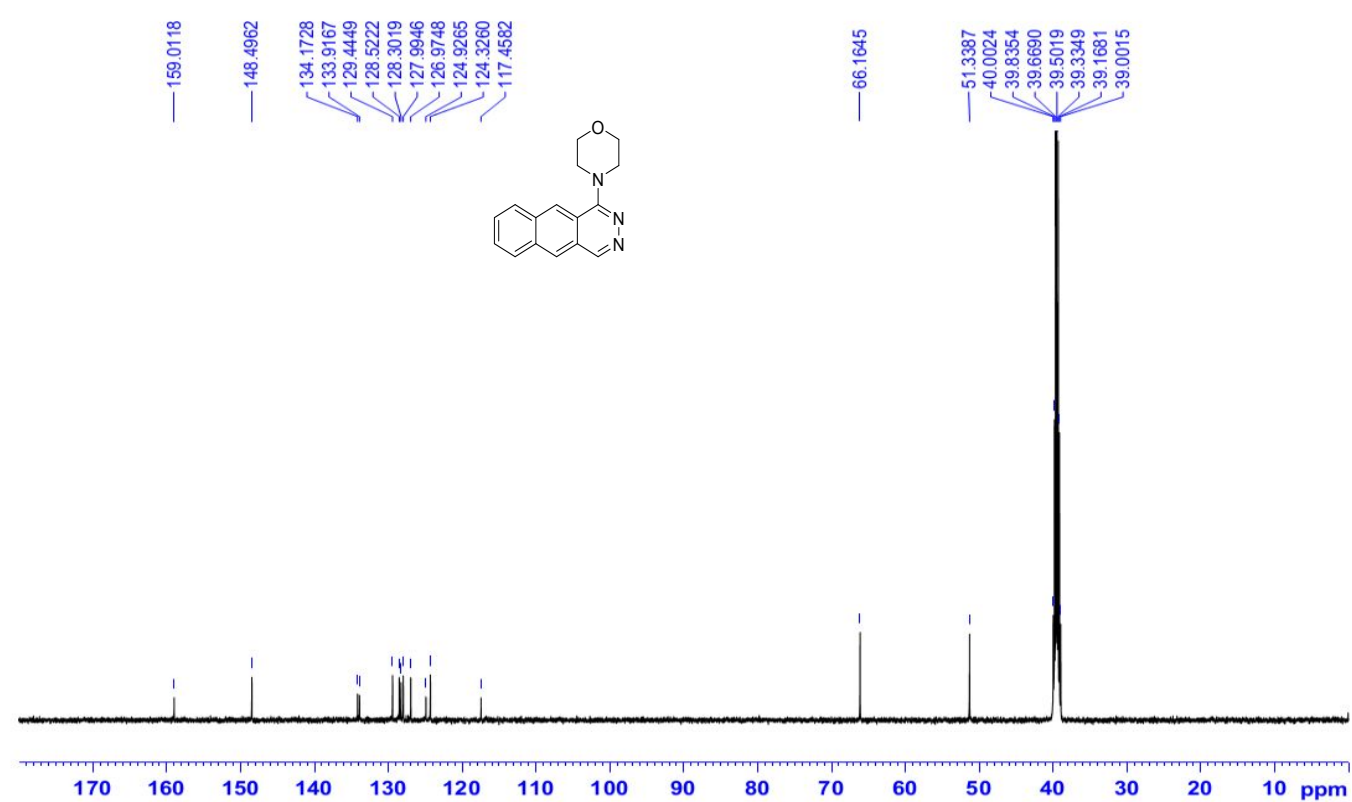


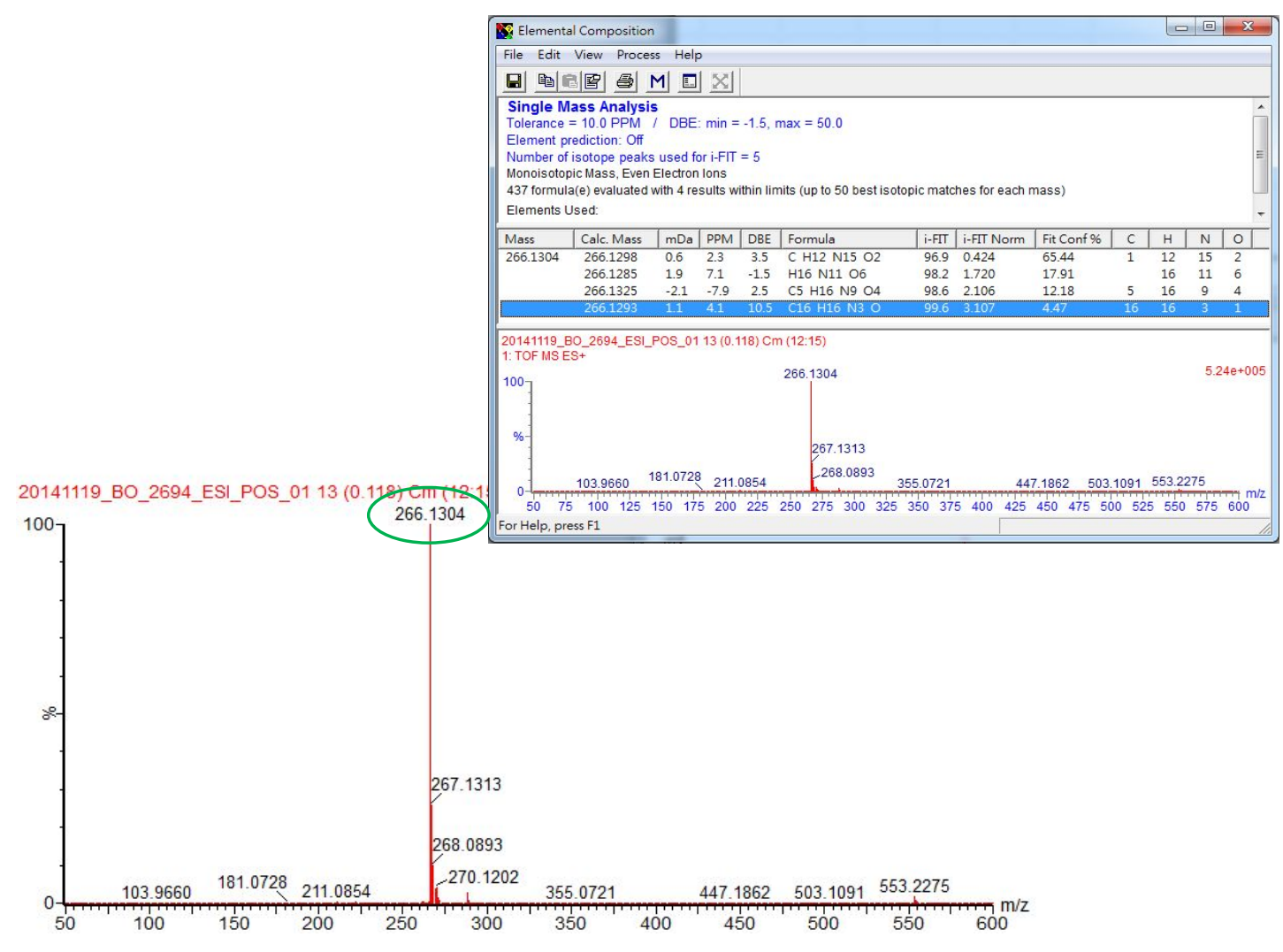




\section{Compound 16e (500 $\left.\mathrm{MHz}, \mathrm{CDCl}_{3}\right)$}
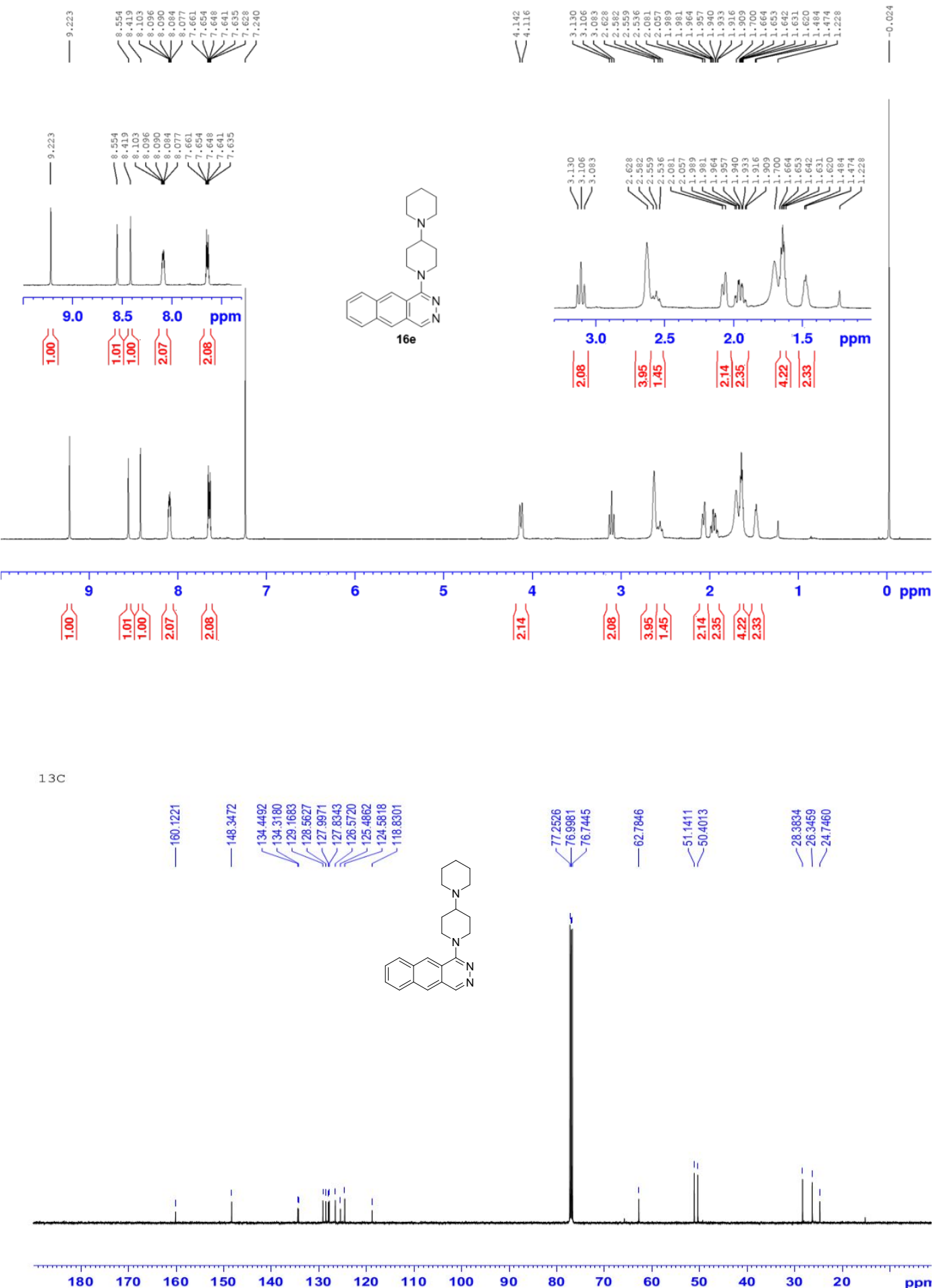


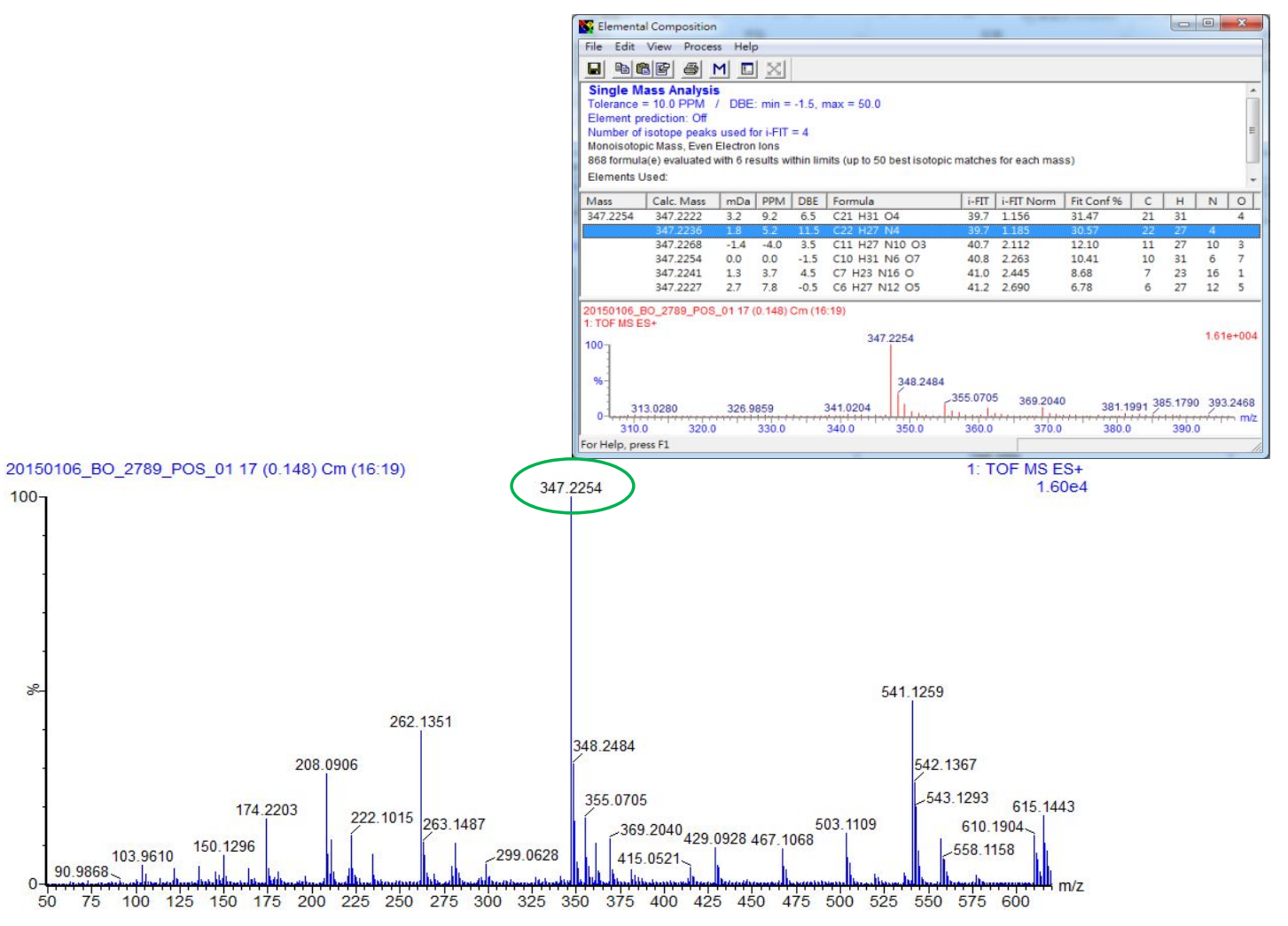


Compound 17a (500 MHz, DMSO- $\left.d_{6}\right)$

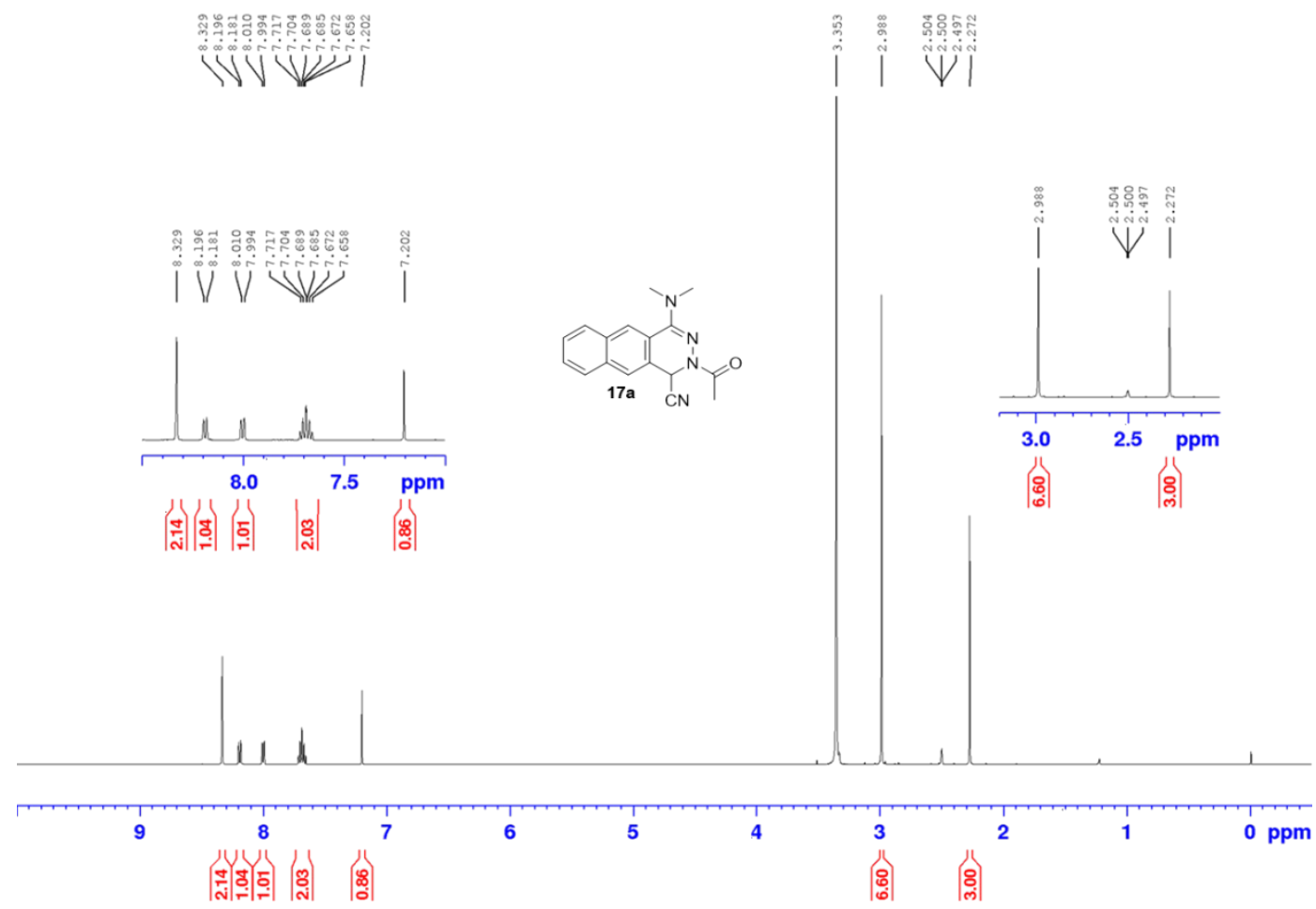

$13 \mathrm{C}$
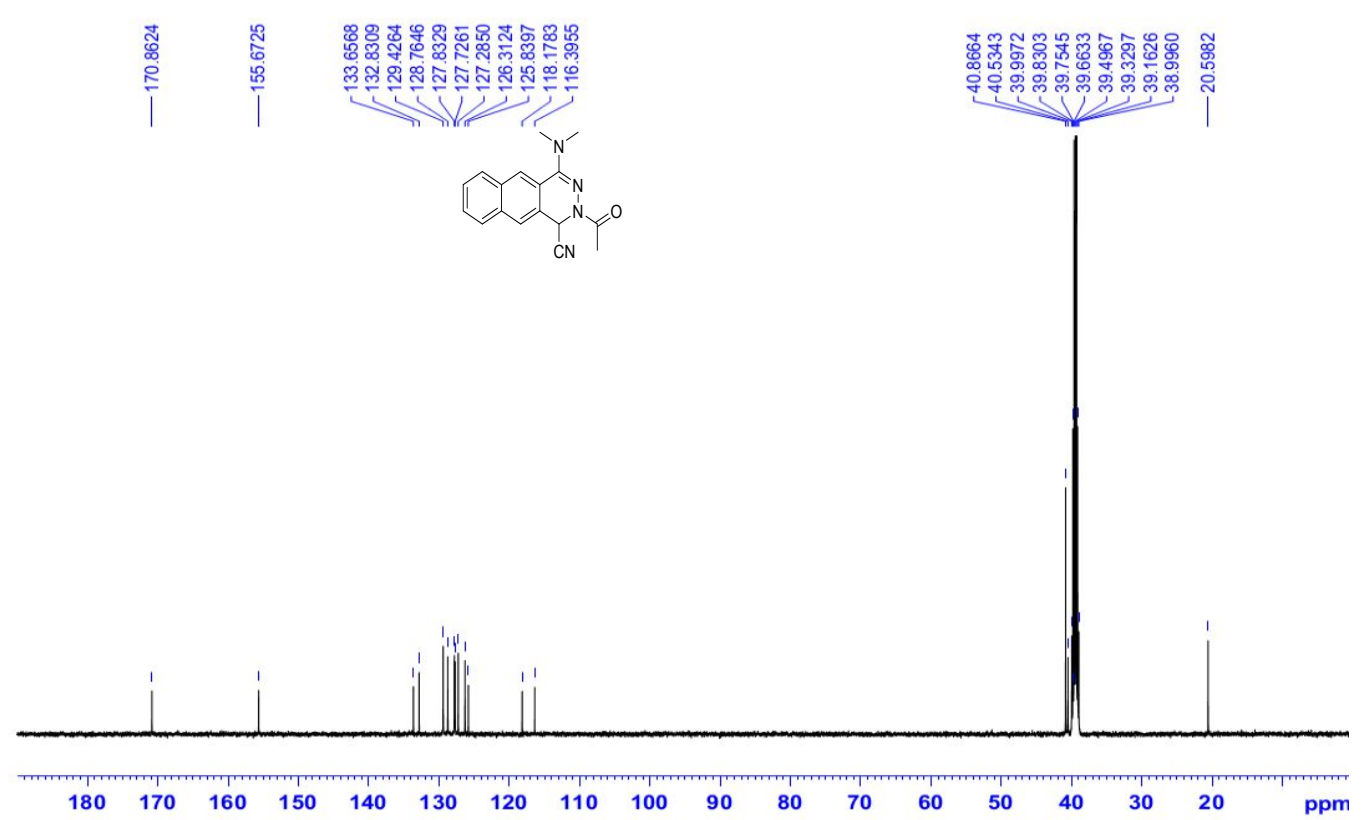


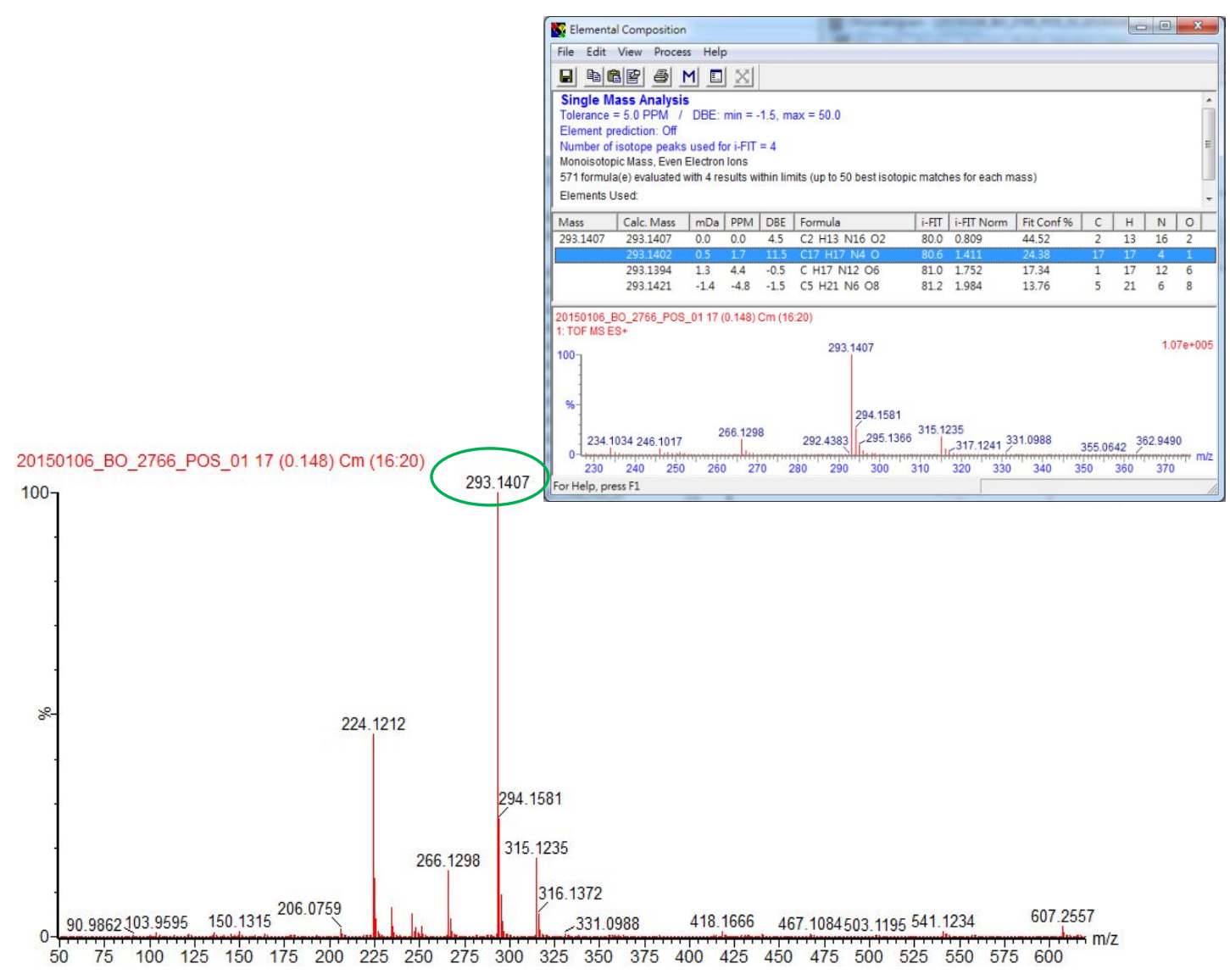




\section{Compound 17b (500 MHz, $\mathrm{CDCl}_{3}$ )}

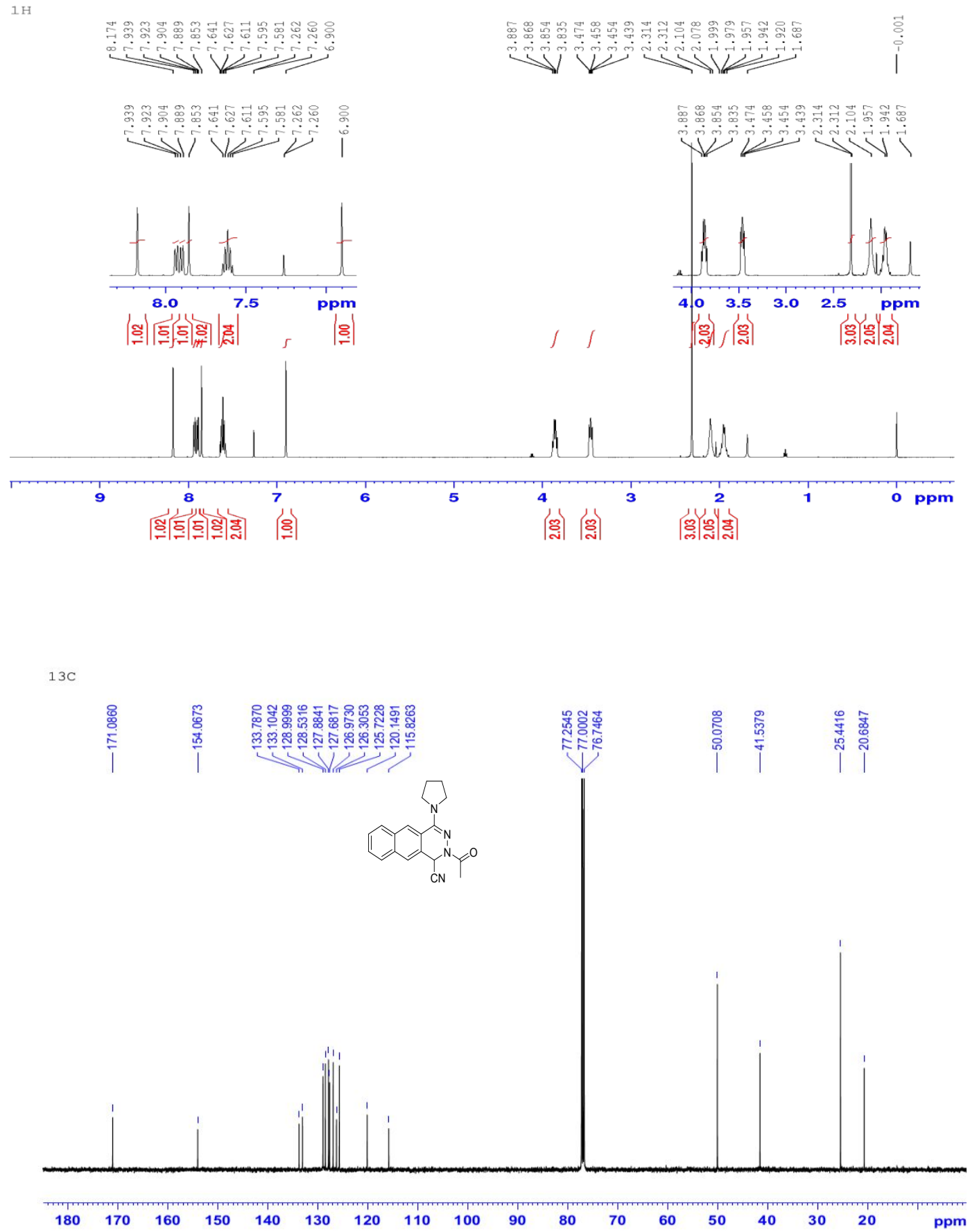




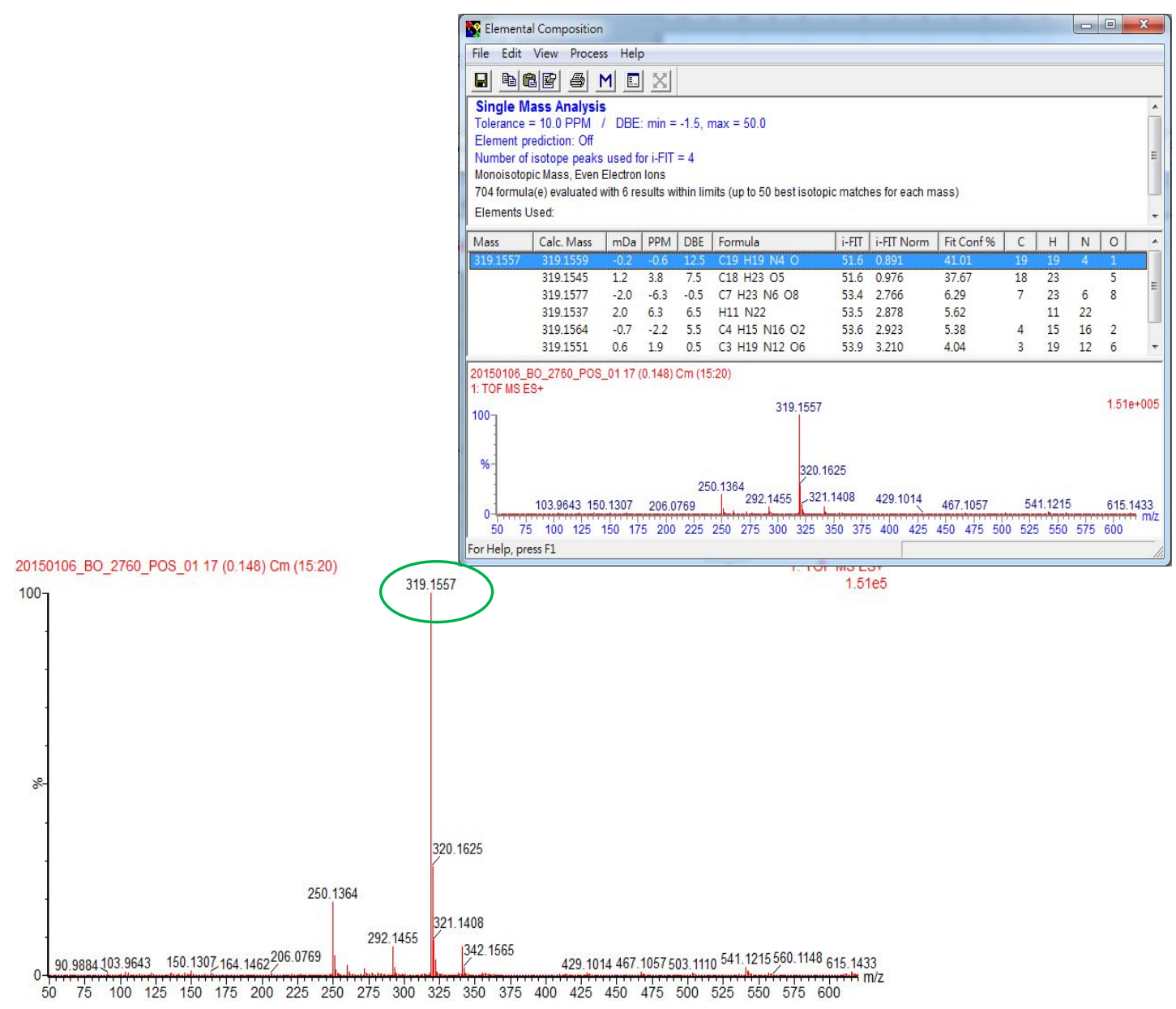




\section{Compound 17c (500 MHz, DMSO-d $\left.d_{6}\right)$}

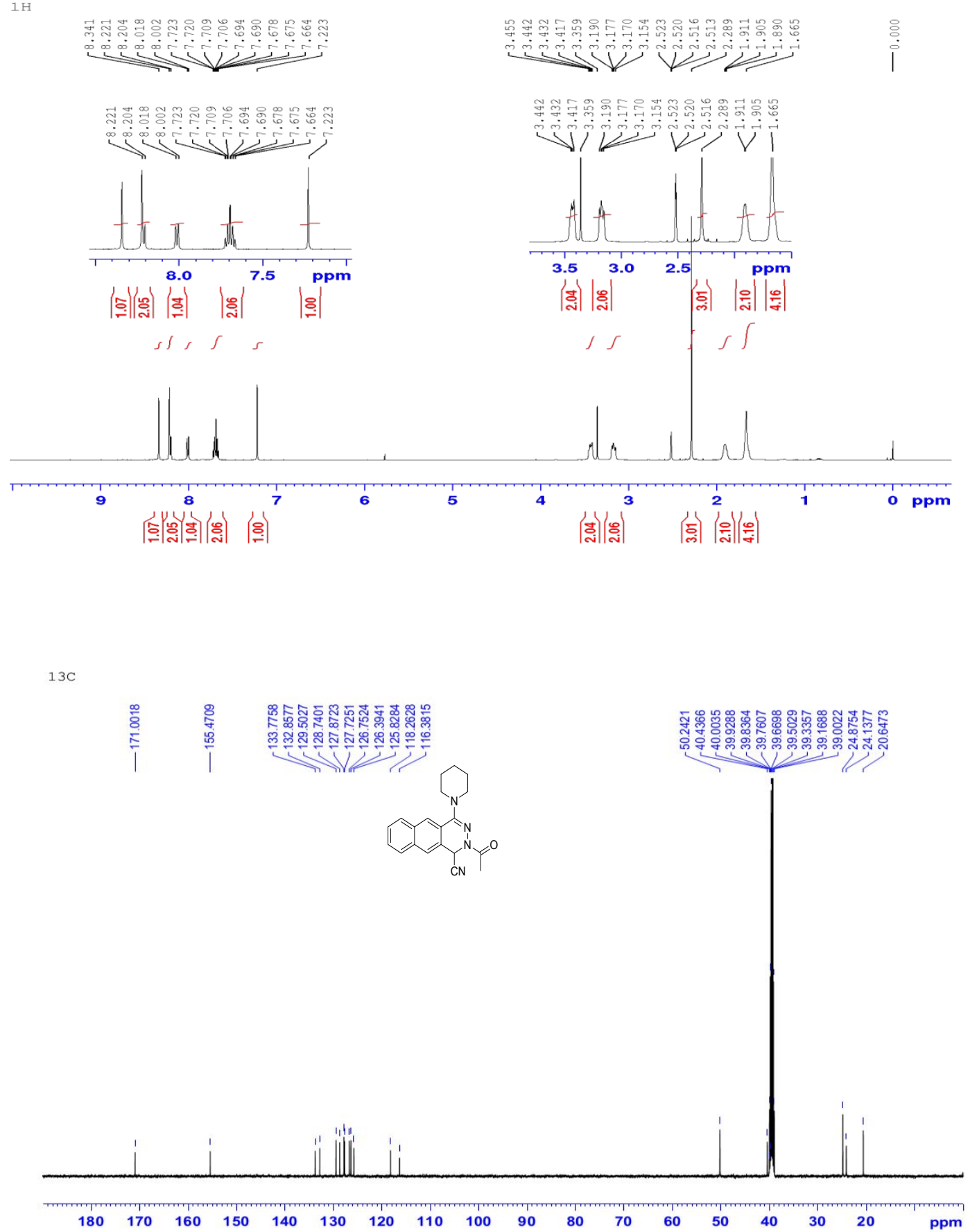


PLUNO

20150106_BO_2753_POS_03 41 (0.330) Cm (20:48)

100

$0.9763^{103.9565} 150.1283$
Elemental Composition

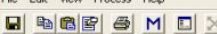

Single Mass Analysis

Tolerance $=15.0 \mathrm{PPM}$
Element prediction: Of

Number of isotope peaks used for $\mathrm{i}-\mathrm{FIT}=5$

182 formula(e) evaluated with 11 results within limits (all results (up to 1000) for each mass)

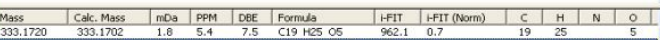

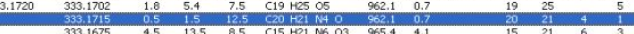

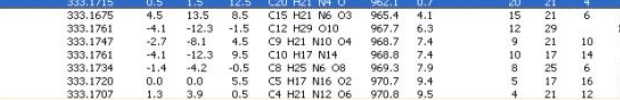

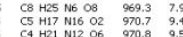

PLUNO
20150106_BO_2753_POS_0 0341 (0.330) cm (20:48)

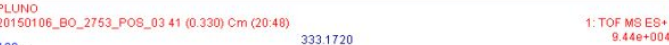

$281.0521 \quad 334.1752$

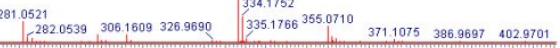

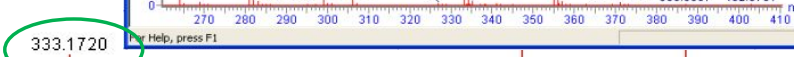

264.1505 .0521

$5.1548 \quad 429.0901 \quad \mid$ $306.1609 \int_{-356}^{355.0710} \quad 429.0901467 .1034$

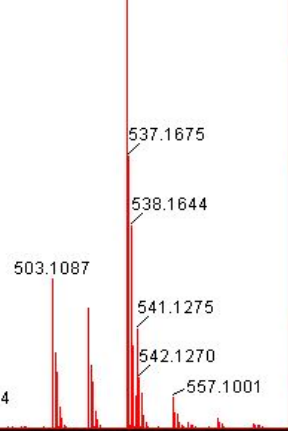

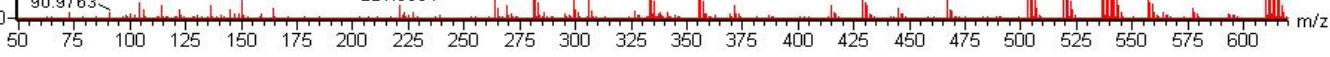




\section{Compound 17d (500 MHz, DMSO- $\left.d_{6}\right)$}

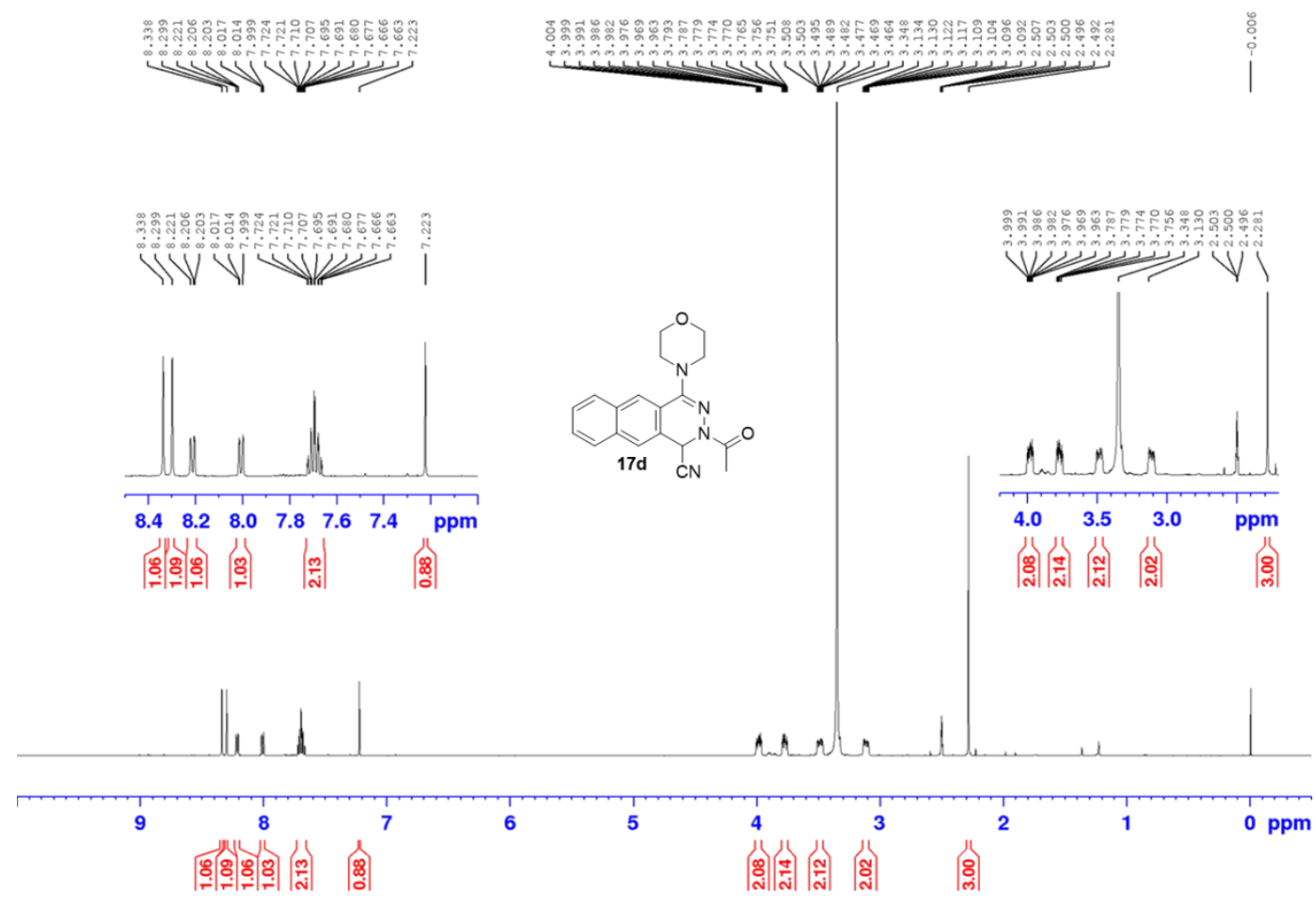

$13 \mathrm{C}$
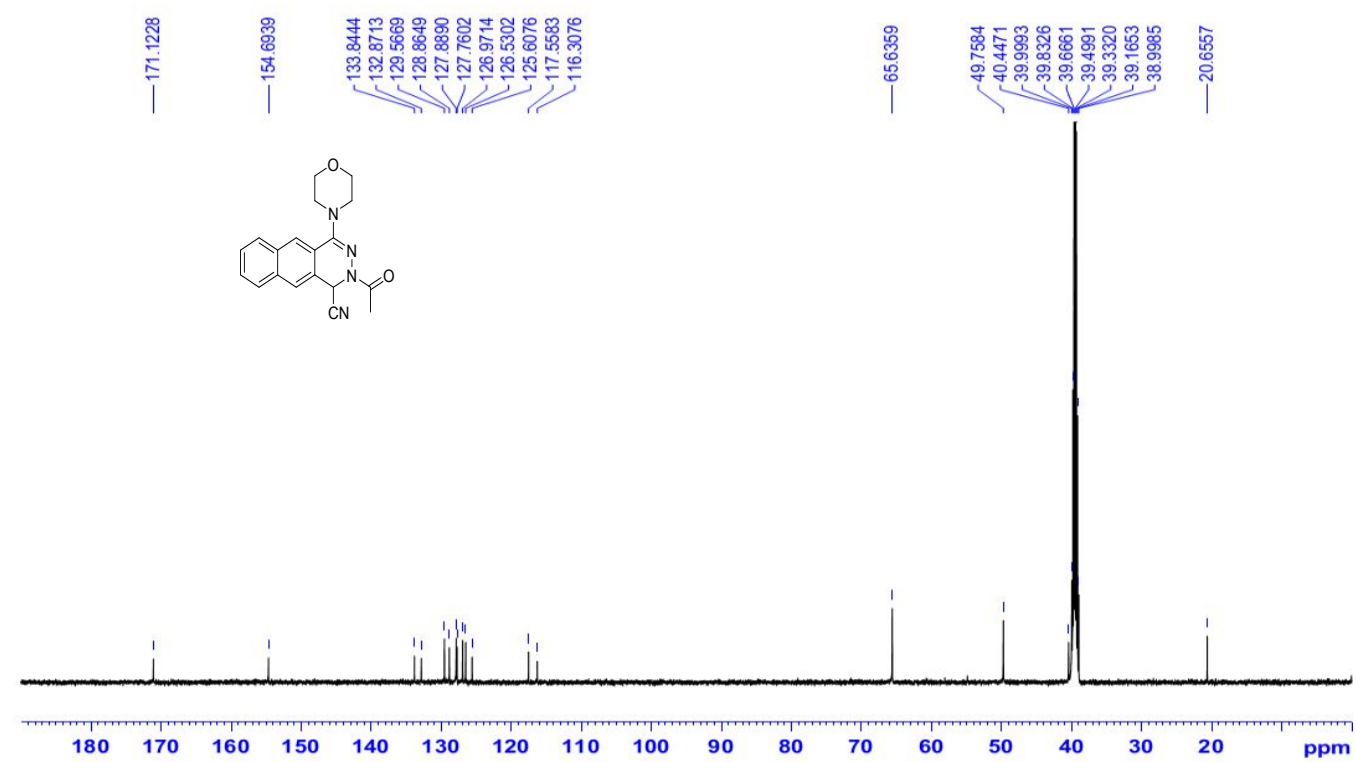


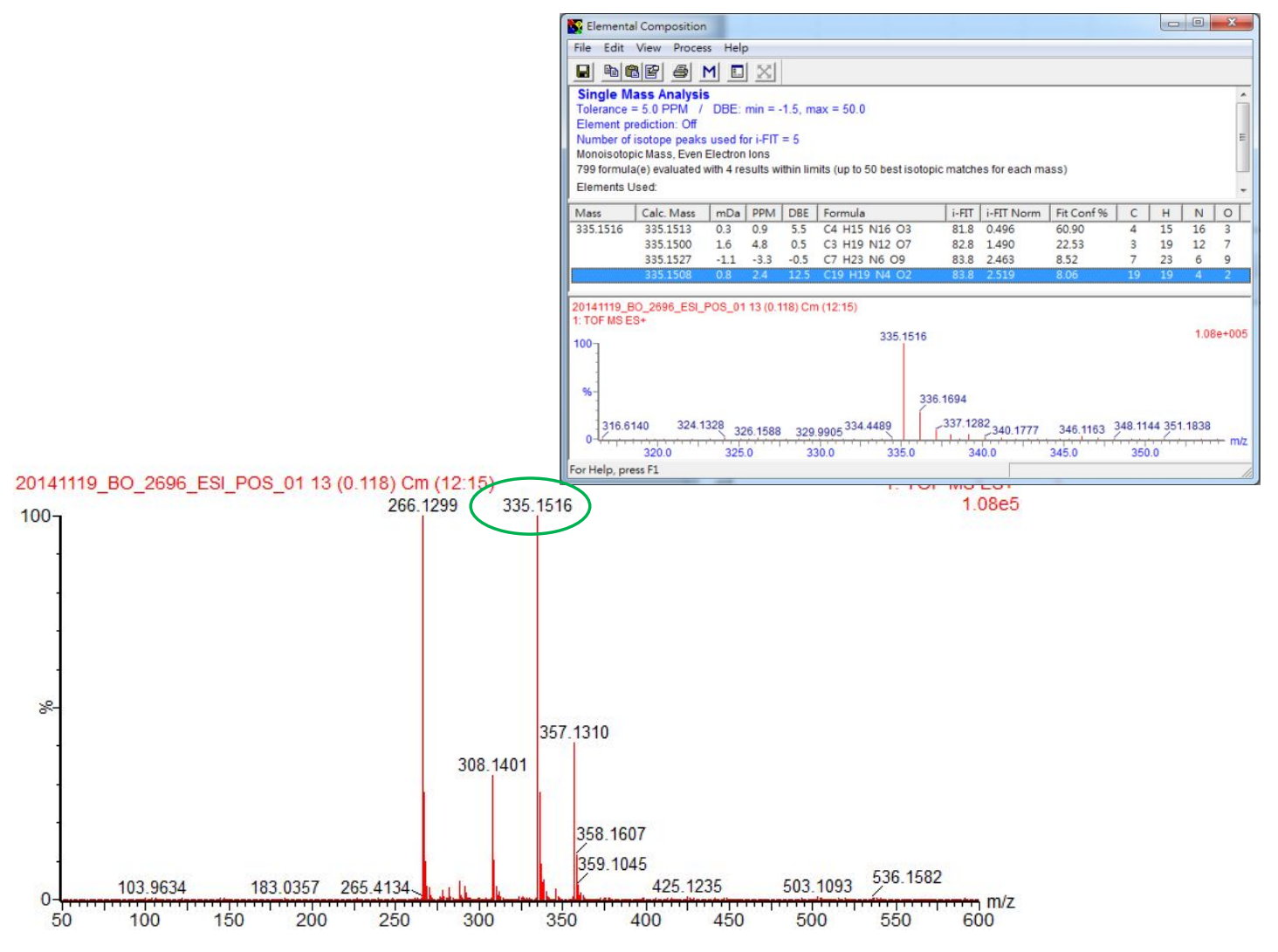




\section{Compound 17e (500 $\left.\mathrm{MHz}, \mathrm{CDCl}_{3}\right)$}

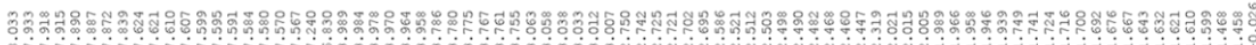
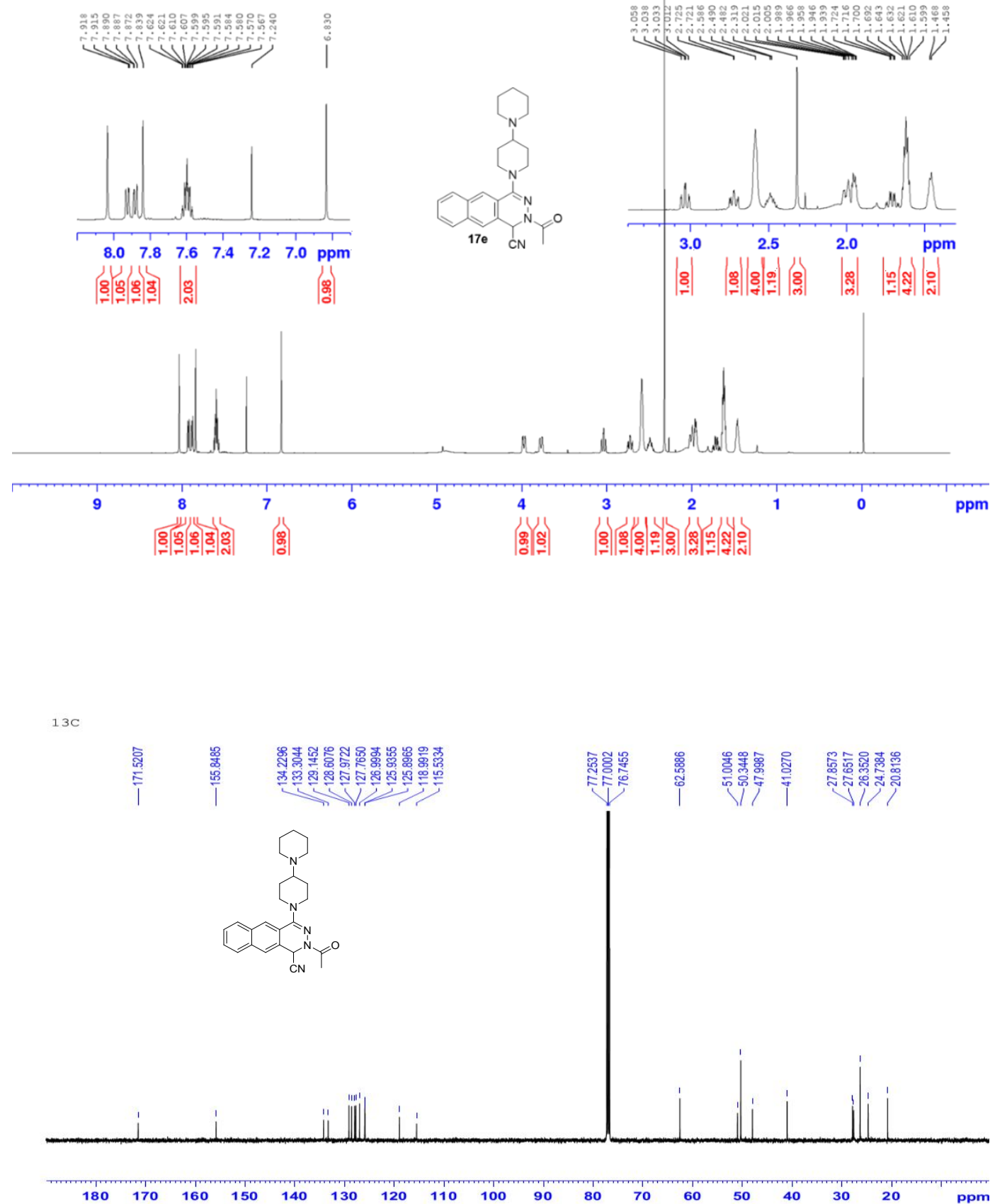
20150106_BO_2790_POS_02 17 (0.148) Cm (11.24)
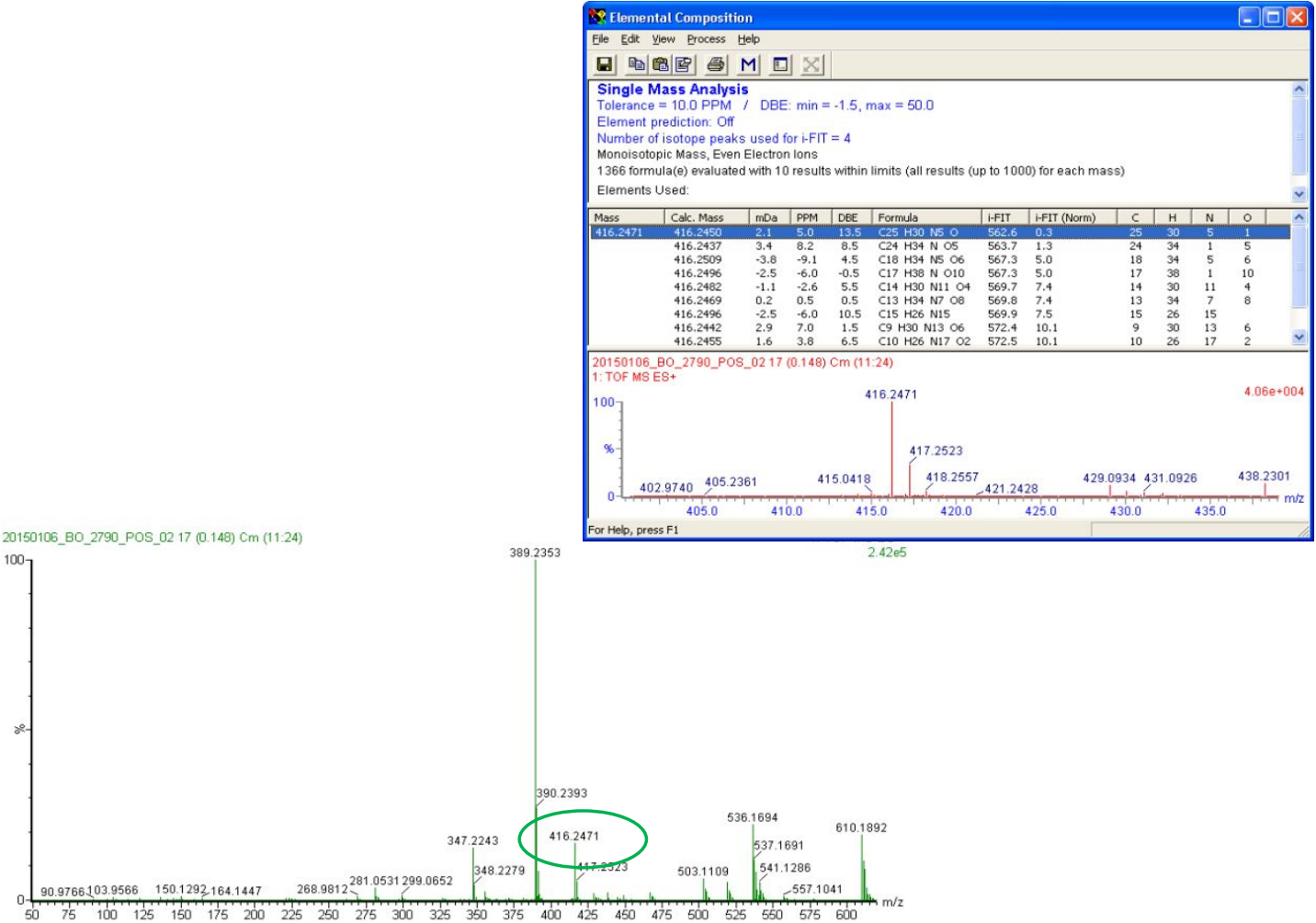

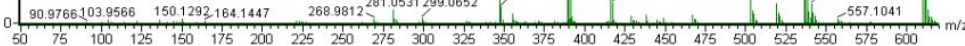


Compound 18a (500 MHz, DMSO- $d_{6}$ )

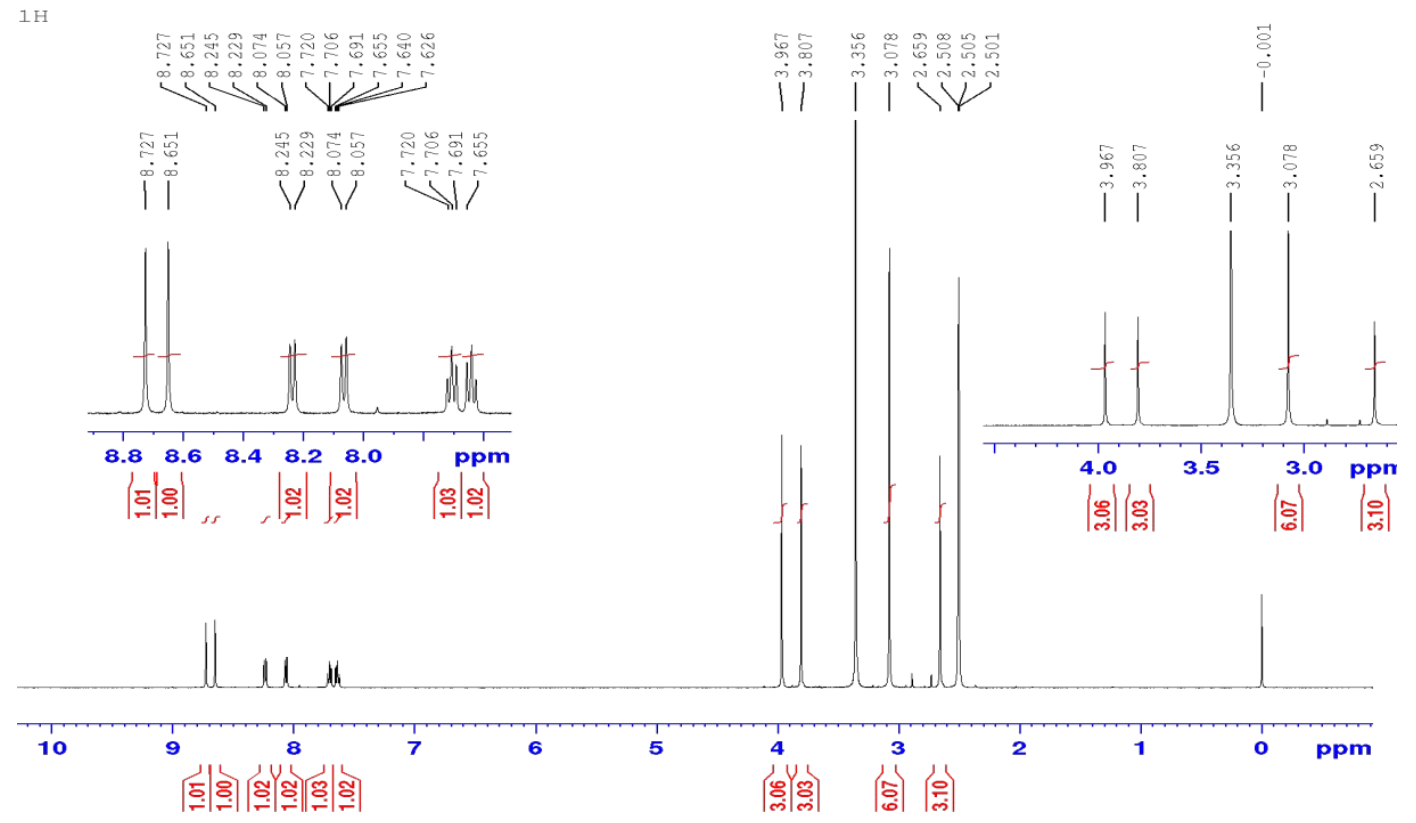

$13 \mathrm{C}$

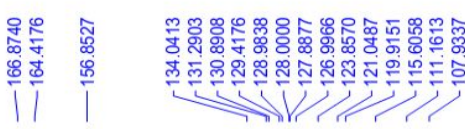
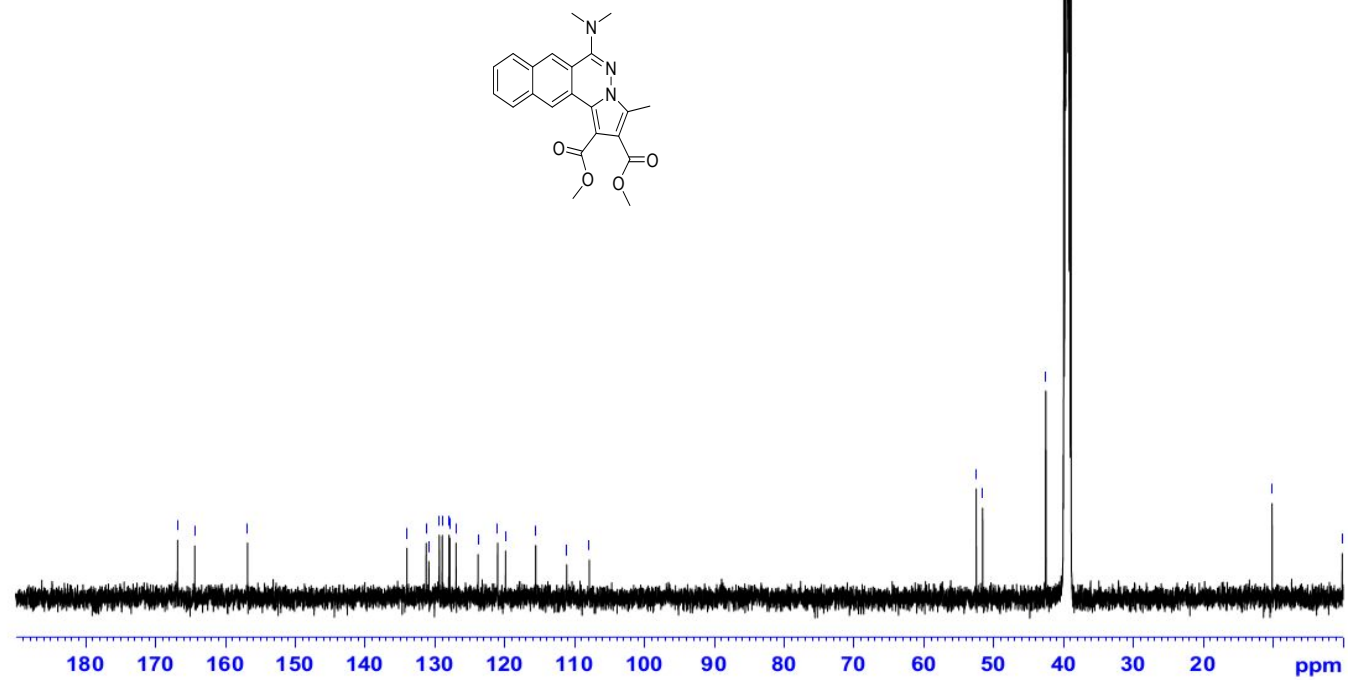

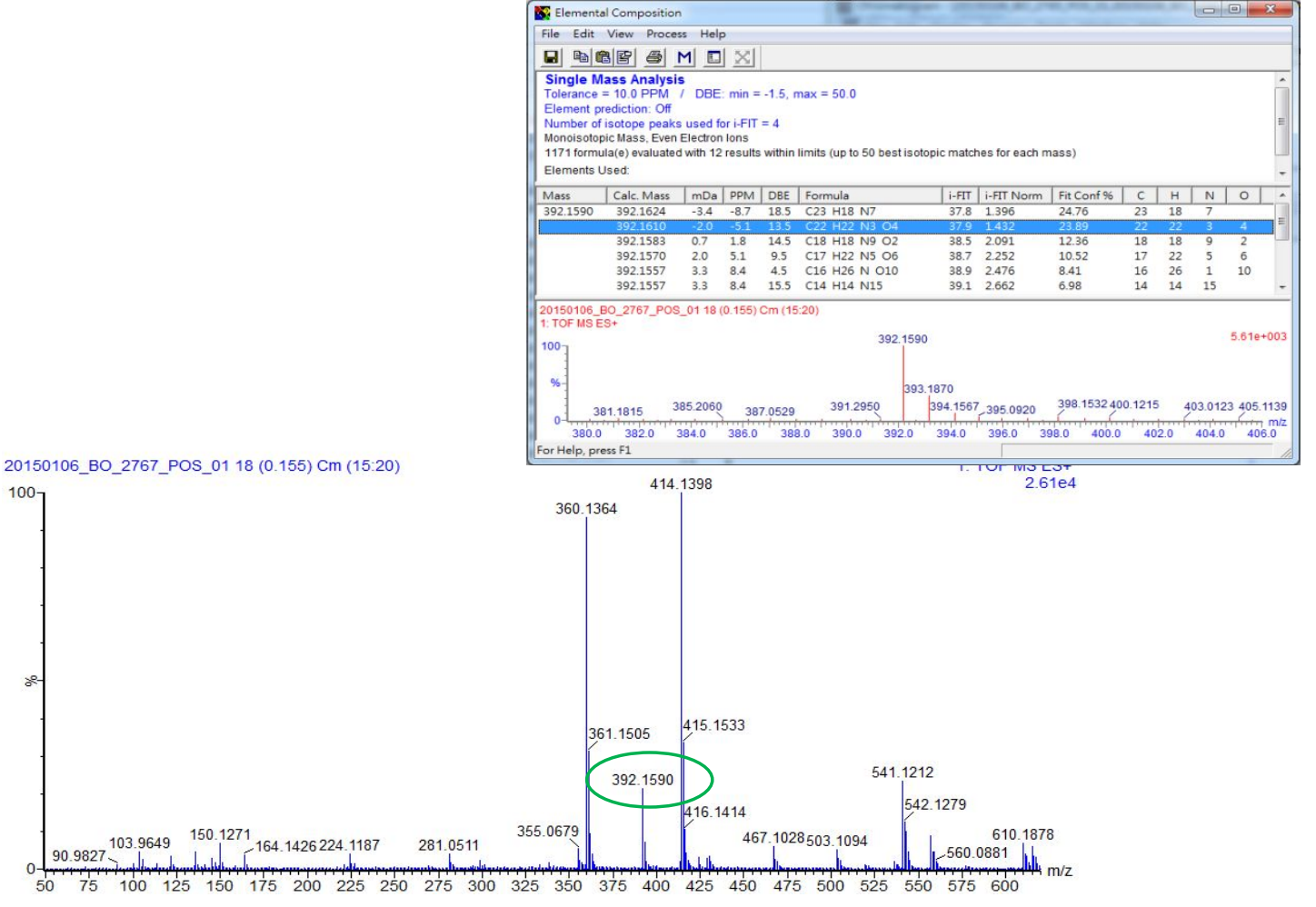


\section{Compound 18b (500 MHz, $\left.\mathrm{CDCl}_{3}\right)$}

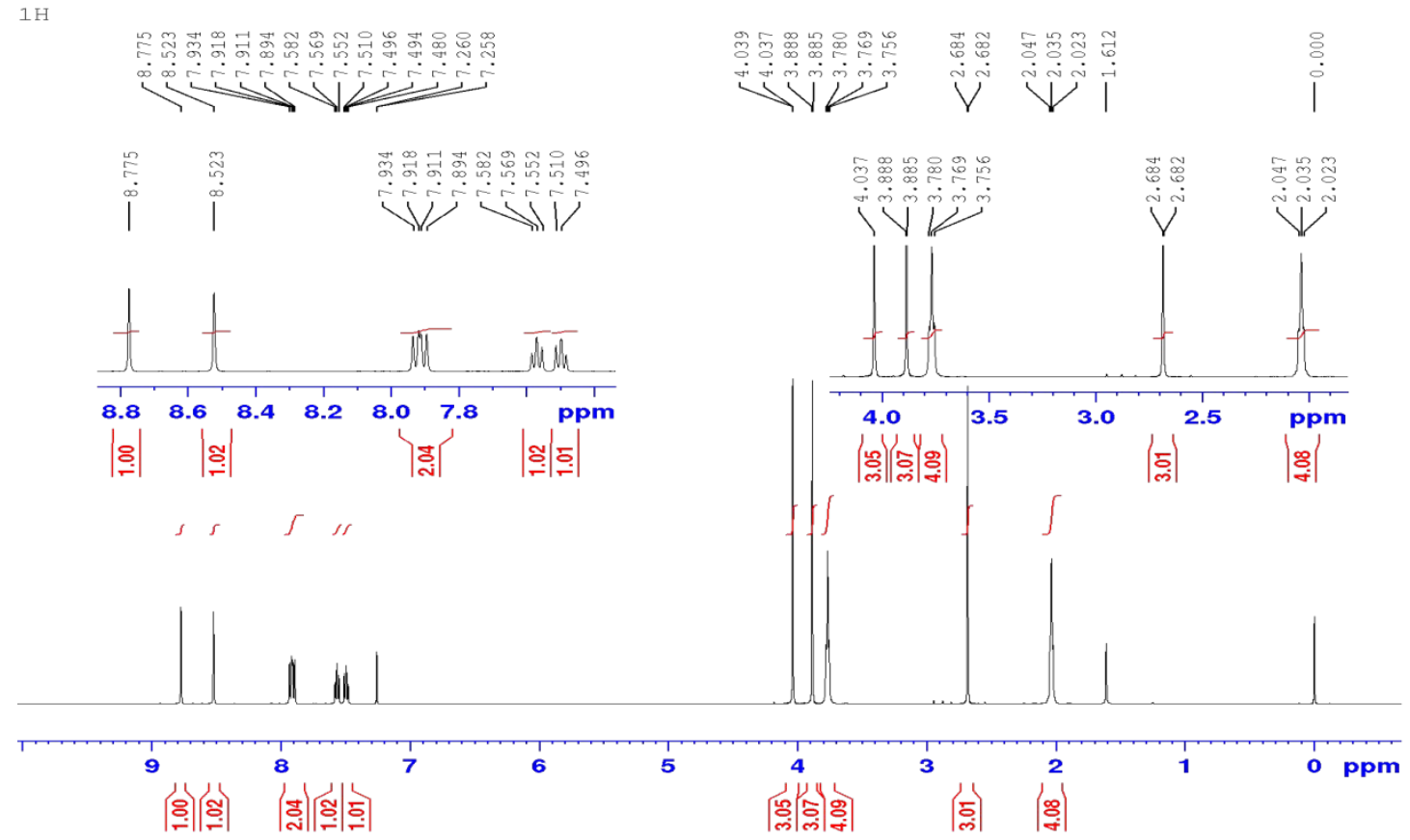

$13 \mathrm{C}$

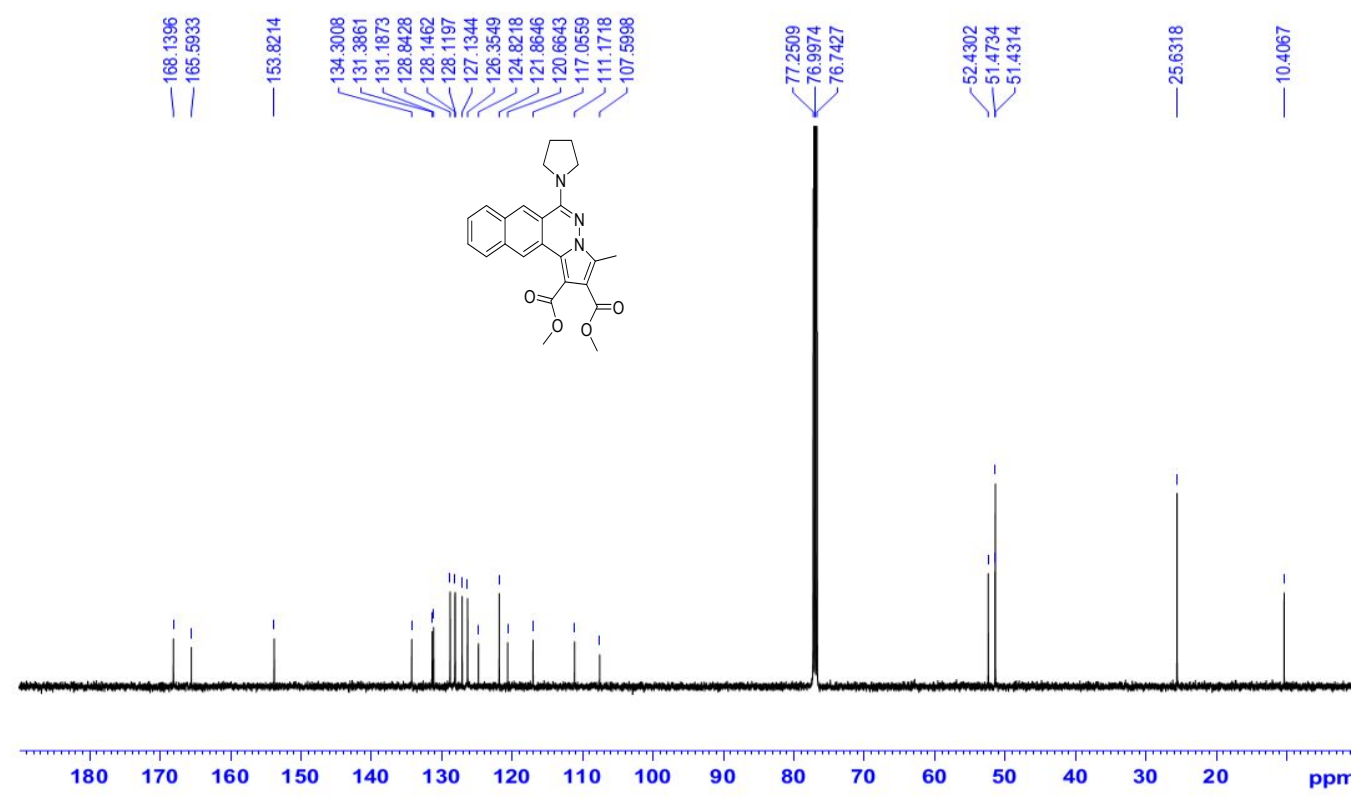




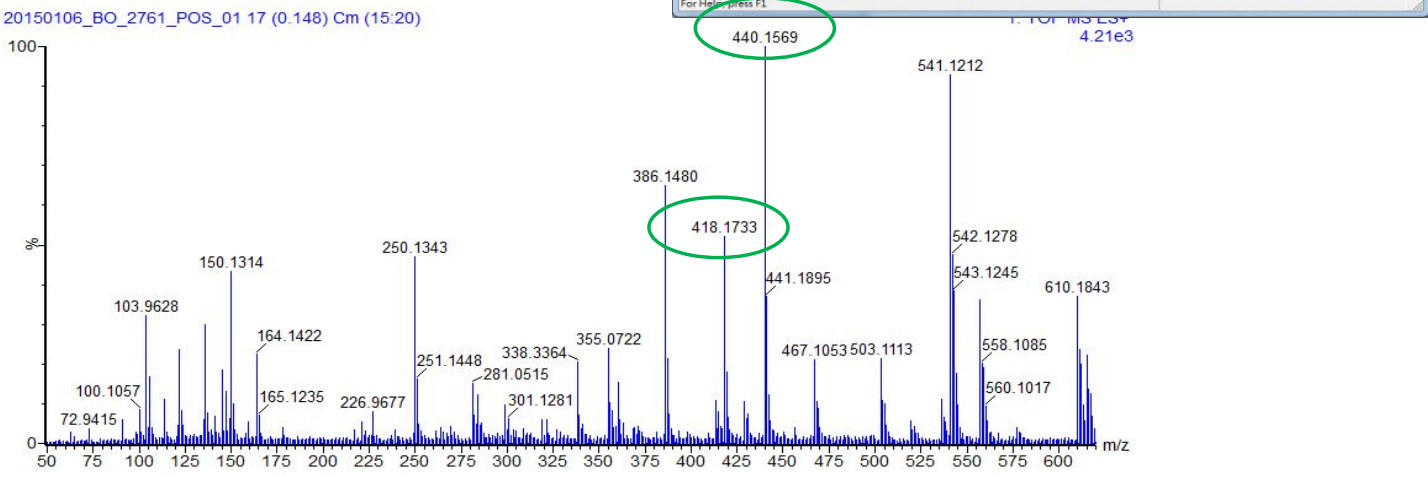




\section{Compound 18c (500 $\left.\mathrm{MHz}, \mathrm{CDCl}_{3}\right)$}
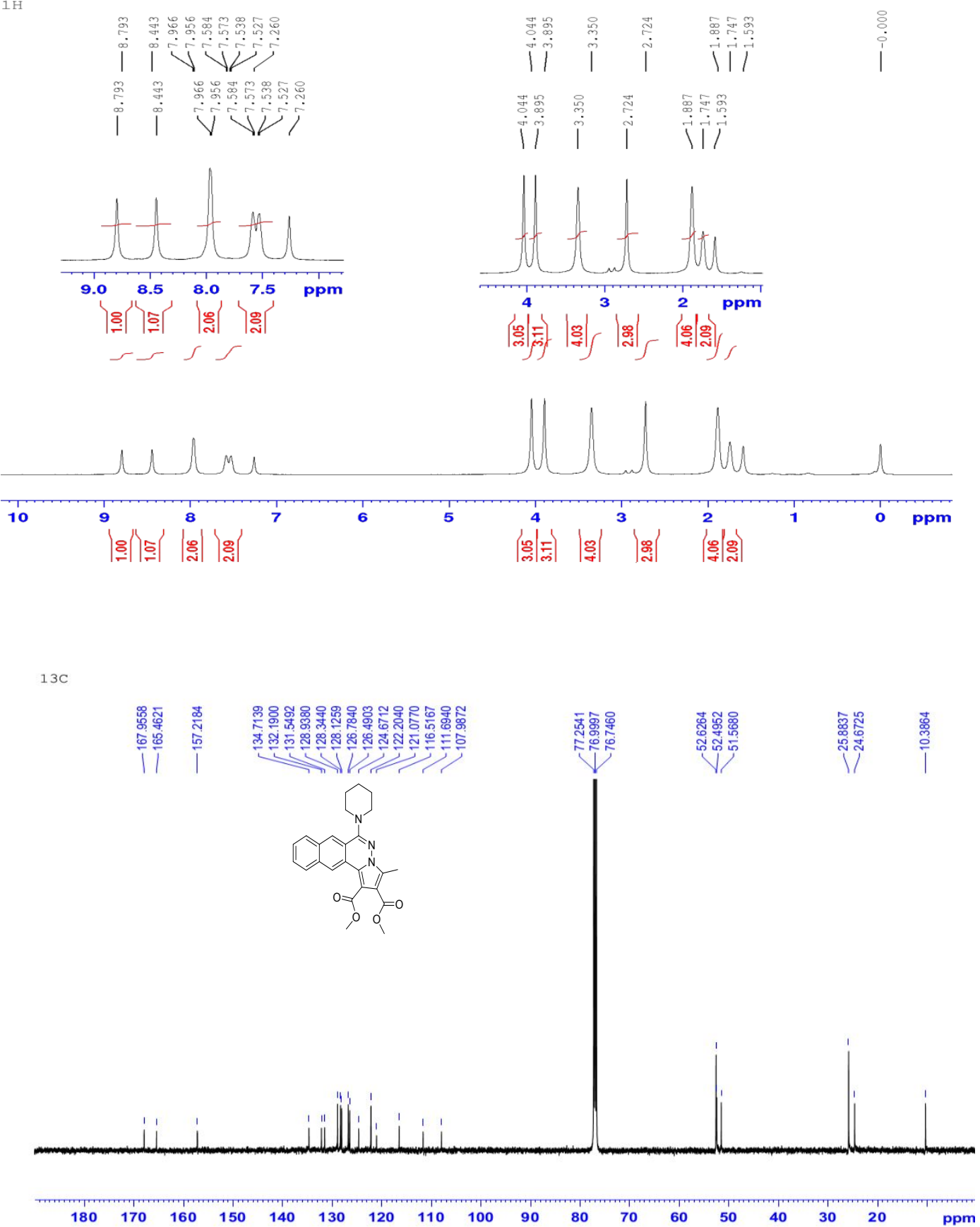


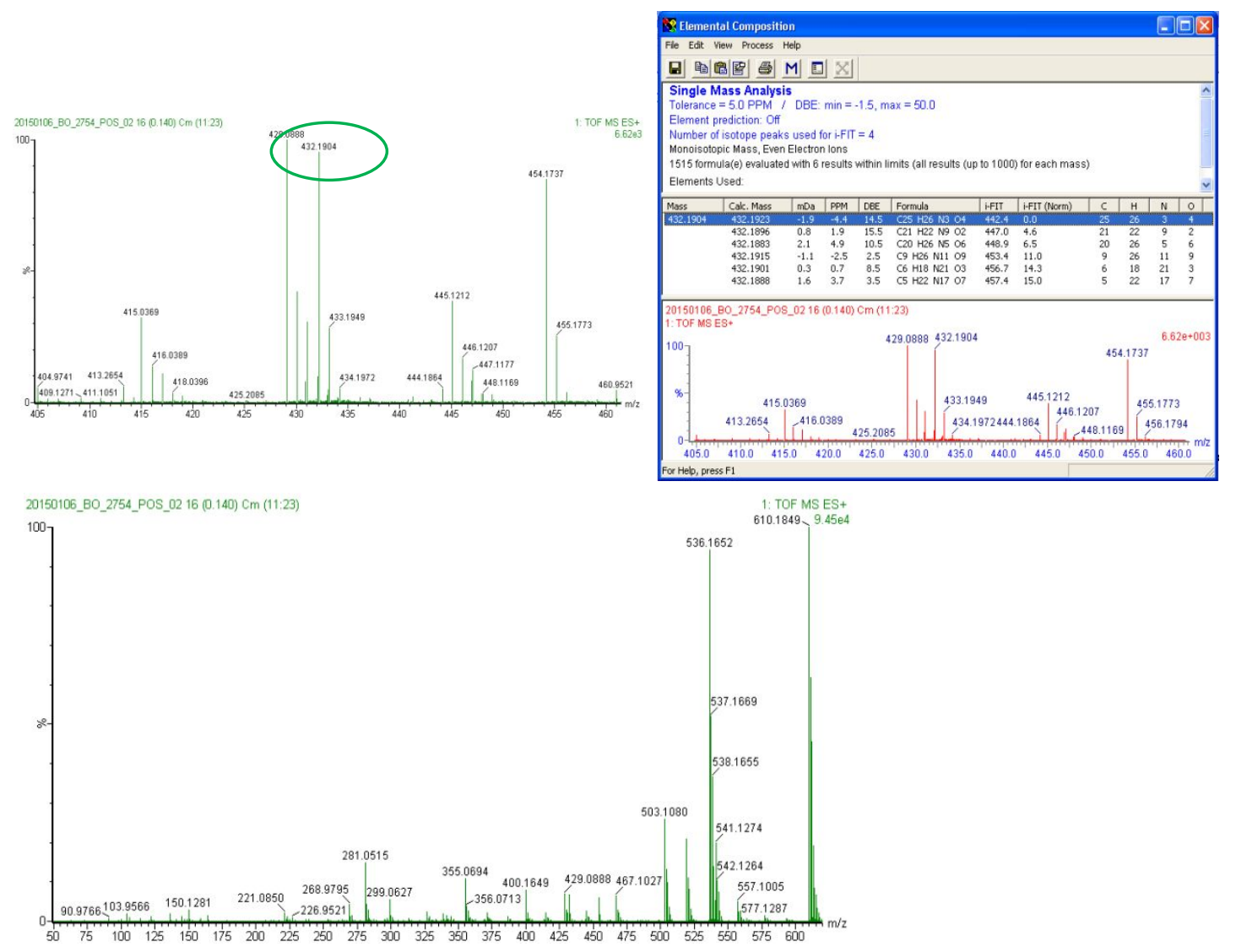


Compound 18d (500 MHz, $\left.\mathrm{CDCl}_{3}\right)$

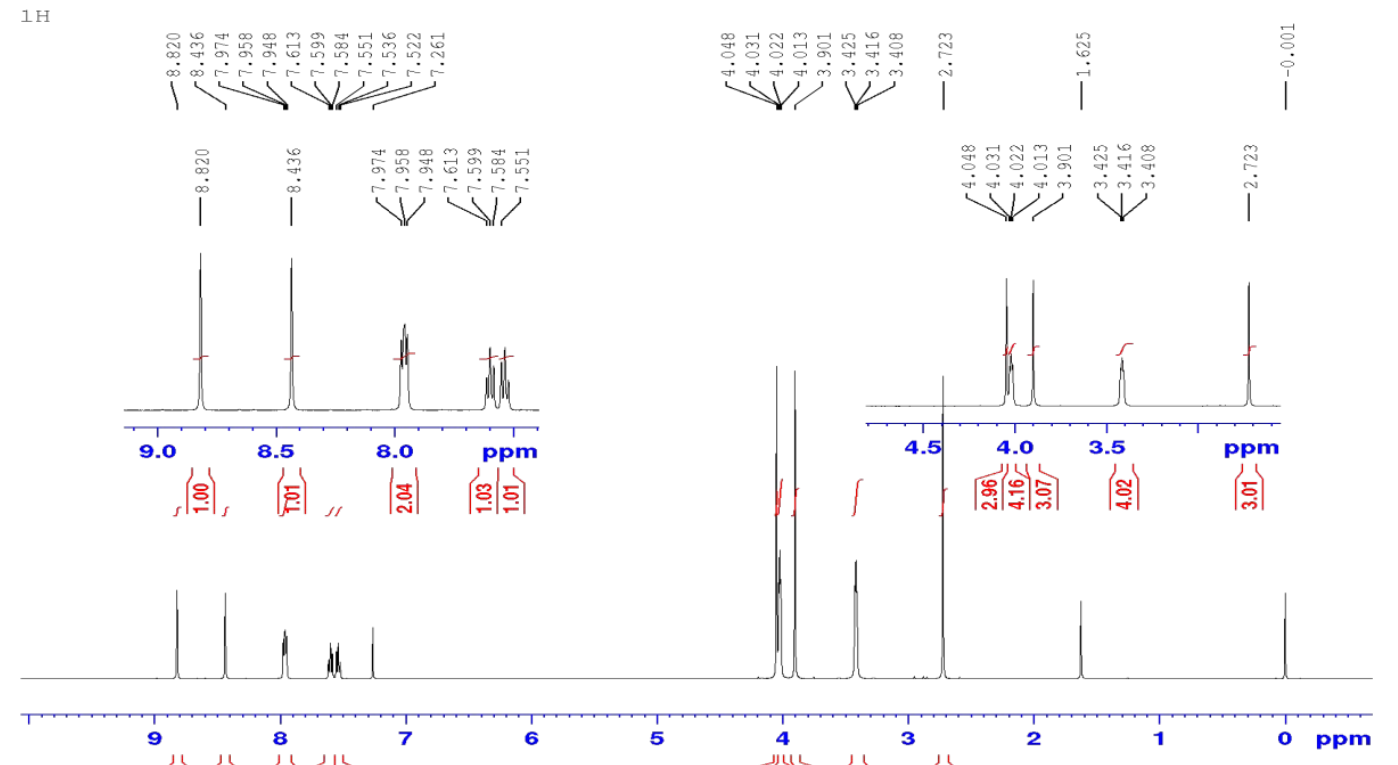

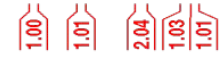

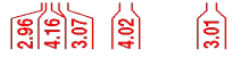

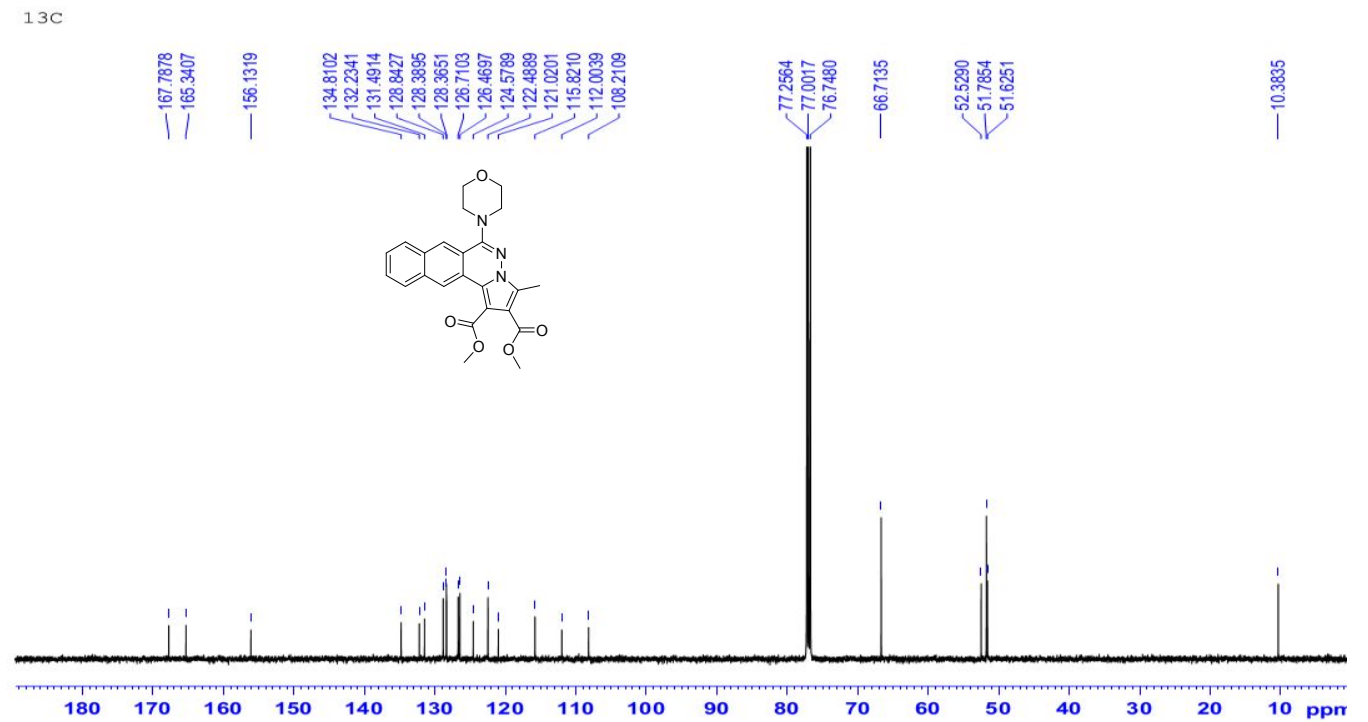




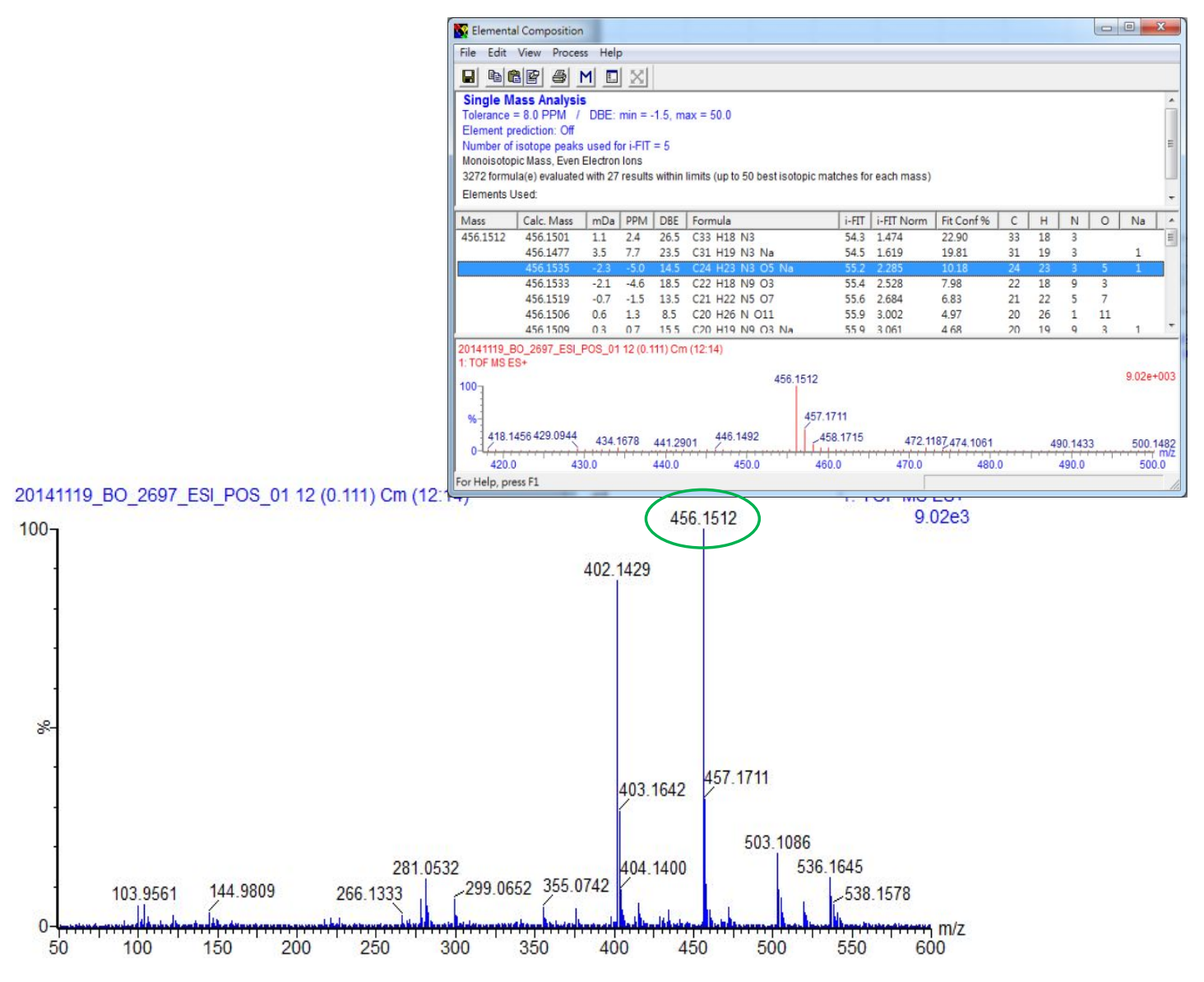


Compound 18e (500 MHz, DMSO- $\left.d_{6}\right)$

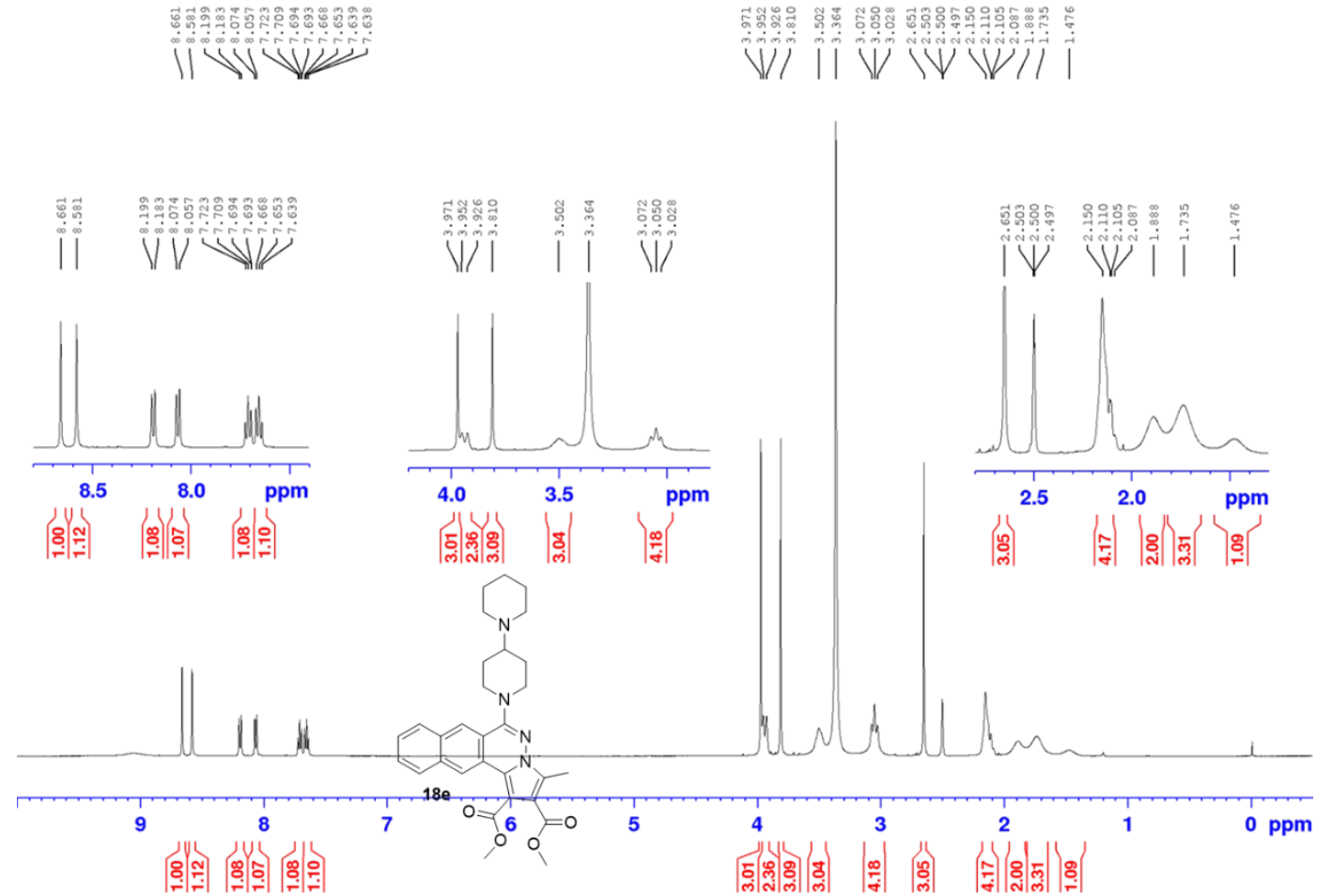

$13 \mathrm{C}$
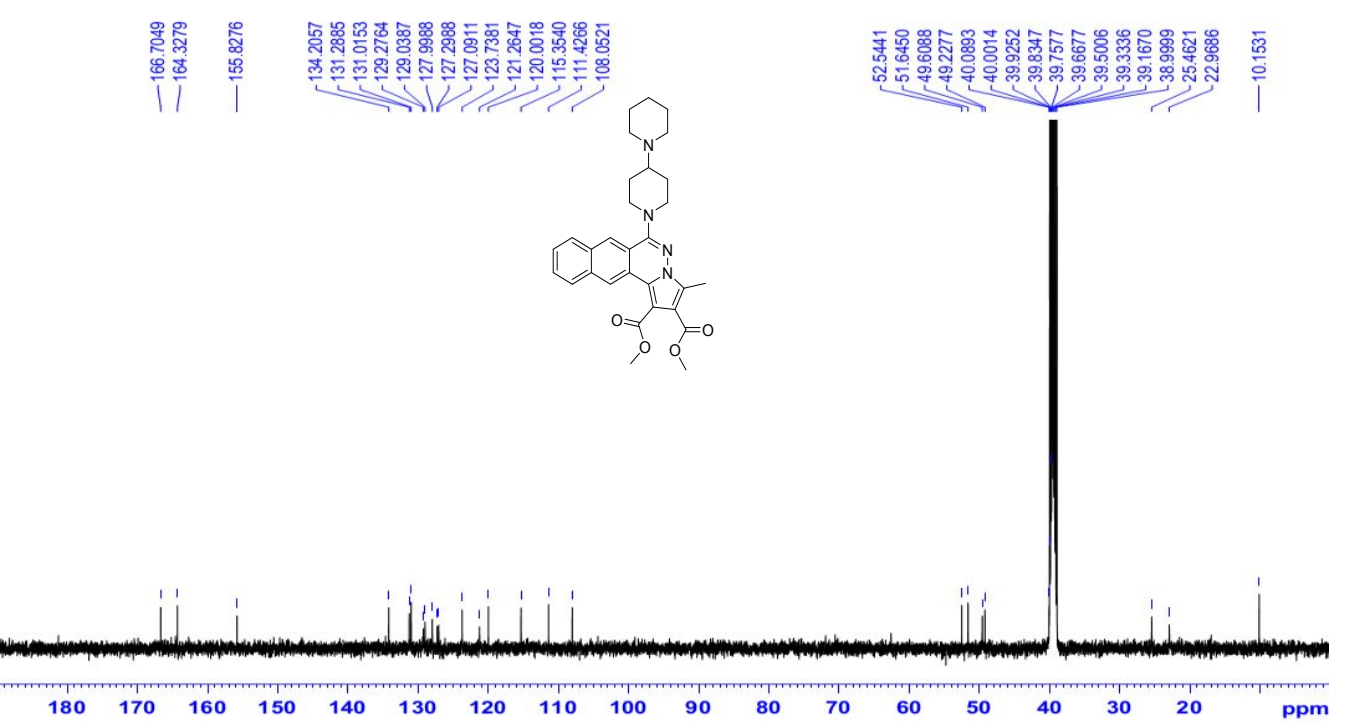


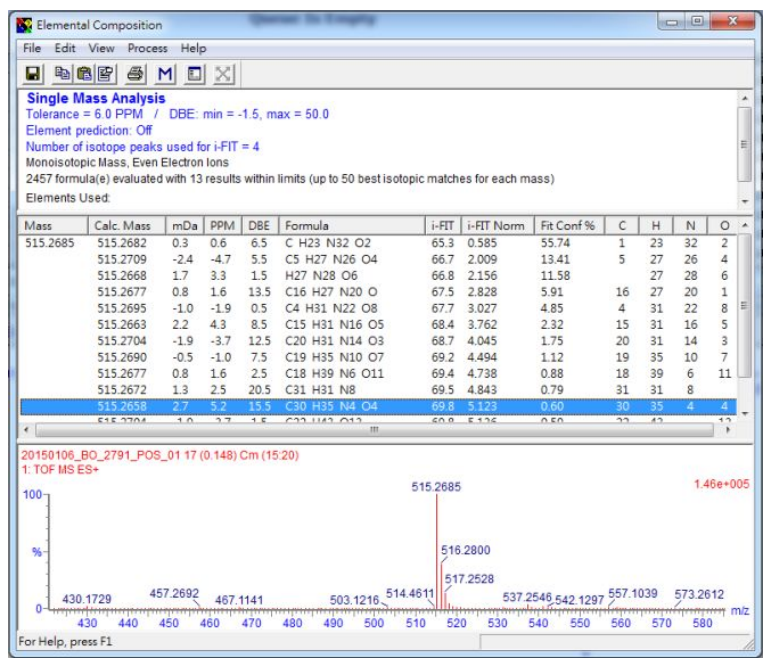

20150106_BO_2791_POS_01 17 (0.148) Cm (15.20)

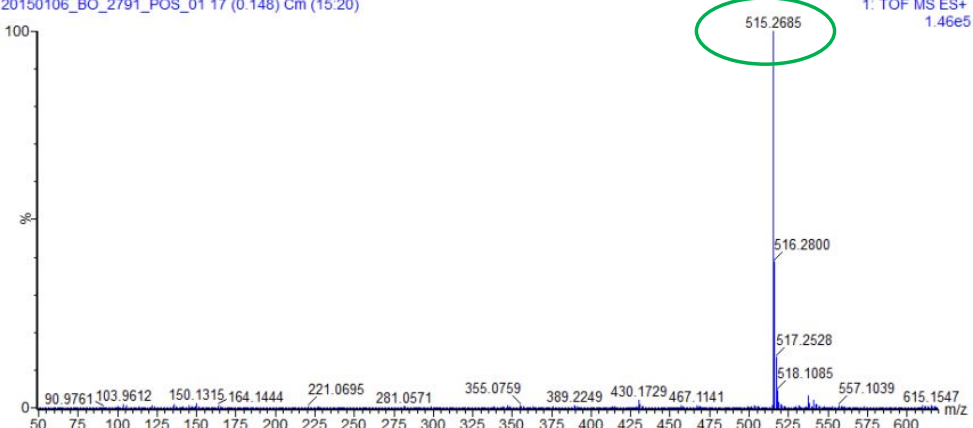


Figure S2. ${ }^{1} \mathrm{H}$ and ${ }^{13} \mathrm{C}$ NMR, EMS-MS spectra and HPLC chromatograms of all synthesized compounds.

\section{Compound 19a (500 MHz, DMSO-d 6 )}

$1 \mathrm{H}$
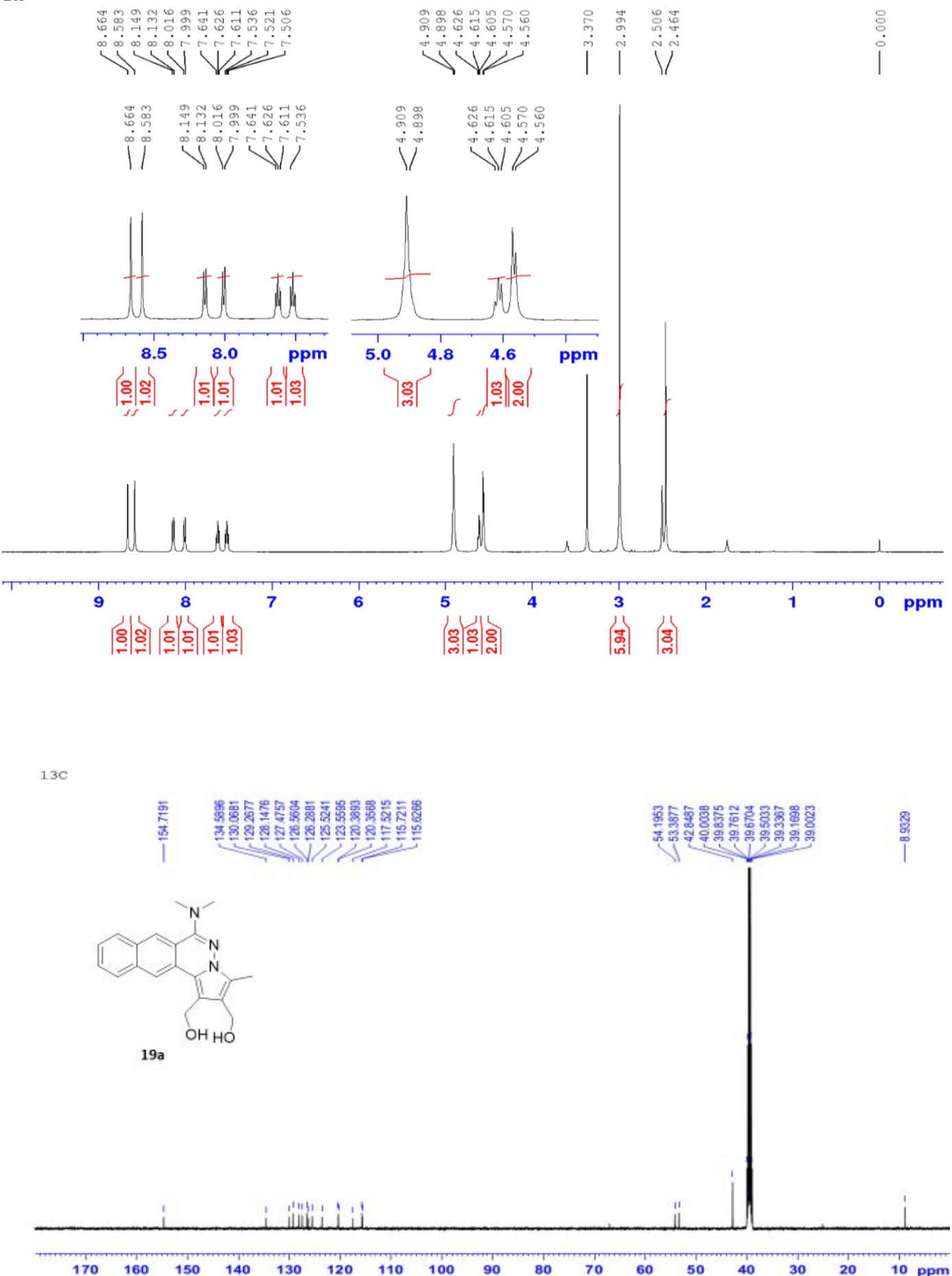

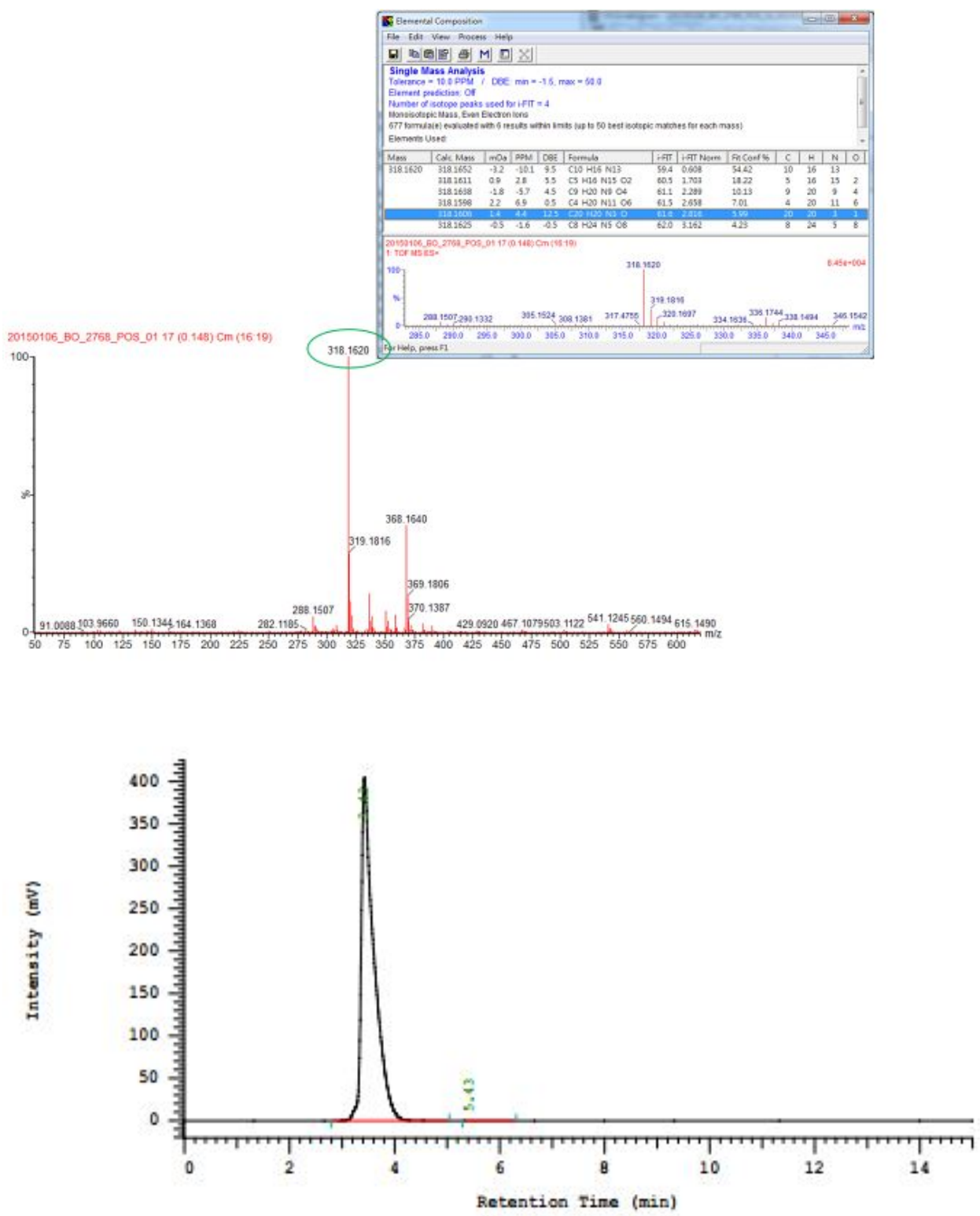

Processing Nethod: CHEN

Column Type: Column

Method Description: CCHI

Method Developer: CHEN

Chrom Type: HPLC Channel : 1

Peak Quantitation: AREA

Calculation Nethod: AREA\&

\begin{tabular}{rrrrr} 
No. & RT & Area & Conc 1 & BC \\
\hline 1 & 3.43 & 6788384 & 99.985 & BB \\
2 & 5.43 & 1022 & 0.015 & BB \\
\hline & & 6789406 & 100.000 & \\
\hline
\end{tabular}

Peak rejection level: 0 
Compound 19b (500 MHz, DMSO-d $d_{6}$ )

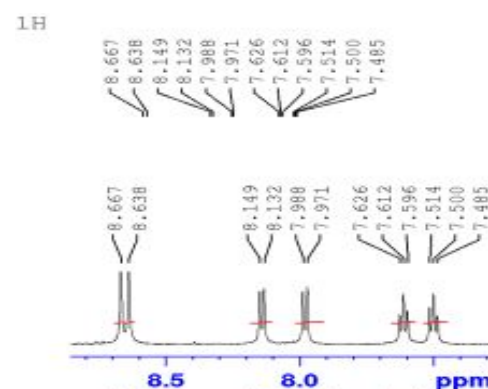

宅各|

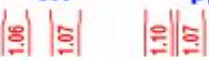
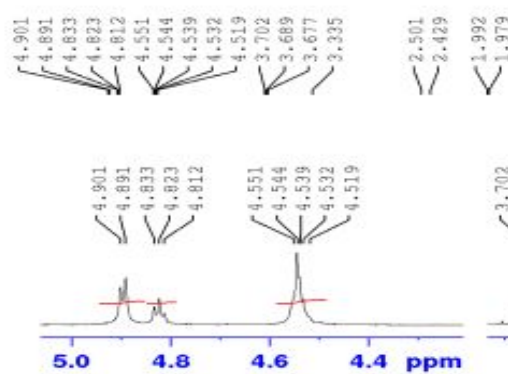

|은 $\mid$ 은|

4.4 ppm

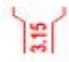

$\left|\frac{n}{5}\right|$

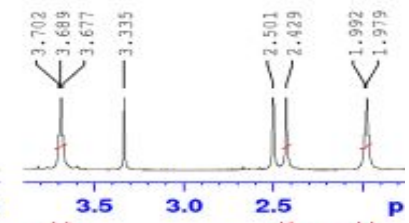

|ร㇒木

㐿

s. $f$

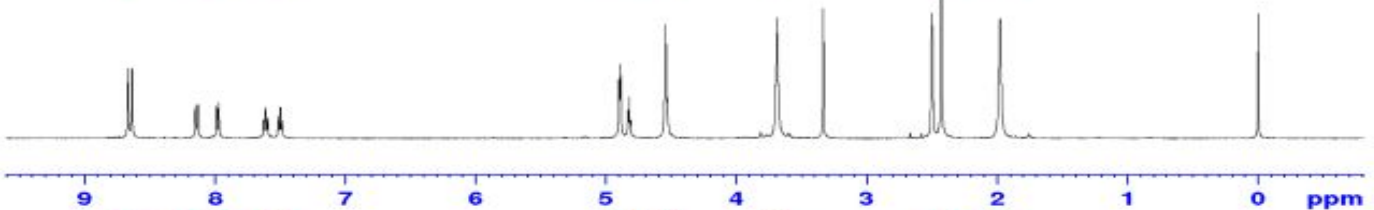

I

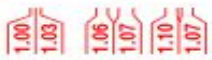

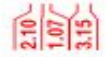

层各

$13 \mathrm{C}$
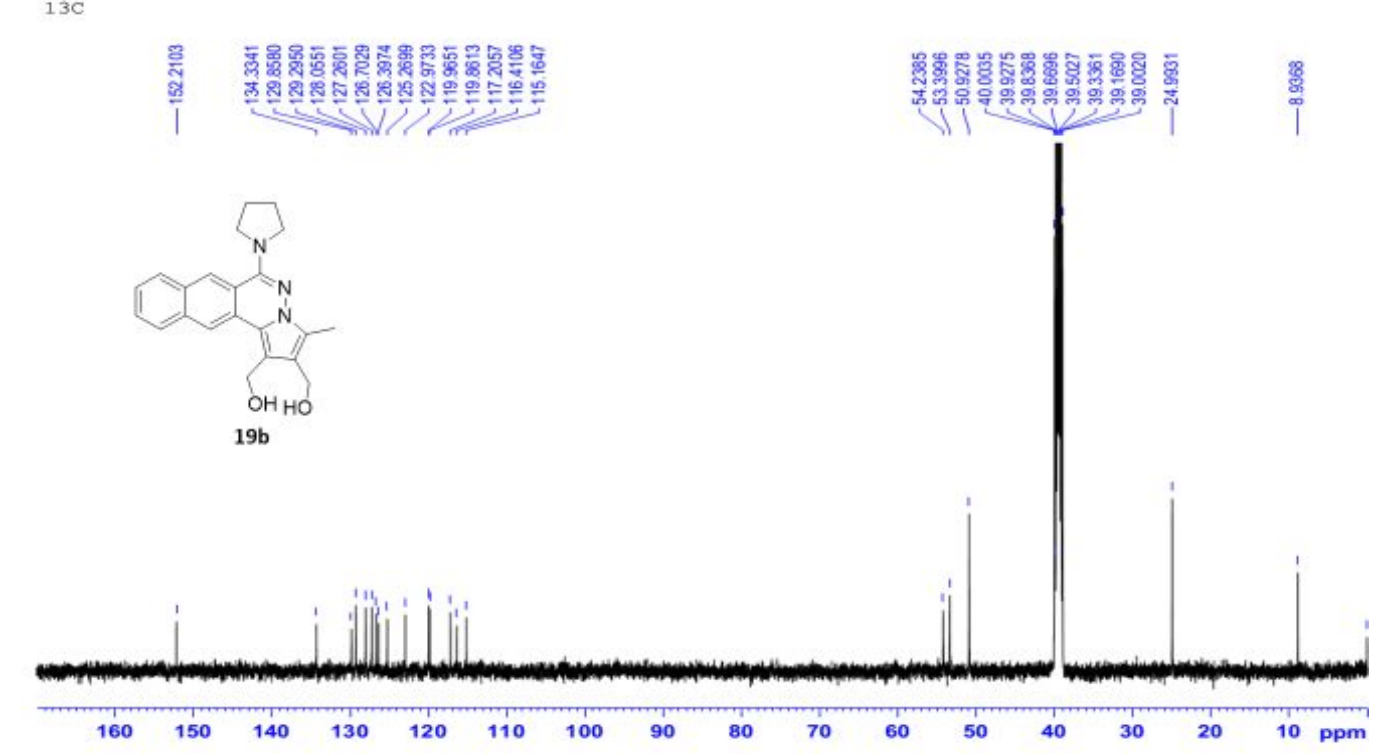

$19 \mathrm{~b}$

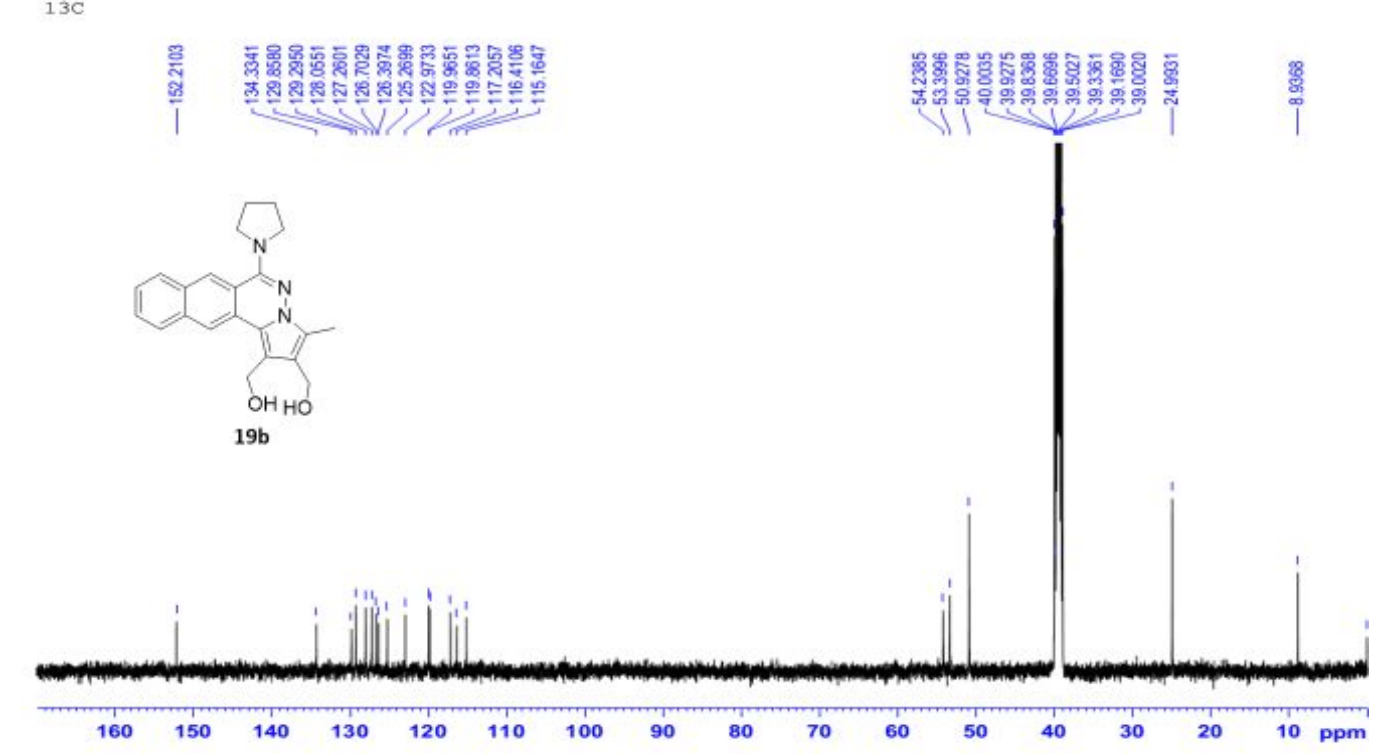

|웜 

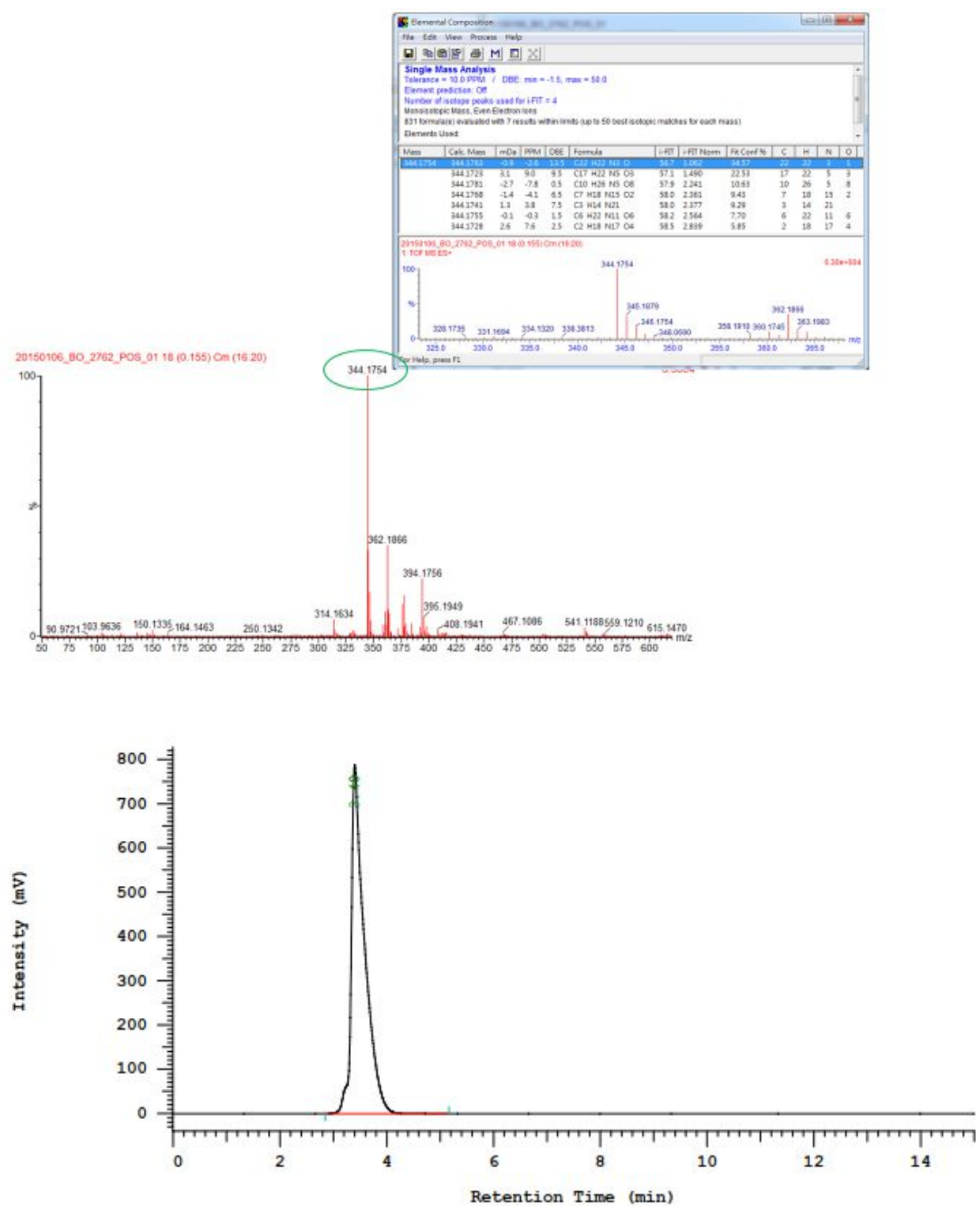

Processing Method: CHEN

Column Type: Column

Method Developer: CHEN

Method Description: CCHI

Chrom Type: HPLC Channel : 1

Peak Quantitation: AREA

Calculation Method: AREA\&

\begin{tabular}{ccccc} 
No. & RT & Area & Conc 1 & BC \\
\hline 1 & 3.40 & 13556523 & 100.000 & BB \\
\hline & & 13556523 & 100.000 & \\
\hline
\end{tabular}

Peak rejection level: 0 


\section{Compound 19c (500 MHz, DMSO-d $\left.d_{6}\right)$}

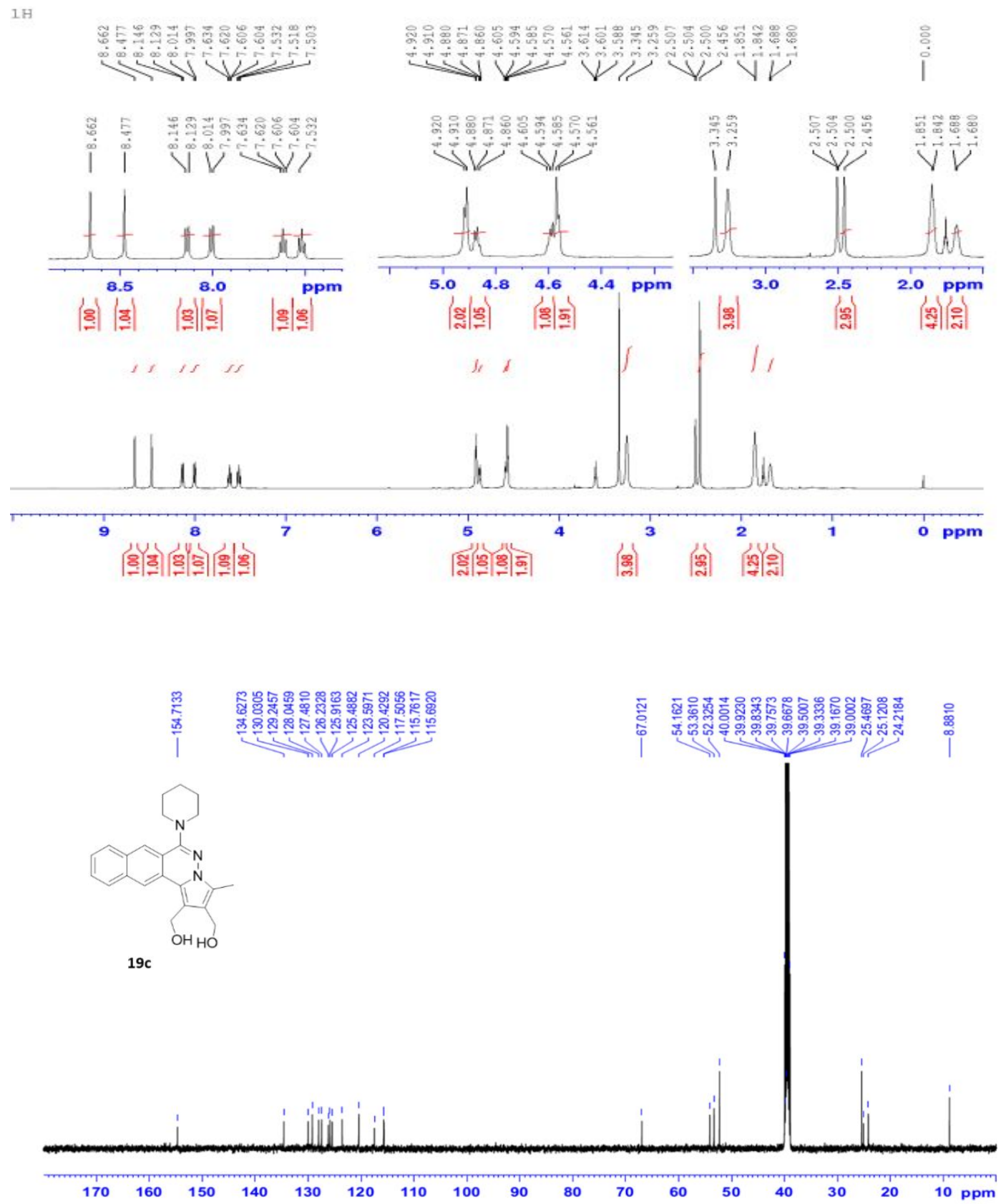



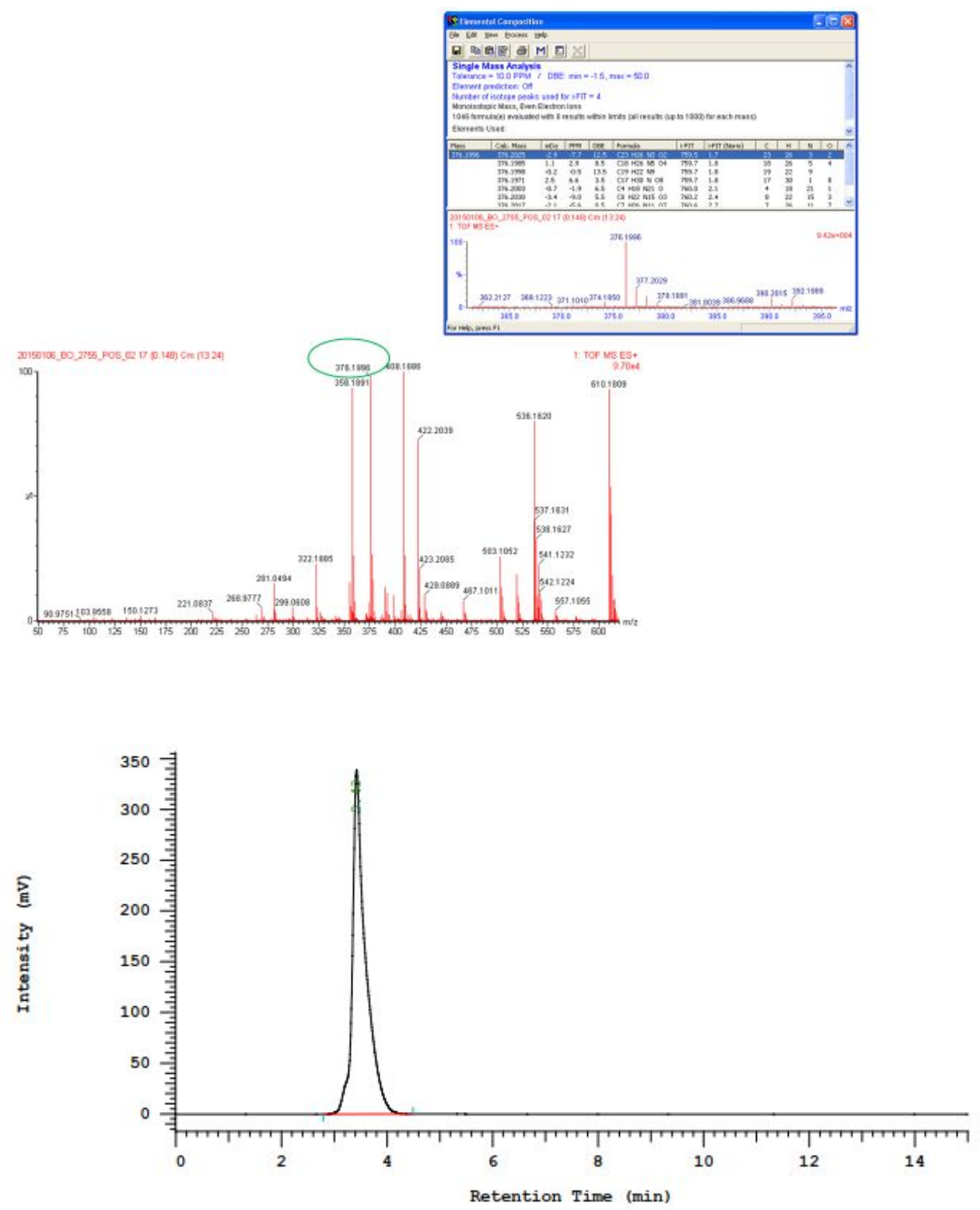

Processing Method: CHEN

Column Type: Column

Method Developer: CHEN

Method Description: $\mathrm{CCH}$

Chrom Type: HPLC Channel :

Peak Quantitation: AREA

Calculation Method: AREAs

\begin{tabular}{ccccc} 
No. & RT & Area & Conc 1 & BC \\
\hline 1 & 3.43 & 5866284 & 100.000 & BB \\
\hline & & 5866284 & 100.000 & \\
\hline
\end{tabular}

Peak rejection level: 0 
Compound 19d (500 MHz, DMSO-d $\left.d_{6}\right)$

$1 \mathrm{H}$

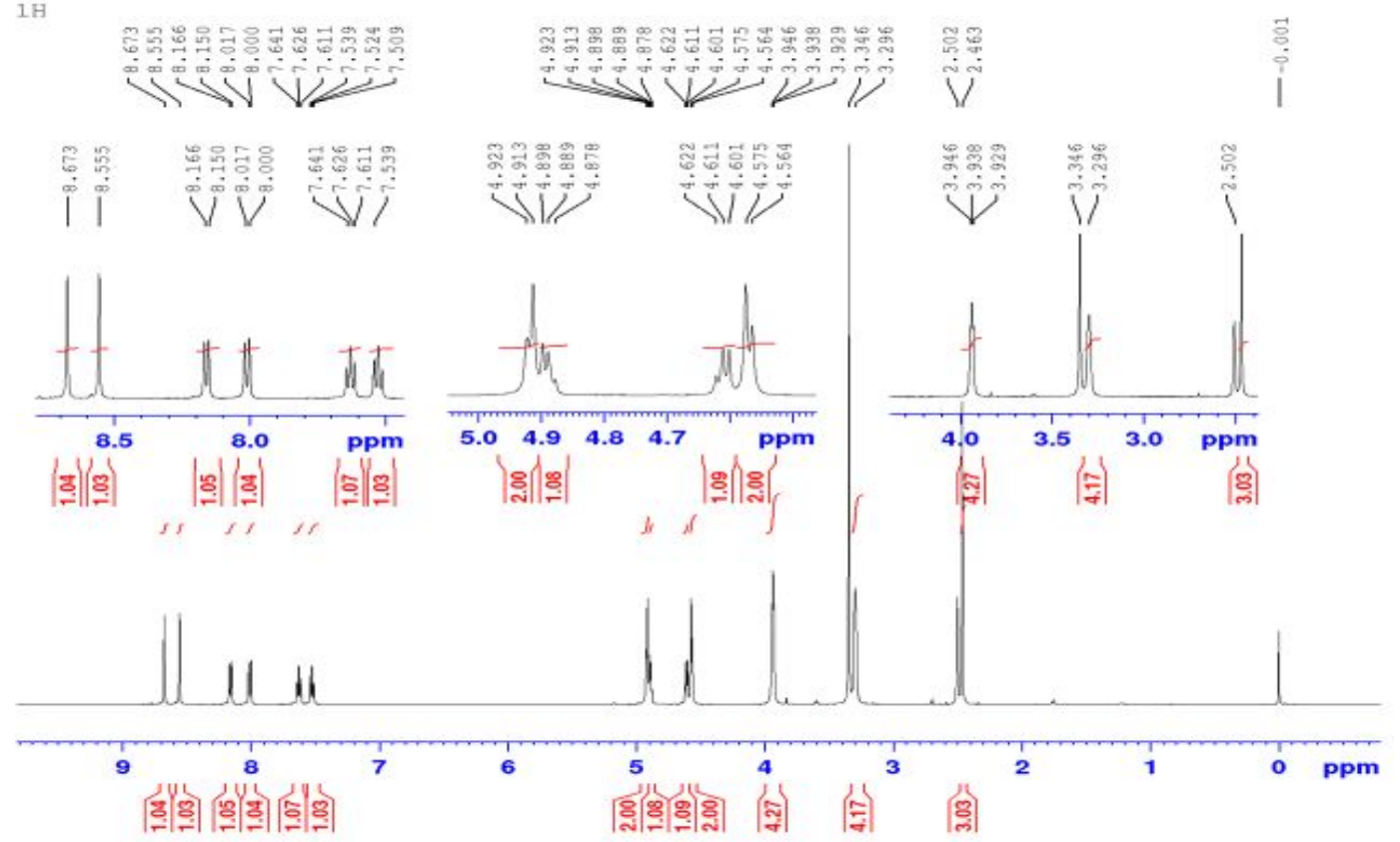

$13 \mathrm{C}$
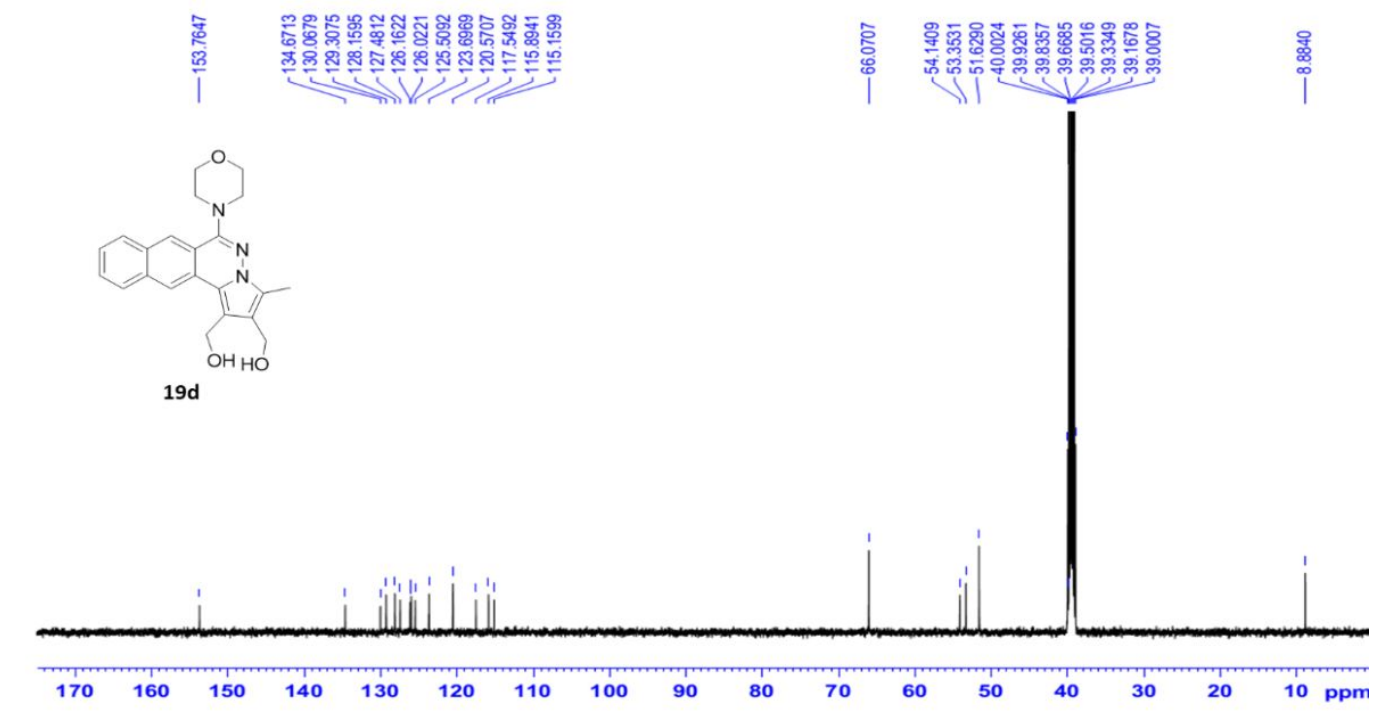

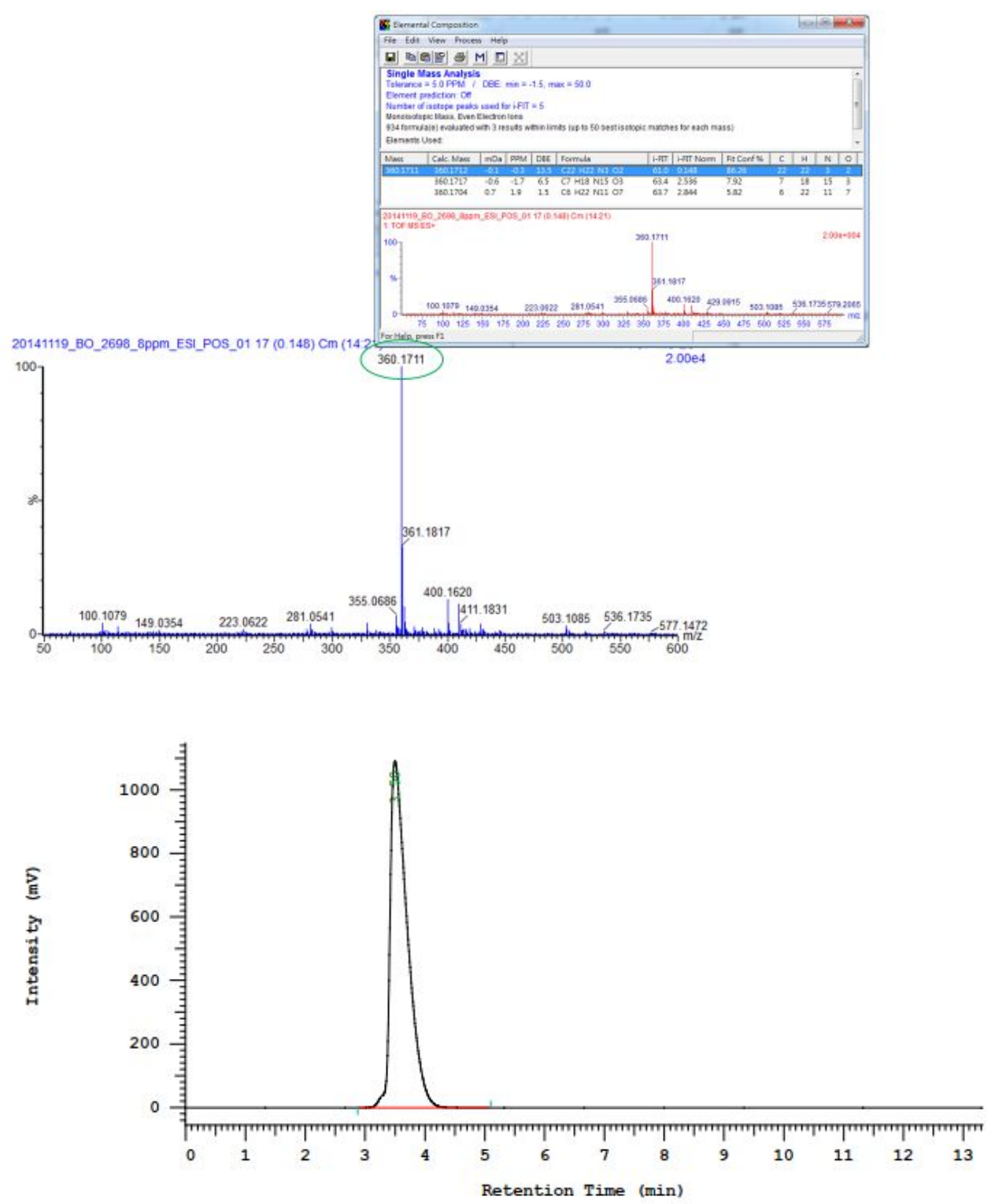

Processing Method: CHEN column Type: column

Method Description: CCHl

Method Developer: CHEN

Peak Quantitation: AREA

Calculation Method: AREA

\begin{tabular}{ccccc} 
No. & RT & Area & Conc 1 & BC \\
\hline 1 & 3.50 & 21780784 & 100.000 & BB \\
\hline & & 21780784 & 100.000 &
\end{tabular}

Peak rejection level: 0 
Compound 19e (500 MHz, DMSO- $\left.d_{6}\right)$

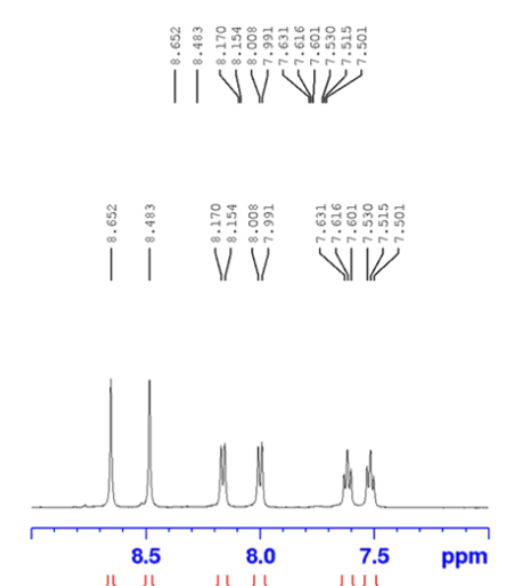

窝

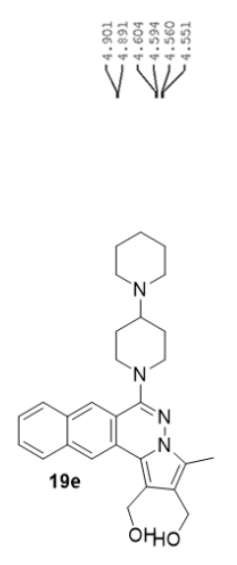

HO

V

Vับ

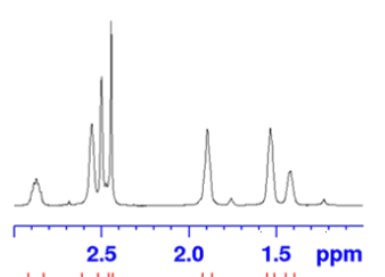

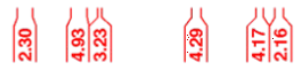

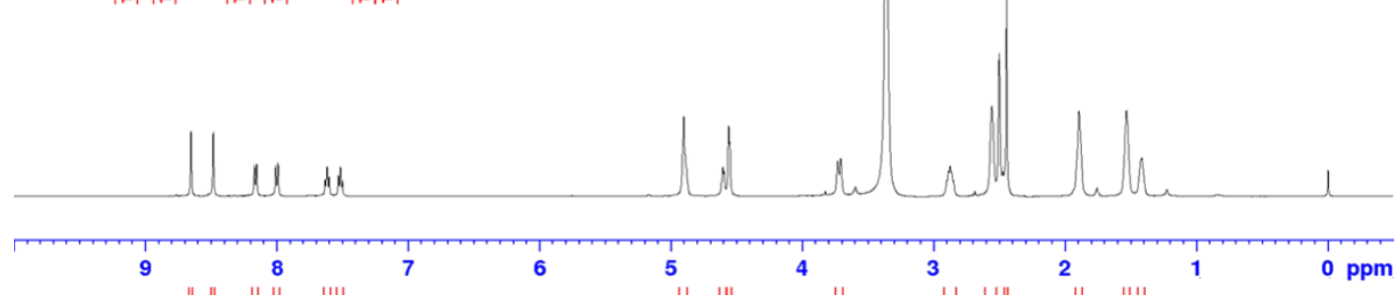

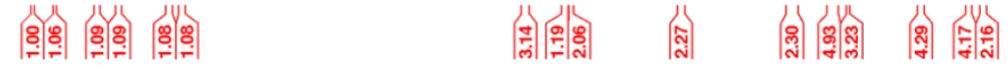

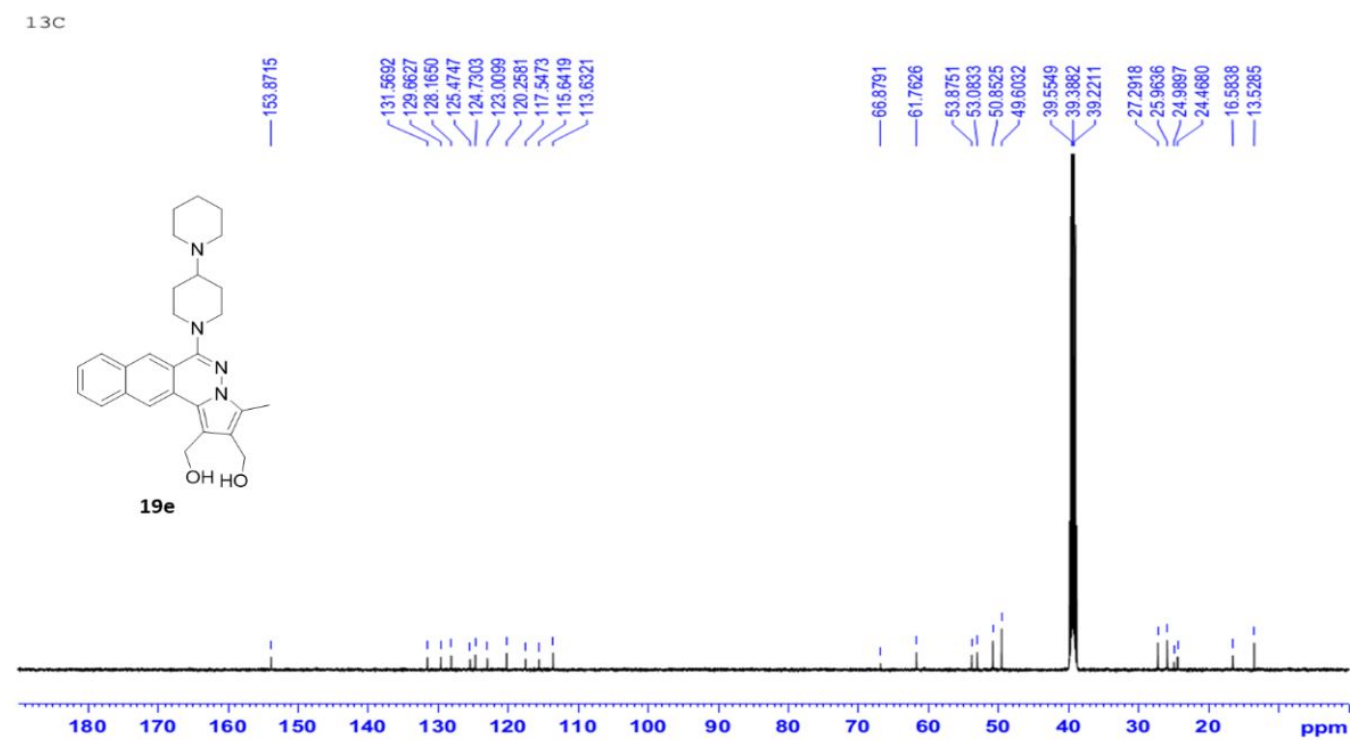



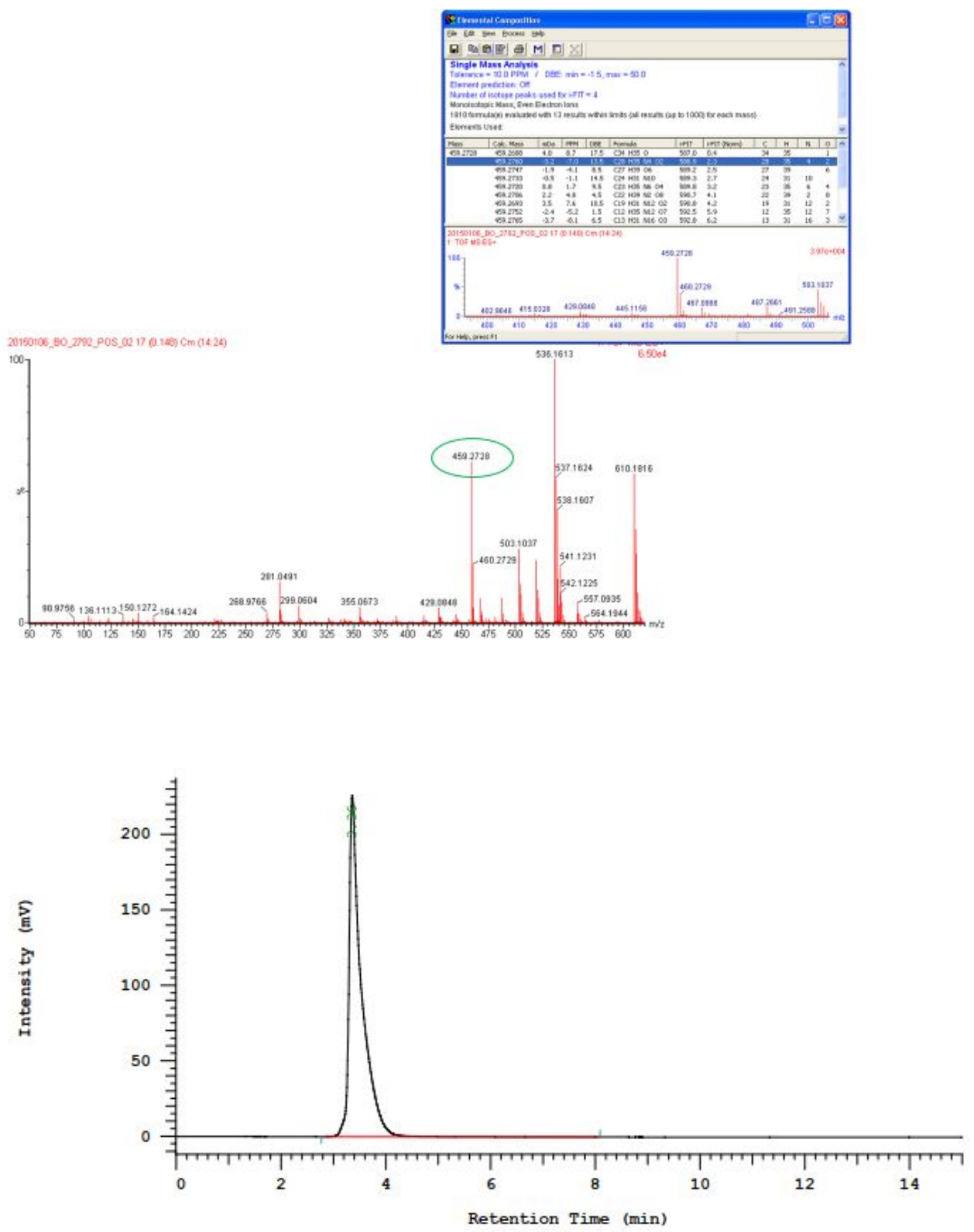

Processing Method: CHEN

Column Type: Column

Method Description: CCH1

Method Developer: CHEN

Chrom Type: HPLC Channel : 1

Peak Quantitation: AREA

Calculation Method: AREAf

\begin{tabular}{ccccc} 
No. & RT & Area & Conc 1 & BC \\
\hline 1 & 3.36 & 3730803 & 100.000 & BB \\
\hline & & 3730803 & 100.000 &
\end{tabular}

Peak rejection level: 0 
Compound 20a (500 MHz, DMSO- $d_{6}$ )
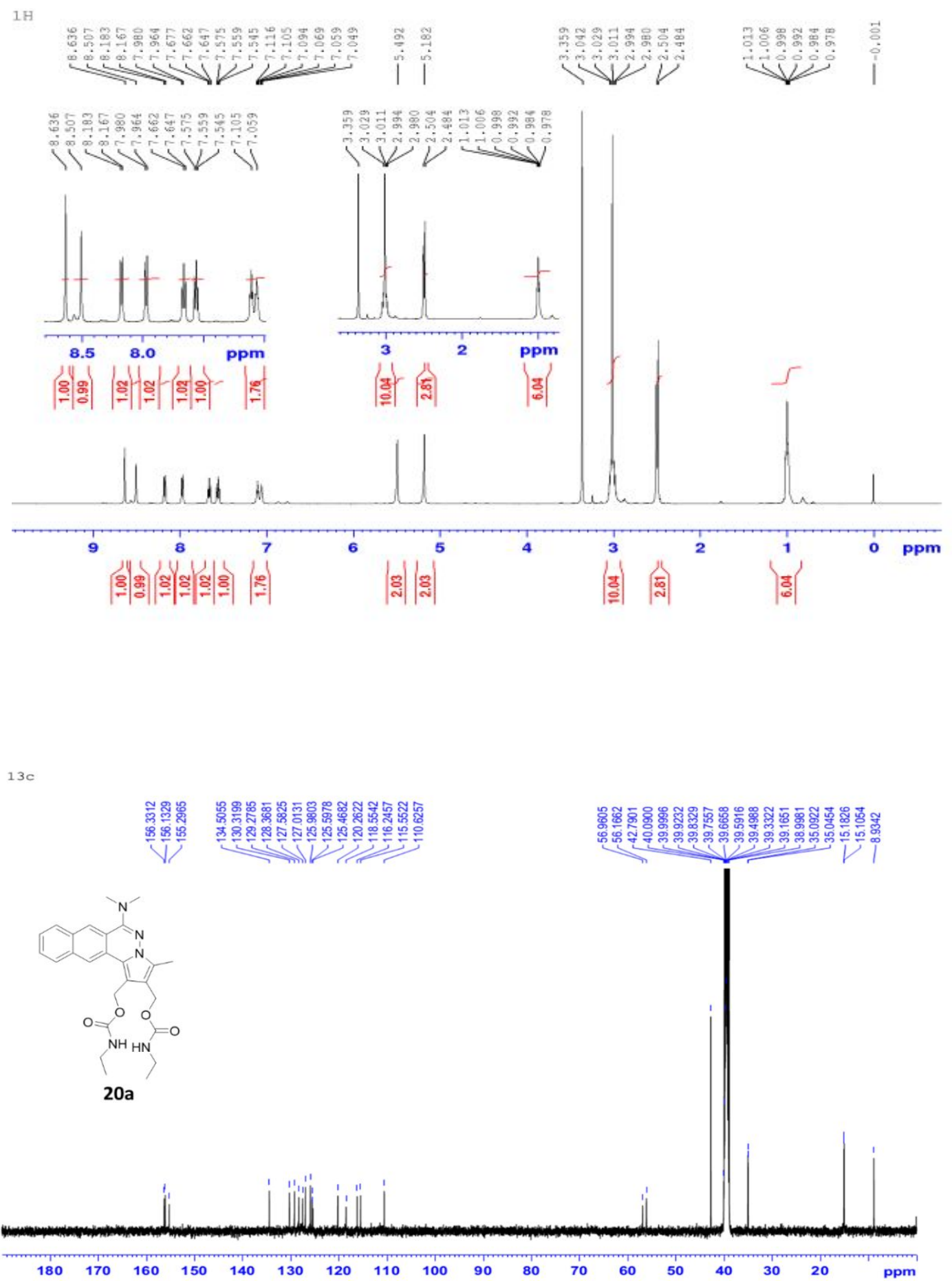
20150106_BO_2772_POS_01 17 (0.148) Cm (15:19)
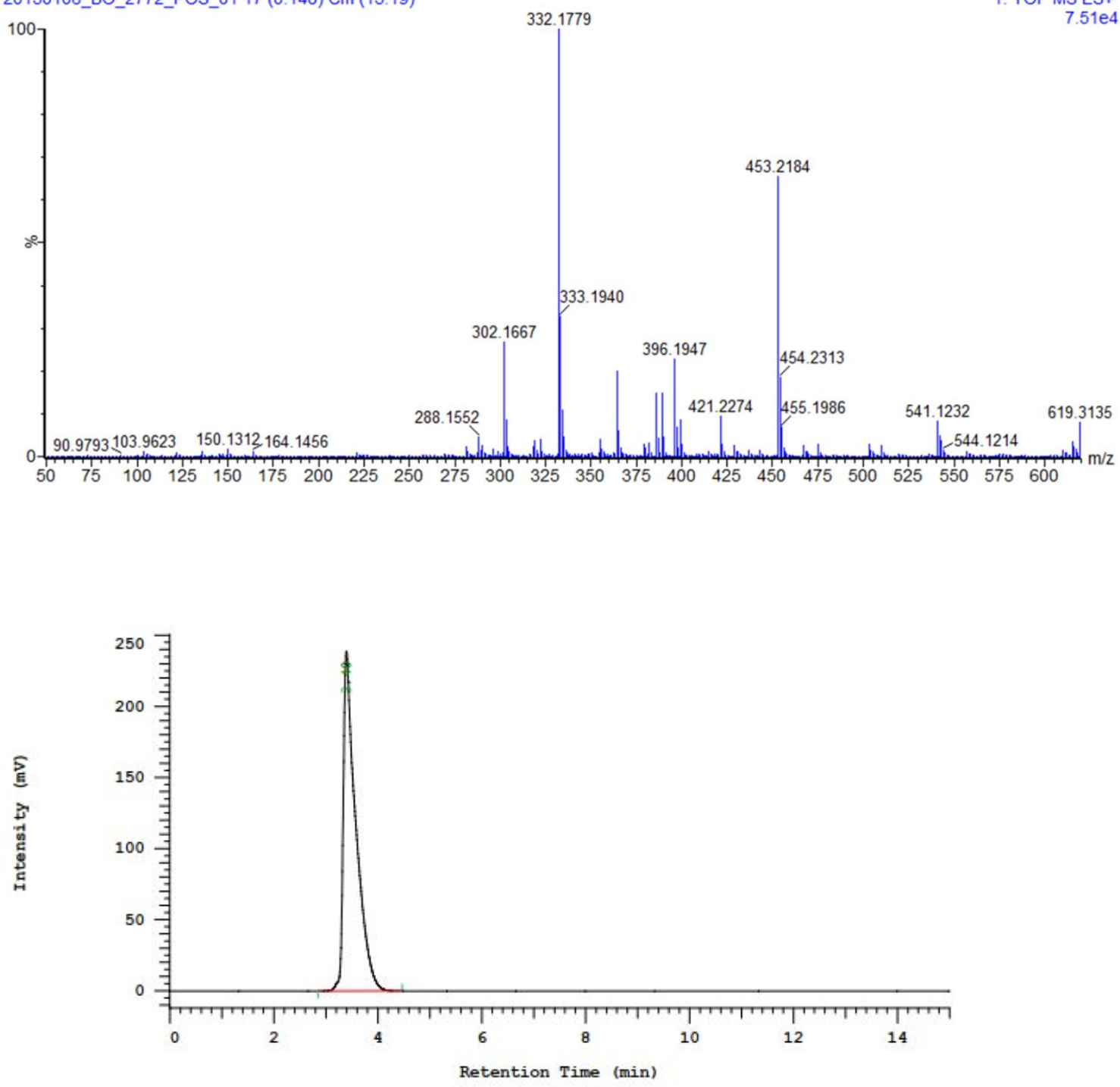

Processing Method: CHEN

Column Type: Column

Method Developer: CHEN

Method Description: $\mathrm{CCH}$

Chrom Type: HPLC Channel : 1

Peak Quantitation: AREA

Calculation Method: AREA

\begin{tabular}{ccccc} 
No. & RT & Area & Conc 1 & BC \\
\hline 1 & 3.40 & 4011100 & 100.000 & BB \\
\hline & 4011100 & 100.000 &
\end{tabular}

Peak rejection level: 0 
Compound 20b (500 MHz, DMSO-d $d_{6}$ )
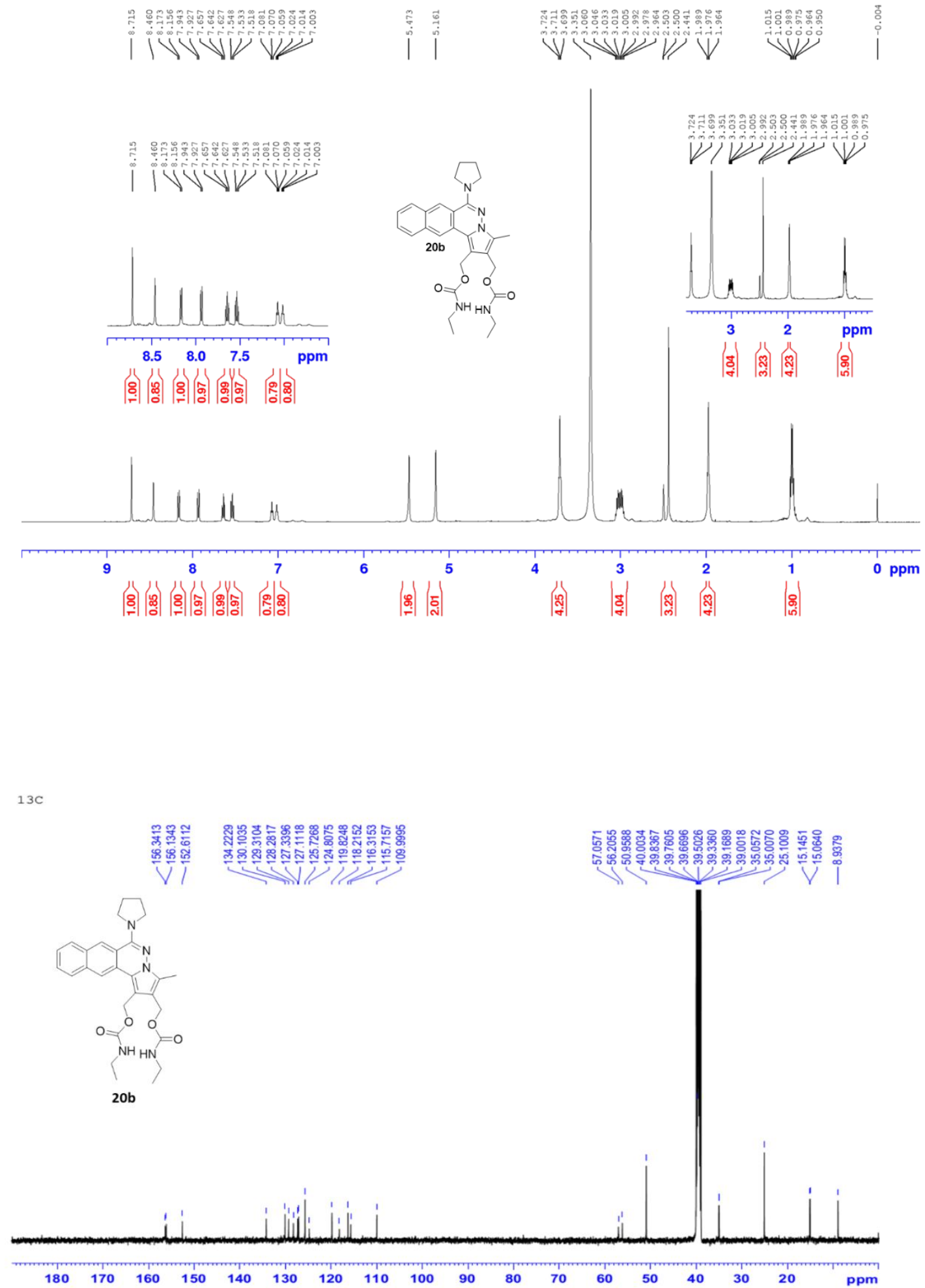

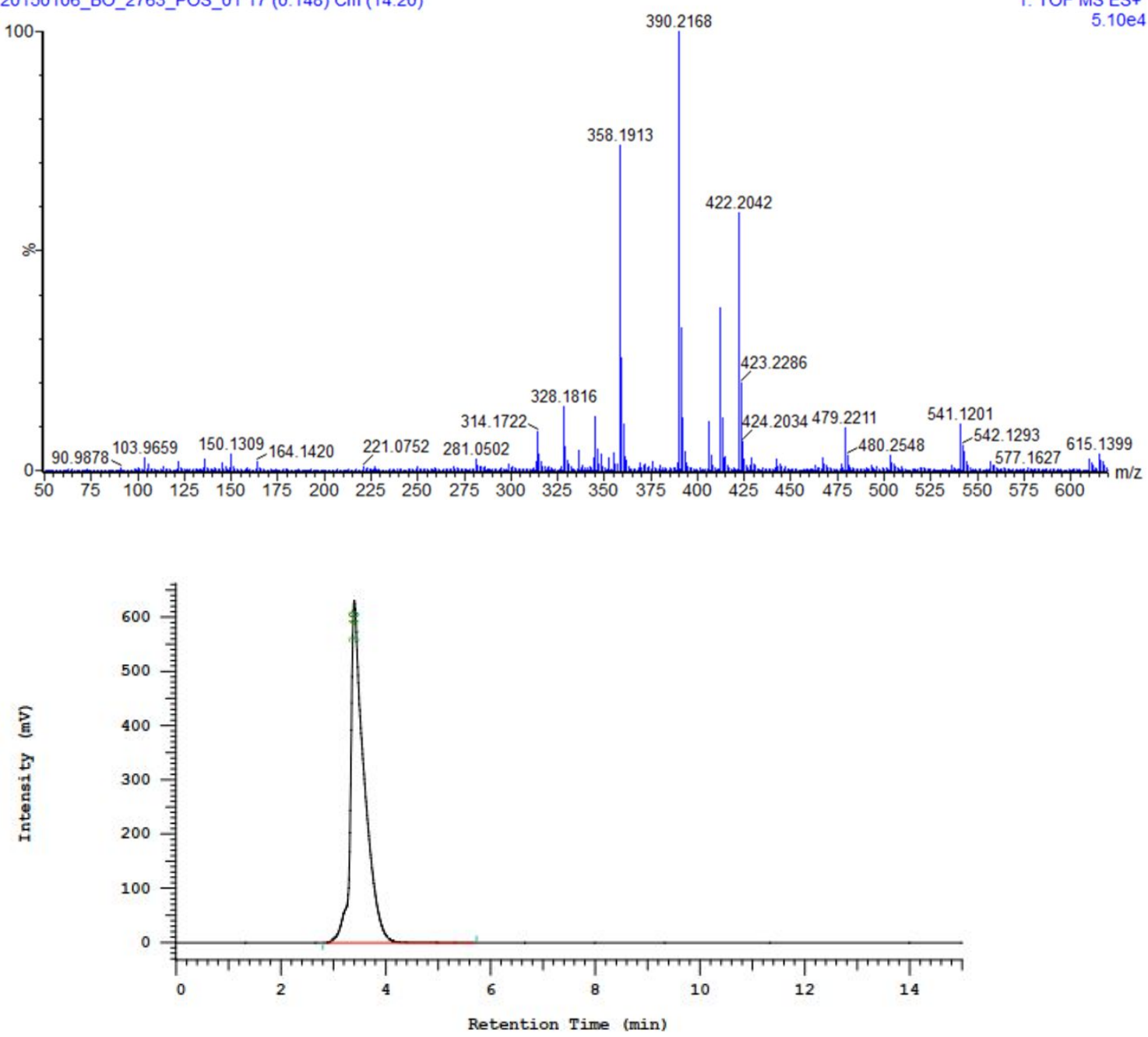

Processing Method: CHEN

Column Type: Column

Retention Time (min)

Method Description: $\mathrm{CCH} 1$

Method Developer: CHEN

Chrom Type: HPLC Channel : 1

Peak Quantitation: AREA

Calculation Method: AREAs

\begin{tabular}{ccccc} 
No. & RT & Area & Conc 1 & BC \\
\hline 1 & 3.40 & 11388340 & 100.000 & BB \\
\hline & & 11388340 & 100.000 & \\
\hline
\end{tabular}

Peak rejection level: 0 
Compound 20c (500 MHz, DMSO- $\left.d_{6}\right)$
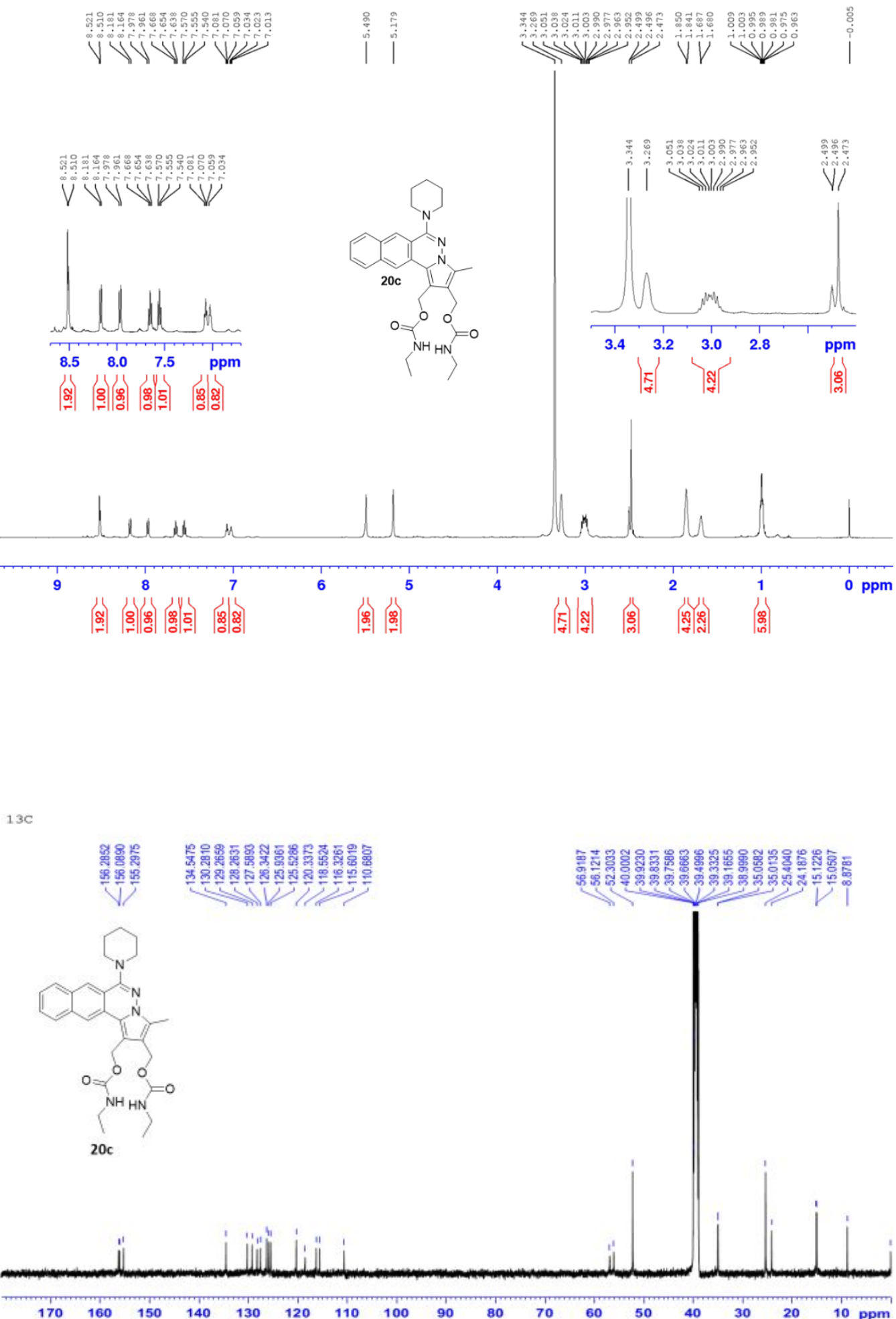

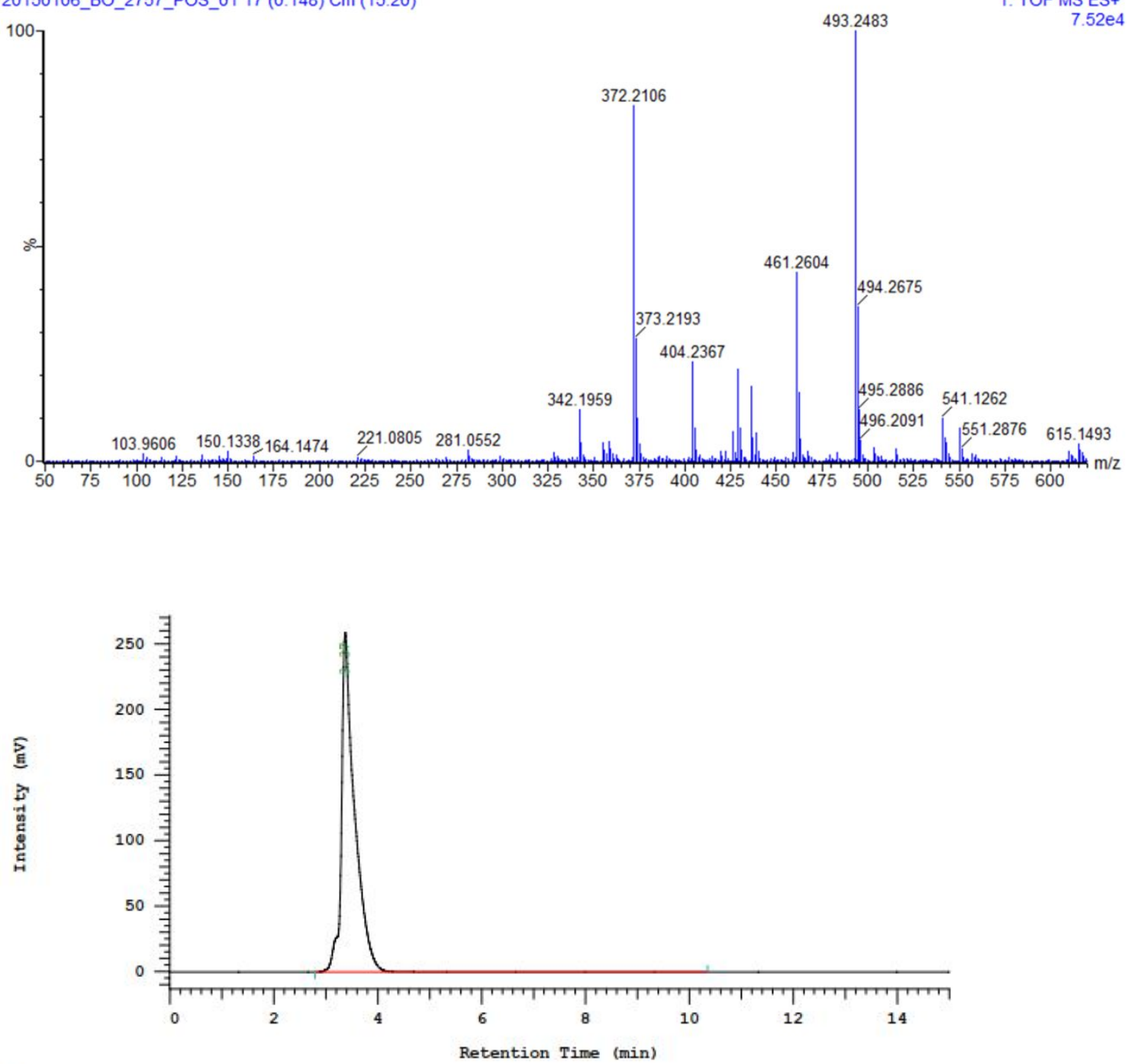

Processing Method: CHEN

Column Type: Column

Method Developer: CHEN

Method Description: CCH1

Chrom Type: HPLC Channel : 1

Peak Quantitation: AREA

Calculation Method: AREAs

\begin{tabular}{ccccc} 
No. & RT & Area & Conc 1 & BC \\
\hline 1 & 3.37 & 4552244 & 100.000 & BB \\
\hline & & 4552244 & 100.000 & \\
\hline
\end{tabular}

Peak rejection level: 0 
Compound 20d (500 MHz, DMSO-d $\left.d_{6}\right)$
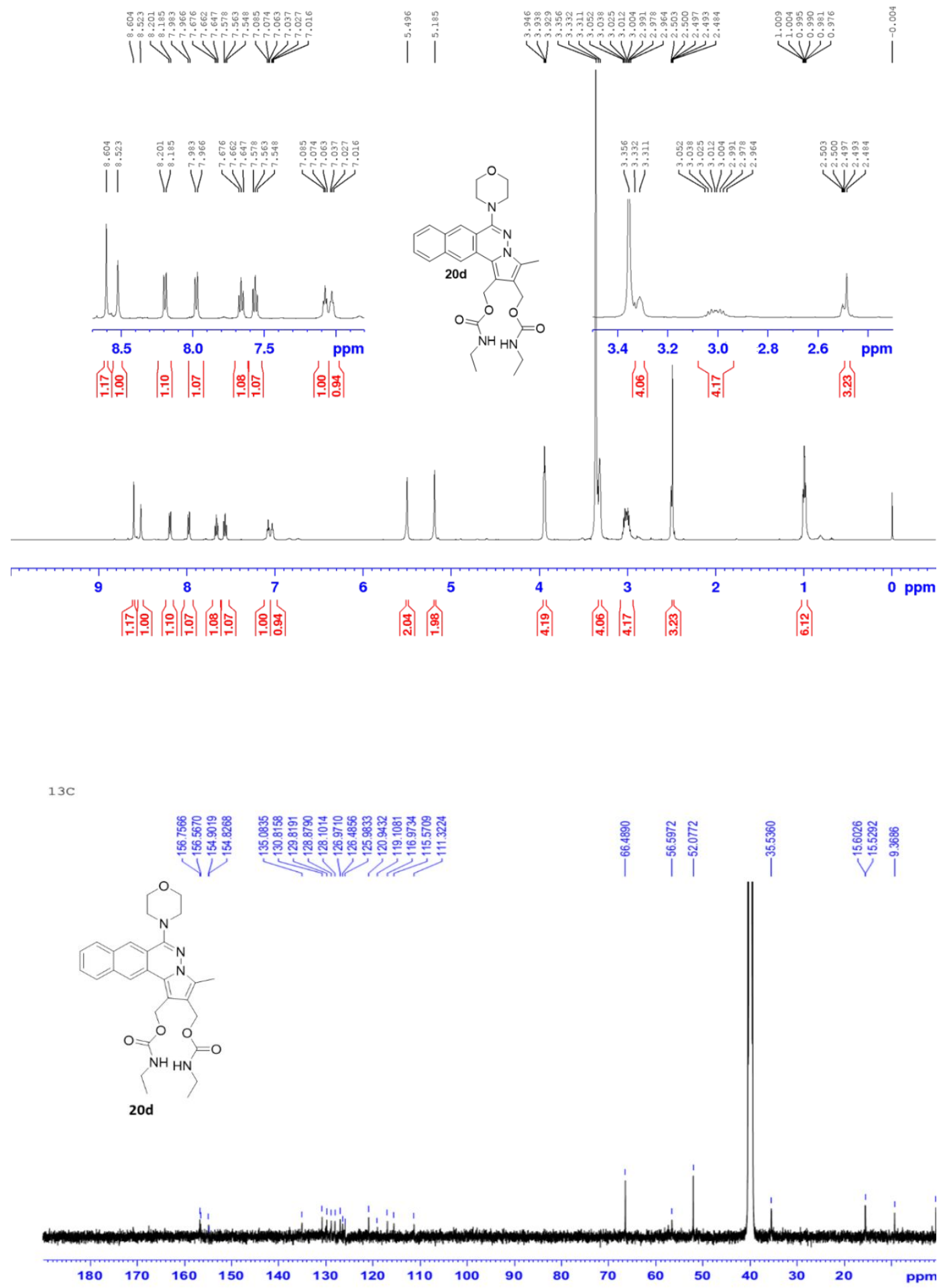

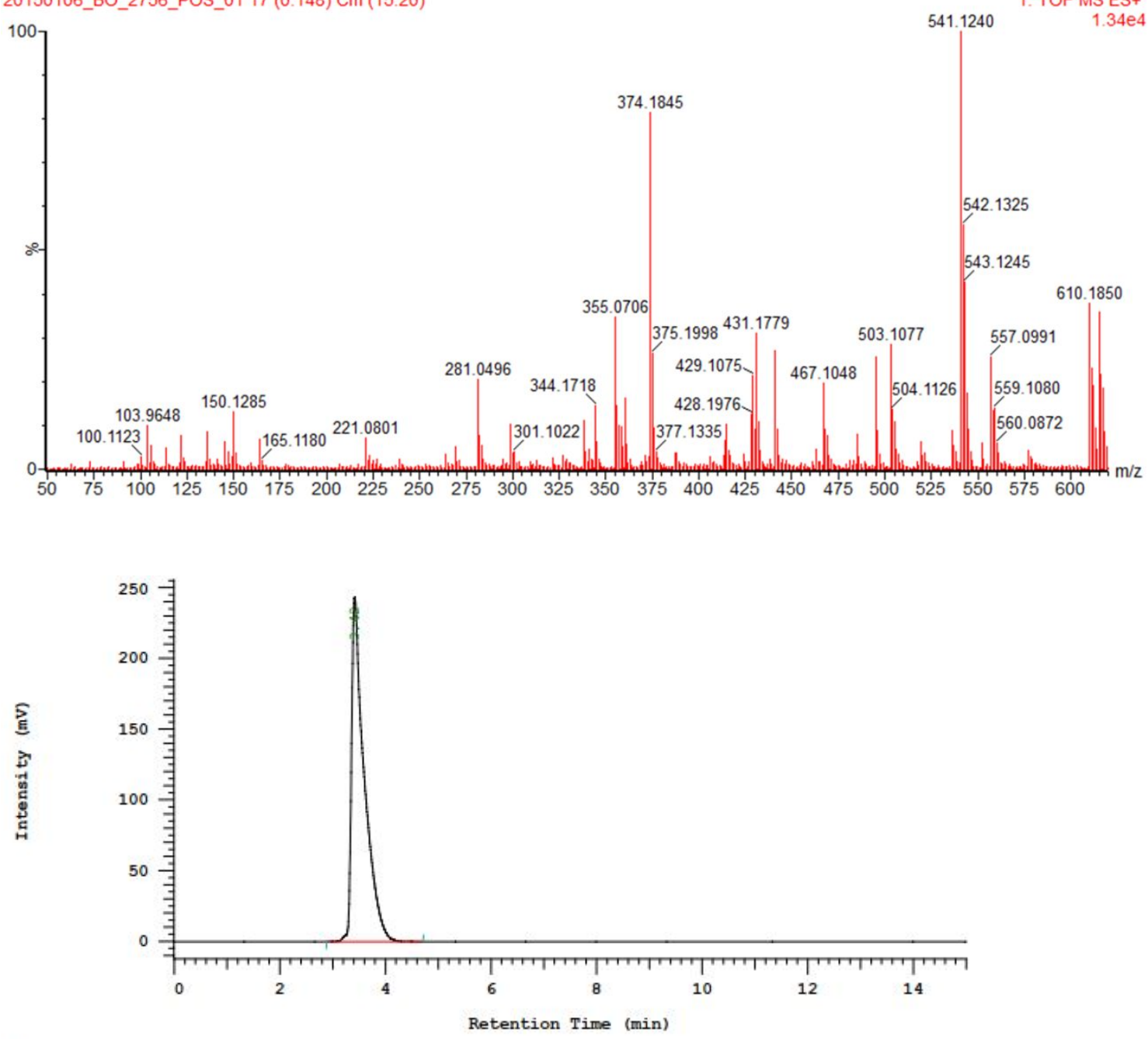

Processing Method: CHEN

Column Type: Column

Method Developer: CHEN

Method Description: CCHI

Chrom Type: HPLC Channel : 1

Peak Quantitation: AREA

Calculation Method: AREAs

\begin{tabular}{ccccc} 
No. & RT & Area & Conc 1 & BC \\
\hline 1 & 3.42 & 4086124 & 100.000 & BB \\
\hline & 4086124 & 100.000 & \\
\hline
\end{tabular}

Peak rejection level: 0 
Compound 20e (500 $\left.\mathrm{MHz}, \mathrm{CDCl}_{3}\right)$

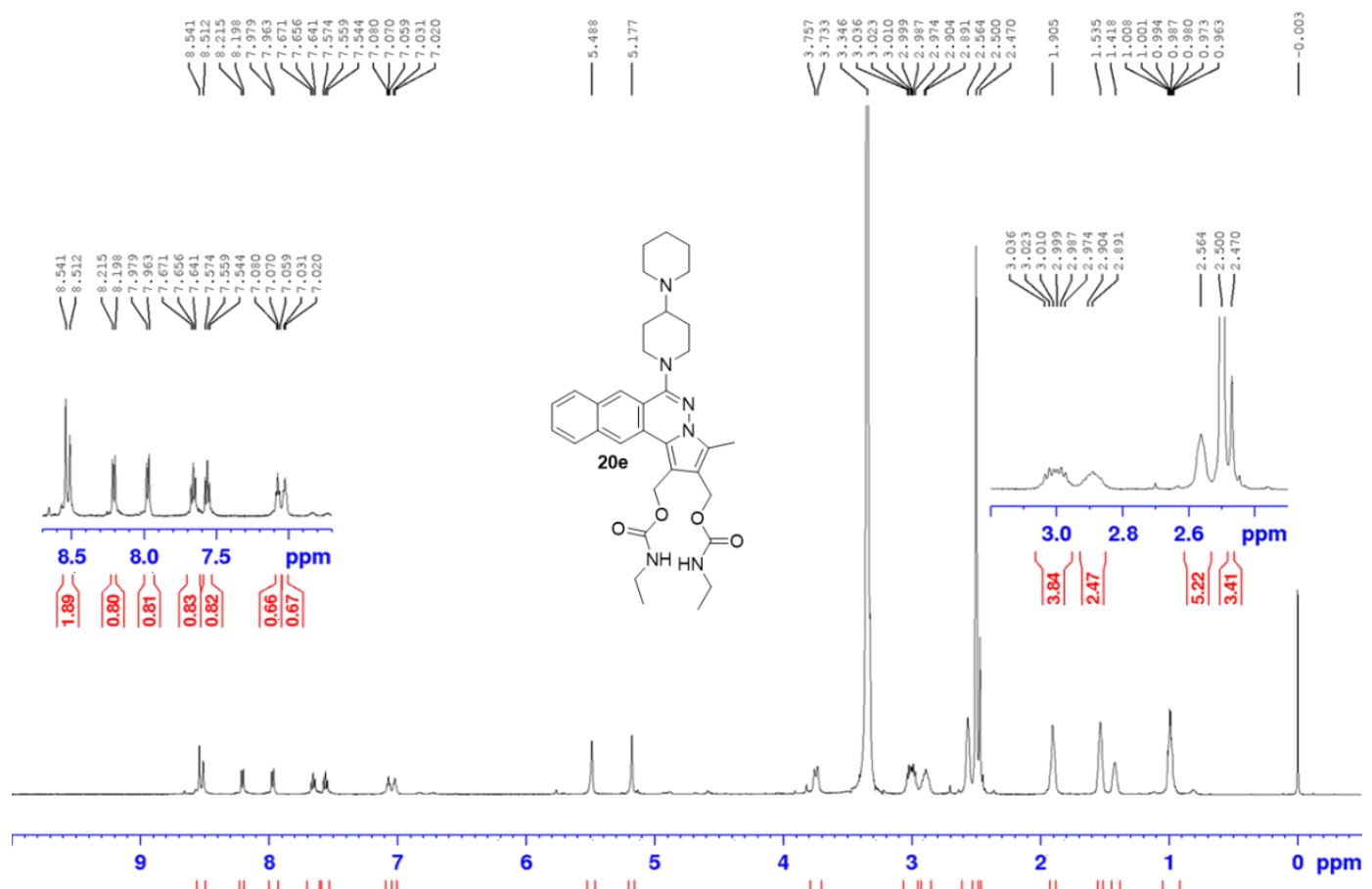

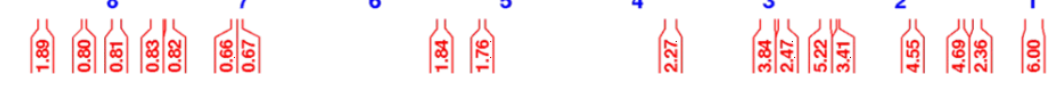

$1 \mathrm{H}$

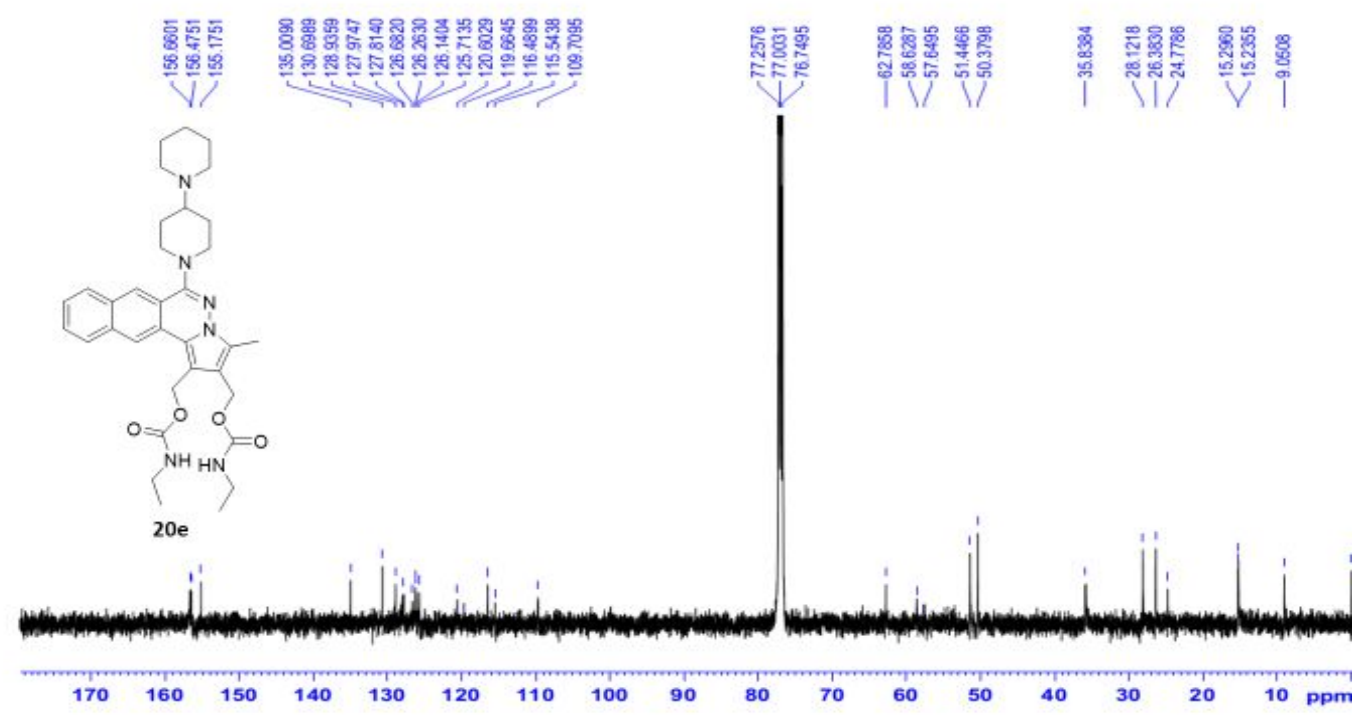


20150106_BO_2793_POS_01 18 (0.155) Cm (15:19)
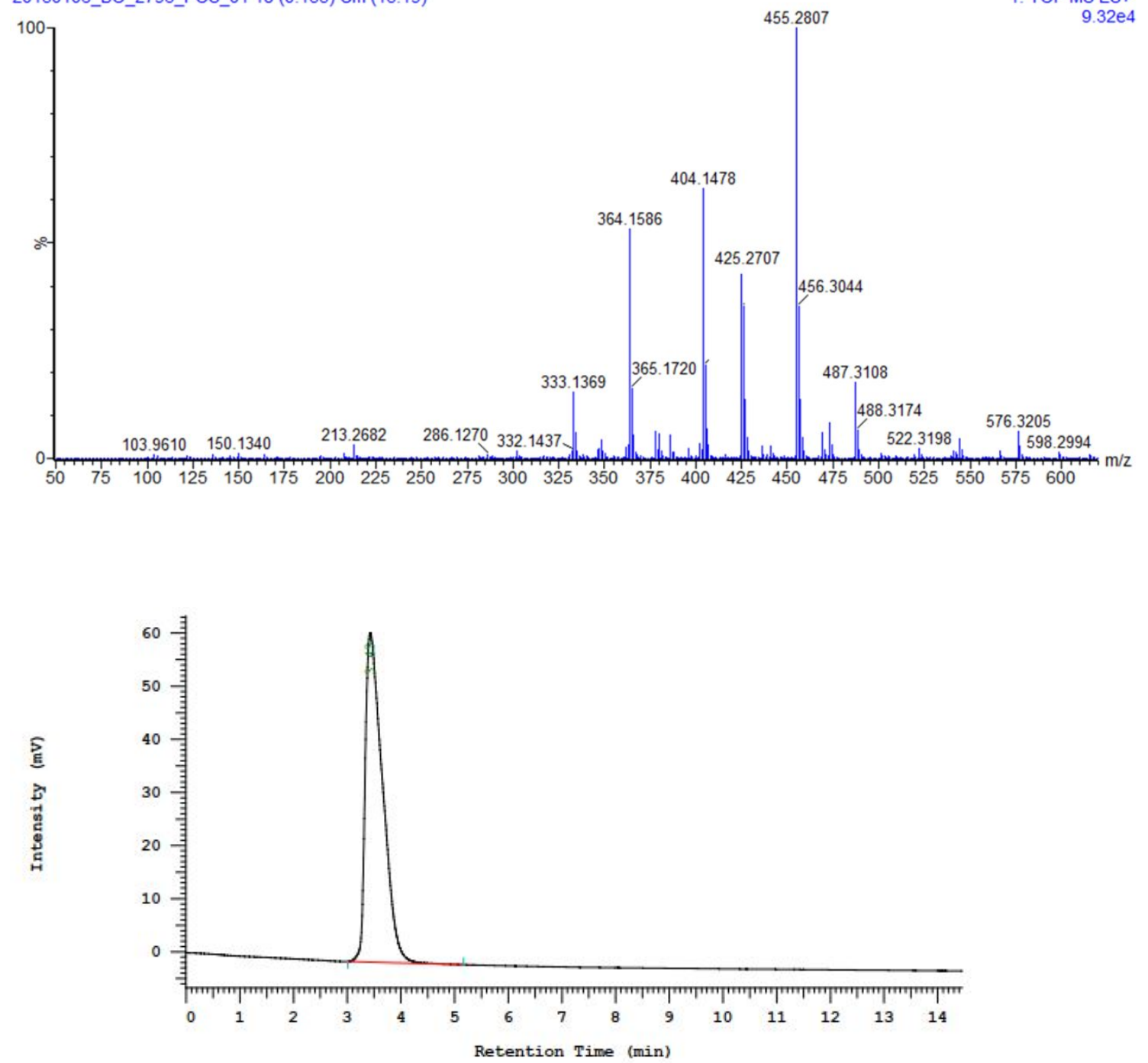

Processing Method: CHEN

Column Type: Column

Method Description: CCHI

Chrom Type: HPLC Channel : 1

Peak Quantitation: AREA

Calculation Method: AREA

\begin{tabular}{ccccc} 
No. & RT & Area & Conc 1 & BC \\
\hline 1 & 3.43 & 1387484 & 100.000 & BB \\
\hline & & 1387484 & 100.000 \\
\hline
\end{tabular}

Peak rejection level: 0
Method Developer: CHEN 


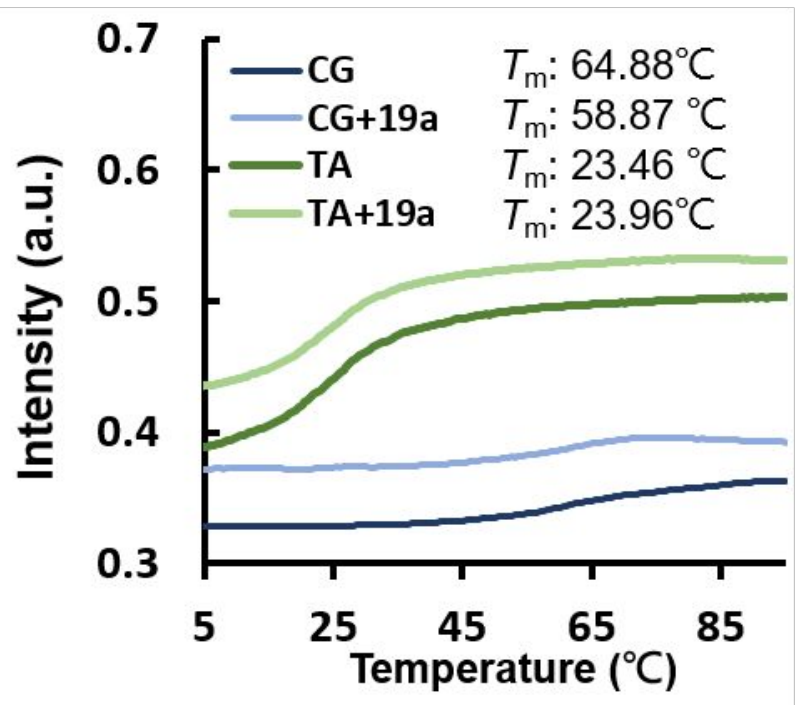

Figure S3. DNA melting temperature (Tm) assay. (A) The $T m$ curves for CG-rich or TA-rich duplexes in the presence or absence of compound 19a were determined by UVabsorption spectrophotometer. 


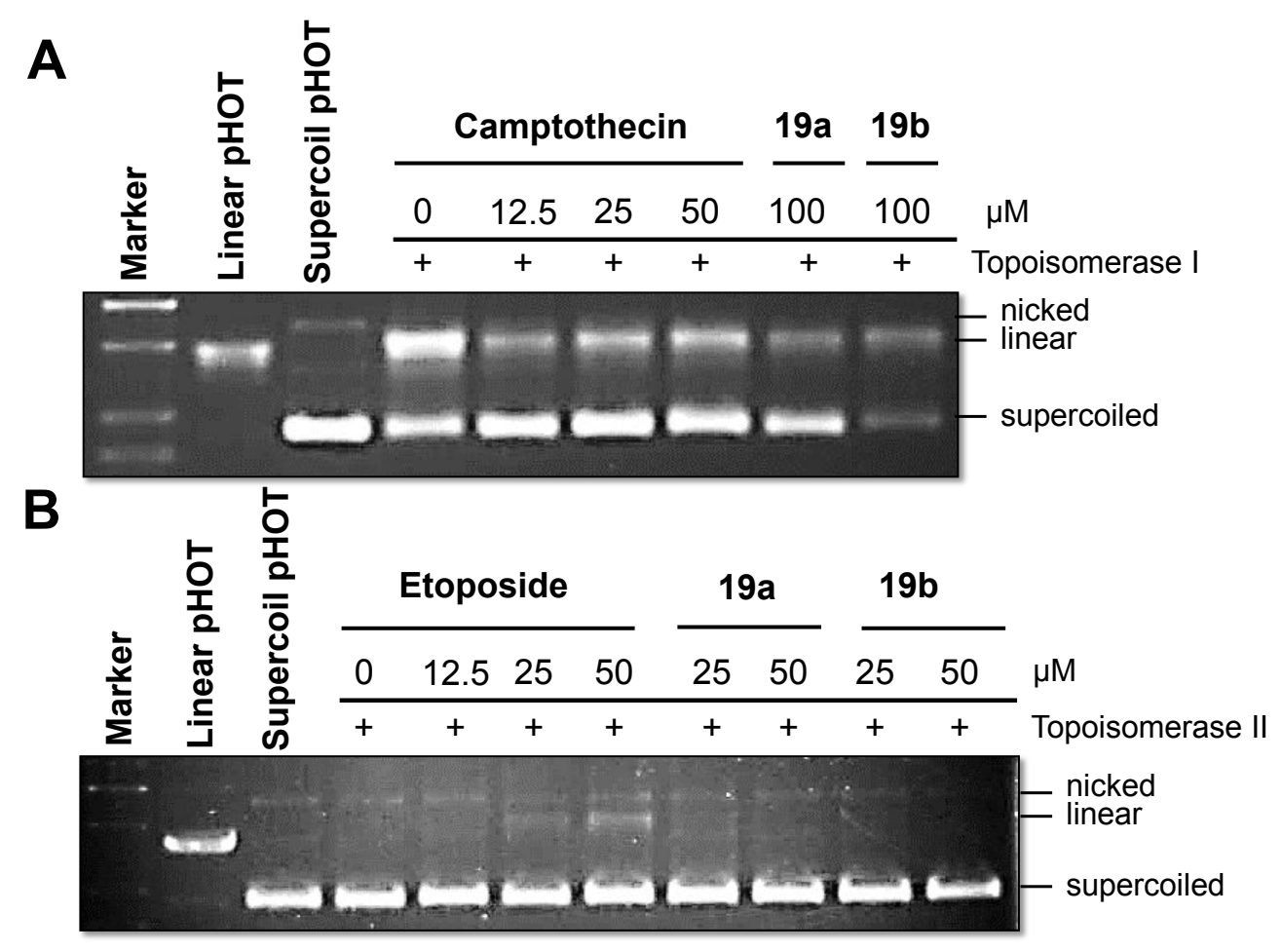

Figure S4. Topo I and Topo II activity assay. The assay kits for Topo I and II were obtained from TopoGEN, Inc. (Port Orange, FL, USA). The assays were performed as previously described. ${ }^{1}$ The supercoiled plasmid DNA (pHOT) was incubated with 2 units of topo I (A) or 4 units of topo II (B) together with different concentrations of compounds 19a or 19b for $30 \mathrm{~min}$. At the end of incubation, the samples were subjected for electrophoretic separation onto a $1 \%$ agarose gel. DNA bands were visualized by staining with ethidium bromide. Camptothecin or Etoposide was included as positive control for topo I or topo II, respectively. Linear and supercoil pHOT were served as negative control. Marker, $1 \mathrm{~kb}$ DNA ladder markers. 


\section{References:}

(1) Chang, S. M.; Jain, V.; Chen, T. L.; Patel, A. S.; Pidugu, H. B.; Lin, Y. W.; Wu, M. H.; Huang, J. R.; Wu, H. C.; Shah, A.; Su, T. L.; Lee, T. C. Design and synthesis of 1,2-bis(hydroxymethyl)pyrrolo[2,1-a]phthalazine hybrids as potent anticancer agents that inhibit angiogenesis and induce DNA interstrand crosslinks. J Med Chem 2019, 62, 2404-2418. 